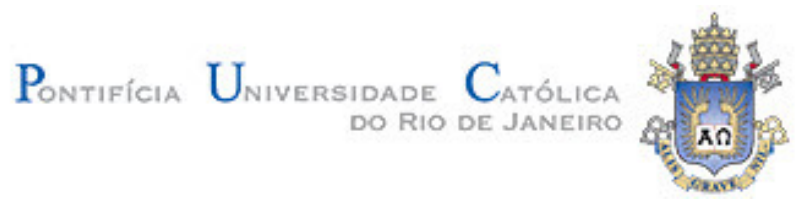

Francisco José Zamith Guimarães

\title{
O Uso de Histórias Como Forma de Explicitar o Conhecimento Tácito
}

\section{Tese de Doutorado}

Tese apresentada ao Programa de Pós-graduação em Informática da PUC-Rio como requisito parcial para obtenção do título de Doutor em Informática

Orientador: Prof. Daniel Schwabe

Rio de Janeiro

Março de 2013 
Francisco José Zamith Guimarães

\section{O Uso de Histórias Como Forma de Explicitar o Conhecimento Tácito}

Tese apresentada como requisito parcial para a obtenção do grau de Doutor pelo Programa de Pósgraduação em Informática do Departamento de Informática do Centro Técnico e Científico da PUC-Rio. Aprovada pela Comissão Examinadora abaixo assinada.

Prof. Daniel Schwabe Orientador Departamento de Informática - PUC-Rio

Prof. Julio Cesar Sampaio do Prado Leite

Departamento de Informática - PUC-Rio

Prof. Carlos José Pereira de Lucena Departamento de Informática - PUC-Rio

Prof ${ }^{a}$. Fernanda Lima Departamento de Ciência da Computação - UNB

Prof ${ }^{a}$. Adriana Pereira de Medeiros Departamento de Computação - UFF

Prof. José Eugenio Leal Coordenador Setorial do Centro Técnico Científico - PUC-Rio 
Todos os direitos reservados. É proibida a reprodução total ou parcial do trabalho sem autorização da universidade, do autor e do orientador.

Francisco José Zamith Guimarães

Graduou-se em Engenharia da Computação na Pontifícia Universidade Católica do Rio de Janeiro em 2000. Mestre em Informática pela Pontifícia Universidade Católica do Rio de Janeiro em 2002. MBA em Gestão do Conhecimento pela COPPE/UFRJ. Trabalhou na Petrobras na Área de Gestão do Conhecimento e atualmente atua na Área de Arquitetura de Processos.

Ficha Catalográfica

Guimarães, Francisco José Zamith

O uso de histórias como forma de explicitar o conhecimento tácito / Francisco José Zamith Guimarães ; orientador: Daniel Schwabe. 2013.

158 f. : il. (color.) ; $30 \mathrm{~cm}$

Tese (doutorado)-Pontifícia Universidade Católica do Rio de Janeiro, Departamento de Informática, 2013.

Inclui bibliografia

1. Informática - Teses. 2. História. 3. Gestão do conhecimento. 4. Ontologia. I. Schwabe, Daniel. II. Pontifícia Universidade Católica do Rio de Janeiro. Departamento de Informática. III. Título.

CDD: 004 


\section{Agradecimentos}

Ao meu professor orientador, Daniel Schwabe, por todo o conhecimento transmitido e pela amizade.

Aos professores membros da banca, pela aceitação do convite de participação na avaliação deste trabalho.

A minha companheira Danielle por estar sempre ao meu lado.

A meus filhos Mateus e Gustavo pela alegria.

A minha mãe e irmã por todo o apoio durante esta jornada.

A todos os funcionários do Departamento de Informática da PUC-RIO.

A todos os amigos da PUC e da Petrobras.

A Petrobras, pelos auxílios concedidos, sem os quais este trabalho não poderia ter sido realizado. 


\section{Resumo}

Guimarães, Francisco José Zamith; Schwabe, Daniel. O Uso de Histórias Como Forma de Explicitar o Conhecimento Tácito. Rio de Janeiro, 2013. 158 p. Tese de Doutorado - Departamento de Informática, Pontifícia Universidade Católica do Rio de Janeiro.

Com o processo de globalização, as empresas estão cada vez mais descentralizadas, o que torna um desafio a troca de conhecimentos entre seus funcionários. Na literatura, há diversas práticas de Gestão do Conhecimento que visam facilitar essa troca de conhecimentos, porém muitas apresentam dificuldades na coleta e reutilização posterior desse conhecimento. Algumas dessas práticas se baseiam na troca de experiências entre os funcionários por meio de histórias. Este trabalho tem por objetivo definir um modelo para a representação (ontologia) de histórias, compreendendo um conjunto de atividades, papéis e ferramentas, visando melhorar a dinâmica coletiva de levantamento e reuso de conhecimentos. Com base na realização de alguns experimentos, constatou-se que o modelo proposto é melhor que outros no que tange ao levantamento e ao reuso de conhecimentos.

\section{Palavras-chave}

Informática; História; Gestão do Conhecimento; Ontologia. 


\section{Abstract}

Guimarães, Francisco José Zamith; Schwabe, Daniel (Advisor). The Use of Stories as a Way to Explicit the Tacit Knowledge. Rio de Janeiro, 2013. 158 p. DSc Thesis - Departamento de Informática, Pontifícia Universidade Católica do Rio de Janeiro.

With the globalization process, companies are increasingly decentralized, which makes it a challenge to exchange knowledge between employees. In literature, several Knowledge Management practices aims at facilitating the knowledge exchange, but many of them have difficulties in collecting and later reuse that knowledge. Some of these practices are based on the employee experience exchange, through sharing stories. The objective of this Thesis is define a model for the representation of stories (ontology), a set of activities, rules and tools to improve the collective dynamic gathering and the reuse of knowledge. Through some experiments we observed that this proposed model is better than other models regarding the collection and reuse of knowledge.

\section{Keywords}

Computer Science; Story; Knowledge Management; Ontology. 


\section{Sumário}

1 Introdução 16

$\begin{array}{lr}\text { 1.1. Estrutura da tese } & 19\end{array}$

$\begin{array}{ll}2 \text { Metodologia } & 21\end{array}$

3 Gestão do Conhecimento 24

3.1. O framework de GC 26

3.2. Os modos de conversão do conhecimento 29

3.3. As práticas de GC 31

3.3.1. Comunidade de prática 31

3.3.2. Taxonomias e ontologias 31

3.3.3. Análise de redes sociais 33

3.3.4. Group storytelling 34

3.3.5. Práticas no framework de GC 36

3.4. Exemplo de uso 36

4 Fundamentos 38

4.1. Web semântica 38

4.2. RDF, RDFS e OWL 39

4.3. Wiki 41

4.4. Semiótica 42

4.4.1. Signo 42

4.4.2. Tipos de raciocínio 43

4.4.3. O papel do pragmatismo 44

5 Trabalhos relacionados $\quad 45$

5.1. Níveis de representação $\quad 47$

5.2. Ontologias para a representação de histórias e narrativas 50

5.2.1. ISRST: An Interest based on Storytelling Model using Rhetorical 
Relations

5.2.2. Virtual Storyteller 53

5.2.3. StoryMapper 56

5.2.4. Tellstory 58

5.2.5. The Event Ontology 61

5.2.6. LODE: An ontology for Linking Open Descriptions of Events 64

5.2.7. Event-Model-F 65

5.2.8. Unified Foundational Ontology (UFO) 67

5.3. Comparação entre as ontologias 69

6 Solução proposta $\quad 72$

6.1. Papéis existentes 73

6.1.1. Atividades por papel 75

6.1.1.1. Patrocinador 75

6.1.1.2. Analista de gestão do conhecimento 76

6.1.1.3. Depoente participante 76

6.1.1.4. Depoente não participante 77

6.1.1.5. Entrevistador 77

6.1.1.6. Curador 77

6.1.1.7. Reutilizador 78

6.2. Processo de trabalho 79

6.3. Ontologia proposta 82

6.3.1. Módulo Depoimento 84

6.3.2. Módulo História 86

6.3.3. Módulo Kuaba 86

6.3.4. Módulo Empresa 87

6.3.5. Exemplo do uso da ontologia proposta 89

6.3.6. Observações sobre a ontologia 90

6.4. Wiki semântico 92

6.4.1. HDEWiki 95

6.5. Demais ferramentas utilizadas 98

6.5.1. Exhibit 98

6.5.2. NetDraw 99 
7 Análise dos resultados $\quad 100$

7.1. Aplicação real utilizada $\quad 100$

7.1.1. O processo de criação do estudo de caso 101

7.1.2. Pontos a serem melhorados no processo 104

7.2. Aplicação da solução 105

7.2.1. Análise dos conteúdos 106

7.2.2. Análise da rede social 109

7.2.3. Resultado da entrevista com os curadores 111

7.3. Experimentos realizados 112

7.3.1. Resultado do teste de associação entre significante e significado115

7.3.2. Resultado do teste de reutilização 116

7.3.3. Resultado do teste de completude 117

7.3.4. Resultado do teste da cauda longa 119

7.3.5. Comentários sobre os experimentos 120

8 Conclusão 122

8.1. Contribuições deste estudo 123

8.2. Limitações do estudo 124

8.3. Trabalhos futuros 125

9 Referências bibliográficas 127

Apêndice I - Diagrama de Casos de Uso 135

Apêndice II - Casos de Uso 136

Apêndice III - Enunciado dos experimentos realizados $\quad 140$

Apêndice IV - Ontologia Proposta 144

wiki.owl 144

Depoimento.owl 146

Historia.owl 150

$\begin{array}{ll}\text { Kuaba.owl } & 151\end{array}$ 
Apêndice V - Modelo Navegacional do wiki semântico 


\section{Lista de figuras}

Figura 1 - Adaptação do framework de Gestão do Conhecimento da APQC.

Fonte: APQC (1998). 17

Figura 2 - Representação da hipótese. Fonte: adaptada de Creswell (2002). 18

Figura 3 - Relação entre Inteligência Artificial e Gestão do Conhecimento na $\begin{array}{ll}\text { perspectiva de métodos de solução. } & 19\end{array}$

Figura 4 - Relação entre os conceitos de dado, informação e conhecimento. Fonte: Adaptado de Probst et al.(2002). 25

Figura 5 - O modelo SECI. Fonte: Nonaka \& Takeuchi (1995). 30

Figura 6 - O conceito de cauda longa exemplificado no Wikipedia. Fonte: Anderson (2006).

Figura 7 - Organização em camadas das linguagens. 39

Figura 8 - Representação gráfica de uma declaração RDF. 40

Figura 9 - Aplicação ISRST - tela principal. Fonte: Nakasone \& Ishizuka (2007).

Figura 10 - O modelo da ontologia de ISRST. Fonte: Nakasone \& Ishizuka (2007).

Figura 11 - Modelo da fábula. Fonte: Swartjes \& Theune (2008). 56

Figura 12 - Interface do StoryMapper. Fonte: Valle (2003). 58

Figura 13 - Fluxo de uma história no sistema Tellstory. Fonte: Santoro \& Brézillon (2005).

Figura 14 - Descrição do personagem no sistema Tellstory. Fonte: Santoro \& Brézillon (2005).

Figura 15 - Ontologia de evento. Fonte: Raimond \& Abdallah (2007).

Figura 16 - Fragmento de UFO-B (conceitos reutilizados de UFO-A em caixa tracejada de fundo branco, conceitos UFO-B em caixa de fundo cinza). Fonte: Adaptada de Guizzardi (2008).

Figura 17 - Fragmento de UFO-C (conceitos reutilizados de UFO-A em caixa tracejada de fundo branco, conceitos reutilizados de UFO-B em caixa de fundo cinza, conceitos UFO-C em caixa de fundo branco). 
Fonte: Adaptada de Guizzardi (2008).

Figura 18 - Visão geral da solução proposta.

Figura 19 - Processo de trabalho proposto.

Figura 20 - Ontologia proposta.

Figura 21 - Módulo Depoimento.

Figura 22 - Módulo História. $\quad 86$

Figura 23 - Módulo Kuaba. Fonte: Medeiros (2006). 87

Figura 24 - Módulo empresa. $\quad 88$

Figura 25 - Exemplo de material a ser transposto para a ontologia (material marcado). Fonte: Relatório histórico da construção da refinaria. $\quad 89$

Figura 26 - Material da figura 25 representado na ontologia (não exaustivo). 90

Figura 27 - Relação da UMBEL com outras ontologias. Fonte: UMBEL (2008)

Figura 28 - O wiki semântico.

Figura 29 - Tela do wiki semântico.

Figura 30 - Visualização do exemplo presente na figura 25 (conteúdo da página).

Figura 31 - Visualização da tela de edição do exemplo presente na figura 30 (conteúdo da página).

Figura 32 - Visão linha do tempo.

Figura 33 - Exemplo de visualização de um grafo: Eventos (vértices triangulares marrons), Significados (vértices circulares rosa), Relações TemRelação.

Figura 34 - O processo para criação de um estudo de caso. Fonte: Korowajczuk \& Almeida (2007)

Figura 35 - Exemplo 1: Eventos (vértices triangulares cinza), Significados (vértices quadrados rosa), Relações TemRelação.

Figura 36 - Exemplo de análise (retângulo = Questão; Elipse = Idéia; retângulo tracejado $=$ Argumento) .

Figura 37 - Rede social de trabalho da construção da refinaria (vértices representam pessoas; arestas contínuas pretas - relacionamento de TrabalharCom; arestas vermelhas tracejadas - relacionamento de Conhecer). 
Figura 38 - Rede social de trabalho da construção da refinaria considerando as entidades envolvidas (vértices triangulares pretos representam entidades; vértices circulares azuis representam pessoas; arestas contínuas pretas - relacionamento de TrabalharCom; arestas tracejadas vermelhas - relacionamento de Conhecer; arestas pontilhadas verdes relacionamento de PessoaIntegra determinada entidade).

Figura 39 - A exemplificação do conceito de cauda longa do experimento. 120

Figura 40 - Visão temporal das linhas do tempo da construção da refinaria, da unidade de produção de petróleo e dos Eventos Históricos.

Figura 41 - Diagrama de Casos de Uso. 135

Figura 42 - Módulo Wiki. 144

Figura 43 - Módulo Depoimento. 146

Figura 44 - Módulo Historia. 150

Figura 45 - Módulo Kuaba. Fonte: Medeiros (2006). 151

Figura 46 - Módulo Empresa. 153

Figura 47 - Modelo navegacional do wiki semântico. 157 


\section{Lista de tabelas}

Tabela 1 - Práticas versus framework de GC. 36

Tabela 2 - Diferenças entre histórias e cenários. 46

Tabela 3 - Diferenças entre histórias e design rationale. 46

Tabela 4 - Assuntos do framework de contexto. Fonte: Santoro \& Brézillon (2005). 60

Tabela 5 - Classes da ontologia de evento. Fonte: Raimond \& Abdallah (2007).

Tabela 6 - Propriedade da ontologia de evento. Fonte: Raimond \& Abdallah (2007).

Tabela 7 - Classes da ontologia de evento. Fonte: Shaw (2009). 64

Tabela 8 - Propriedades da ontologia de evento. Fonte: Shaw (2009). 64

Tabela 9 - Classes principais da ontologia Event-Model-F. Fonte: Scherp et al. (2009). 66

Tabela 10 - Comparação entre ontologias de eventos. Fonte: Adaptado a partir de Scherp (2009) e Shaw (2009).

Tabela 11 - Papéis desempenhados nas fases do framework de GC, com o respectivo esforço (bolinha cheia indica grande esforço, meia bolinha indica médio esforço).

Tabela 12 - Ferramentas utilizadas nas fases do framework de GC. 99

Tabela 13 - Distribuição de Eventos e Significados do planejamento da construção de uma refinaria. 105

Tabela 14 - Resultado das entrevistas. 112

Tabela 15 - Relacionamento entre os problemas associados ao problema central desse trabalho e os experimentos.

Tabela 16 - perfil do universo de pessoas que responderam os experimentos. 114

Tabela 17 - Resultados do teste de associação entre significante e significado. Nota: Os itens em vermelho e sublinhados são respostas $\begin{array}{ll}\text { erradas. } & 115\end{array}$

Tabela 18 - Resultados do teste de reuso. 117 
Tabela 19 - Resultados do teste de completude.

Tabela 20 - Resultados do teste da cauda longa. 
1

\section{Introdução}

As empresas cada vez mais atuam além de suas fronteiras, processo este decorrente da globalização. Por isso, seus funcionários encontram-se dispersos geograficamente uns dos outros. Com a descentralização, a troca de conhecimentos entre esses funcionários torna-se difícil, pois a interação presencial ocorre de forma esporádica.

Outro ponto preocupante diz respeito à perda de $\operatorname{conhecimentos}^{1} \mathrm{em}$ decorrência da saída de funcionários das empresas, seja por aposentadoria ou por iniciativas de outsourcing ${ }^{2}$.

Procurando equacionar tais questões, muitas empresas utilizam algumas práticas de Gestão do Conhecimento ${ }^{3}$ (GC), visando "diminuir” essa distância entre os funcionários. Comunidade de prática, páginas amarelas, bases de lições aprendidas são alguns exemplos destas práticas.

O framework de GC da $\mathrm{APQC}{ }^{4}$ (figura 1) apresenta os processos para realizar a gestão dos conhecimentos. De forma geral, começa pela criação, identificação e coleta de conhecimento interno na empresa. Posteriormente, organiza-se e compartilha-se o conhecimento coletado. À medida que surge a necessidade desse conhecimento, ele deve ser adaptado e usado, o que gerará novos conhecimentos a partir de sua reutilização.

${ }^{1}$ Conhecimento é o conjunto total incluindo cognição e habilidades que os indivíduos utilizam para resolver problemas. Inclui tanto a teoria quanto a prática, as regras do dia a dia e as instruções sobre como agir. Baseia-se em dados e informações, mas, ao contrário deles, está sempre ligado às pessoas. É construído por indivíduos e representa suas crenças sobre relacionamentos causais (Probst et al., 2002).

2 Outsourcing é a prática de comprar componentes ao invés de fazer-los dentro da própria empresa (Brigham \& Ehrhardt, 2002).

${ }^{3}$ Gestão do conhecimento é uma forma sistemática de gerir os conhecimentos em uma organização. Isso é feito mediante uma série de práticas que abrangem uma ou mais etapas do framework de GC

${ }^{4}$ American Productivity \& Quality Center é uma entidade sem fins lucrativos, fundada em 1977, que tem por missão melhorar a produtividade e a qualidade nas empresas ao redor do mundo. A partir de 1993, a entidade se tornou uma das referências em gestão do conhecimento. 


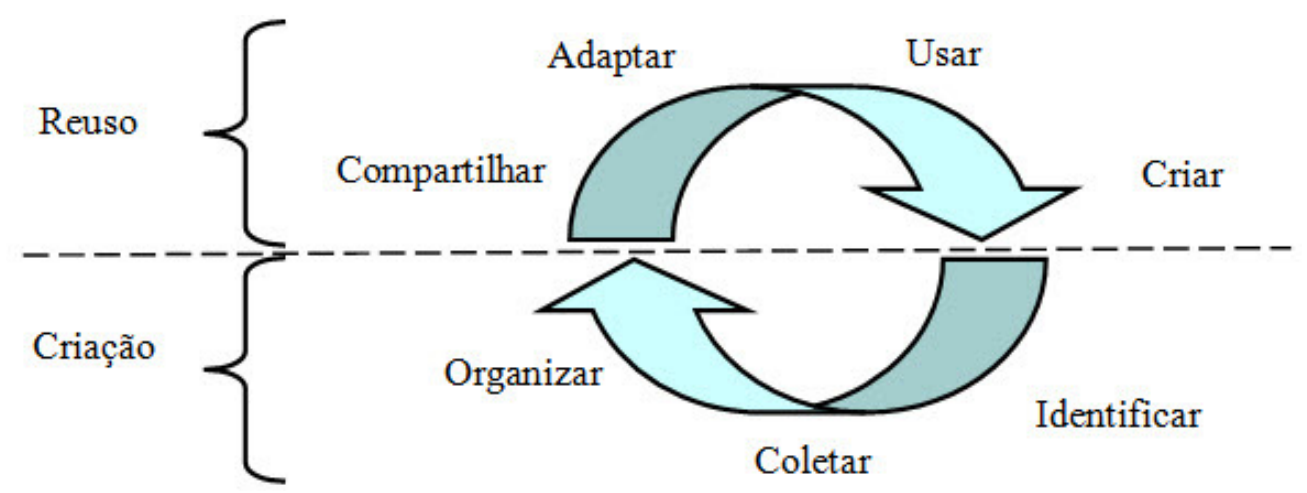

Figura 1 - Adaptação do framework de Gestão do Conhecimento da APQC. Fonte:

APQC (1998).

No escopo deste trabalho, evidencia-se que a etapa de coleta e a adaptação apresentam algumas dificuldades.

$\mathrm{Na}$ etapa de coleta, muitas vezes, os indivíduos têm dificuldades para externalizar o seu conhecimento, especialmente quanto ao uso de estruturas que restrinjam a explicitação do conhecimento. Um exemplo disso é o uso de formulários. Os trabalhos de LINDE (2001), WHYTE \& CLASSEN (2012) são alguns exemplos que corroboram este problema, principalmente quando o conhecimento que se quer coletar é tácito ${ }^{5}$. Conforme será apresentado na seção 3.2, a externalização do conhecimento tácito utiliza os mecanismos de metáforas, analogias, ou modelos, que são bem explicitados por meio de histórias (Nonaka \& Takeuchi,1995).

$\mathrm{Na}$ etapa de adaptação, em alguns casos, a dificuldade está em fazer isso de maneira adequada. Por exemplo, o telhado dos supermercados de uma multinacional americana que atua no Brasil, país onde não neva, é construído para resistir a uma carga de dois metros de neve, como nos Estado Unidos, país onde neva. Dessa forma, apesar de se reutilizar um conhecimento compartilhado, este não é adaptado de forma adequada, uma vez que não traz consigo uma informação de contexto compatível à sua utilização.

O problema central que este trabalho busca responder é: Como gerir o conhecimento produzido coletivamente.

Algumas questões a partir deste problema central são:

5 Conhecimento tácito é altamente pessoal e, dificilmente, formalizado, sendo difícil comunicá-lo e compartilhá-lo com outros. Está profundamente enraizado nas ações e experiências dos indivíduos (Willians, 2006). 
a) Como melhorar a eficácia da coleta de conhecimento no contexto de uma comunidade a respeito de determinado evento?

b) Existe uma forma que represente o conhecimento que permita o seu posterior reaproveitamento de uma forma melhor do que a narrativa puramente textual?

Este trabalho procura discutir a seguinte hipótese: A utilização de depoimentos registrados de forma estruturada como meio de captura das informações de uma história propicia uma melhoria tanto na etapa de coleta como também na etapa de reuso no framework de GC.

Para avaliar a hipótese, foram realizados quatro experimentos seguindo a metodologia descrita no capítulo 2. A figura 2 ilustra a questão.

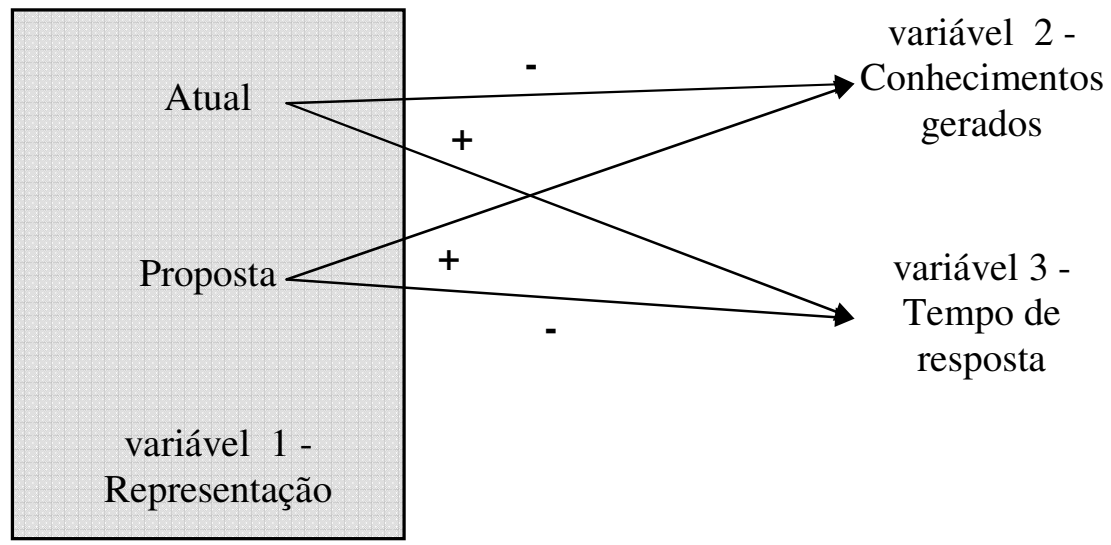

Figura 2 - Representação da hipótese. Fonte: adaptada de Creswell (2002).

Este trabalho tem como proposta de solução um modelo para representação (ontologia) que facilite a construção do discurso, além de um conjunto de atividades, papéis e ferramentas com esse mesmo fim.

É importante frisar que o foco é na Gestão do Conhecimento, que difere bastante de uma abordagem de Inteligência Artificial. Aqui, busca-se facilitar a interpretação humana das informações coletadas, o que difere muito de trabalhos em Inteligência Artificial, que buscam métodos e heurística para automatizar totalmente esse processo. A figura 3 ilustra essa questão. 


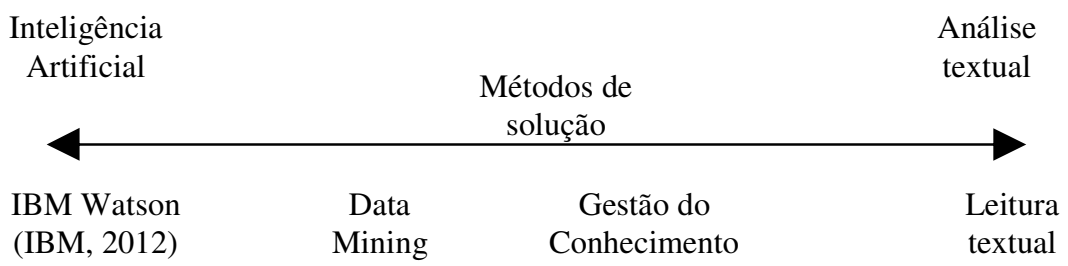

Figura 3 - Relação entre Inteligência Artificial e Gestão do Conhecimento na perspectiva de métodos de solução.

A solução proposta utiliza uma estrutura mais flexível para a explicitação do discurso sobre uma história. Para isso, utilizou-se: uma ferramenta colaborativa, wiki semântico, que permitiu a participação de várias pessoas na narrativa de uma história; um conjunto de papéis para auxiliar a dinâmica de coleta e reuso; e uma ontologia que auxiliou a coleta e o reuso das narrativas coletadas.

\subsection{Estrutura da tese}

Esta tese compõe-se de oito capítulos, incluindo esta Introdução.

No capítulo 2, descreve-se a metodologia utilizada na elaboração desse trabalho.

No capítulo 3, desenvolvem-se os conceitos de Gestão do Conhecimento, apresenta-se o framework de GC, os modos de conversão de conhecimento propostos por Nonaka \& Takeuchi (1995) e algumas práticas de GC que serão utilizadas neste trabalho: comunidades de prática, taxonomias e ontologias, análise de redes sociais e group storytelling.

No capítulo 4, abordam-se os fundamentos utilizados na solução proposta, incluindo-se os conceitos de web semântica, wiki e Semiótica.

No capítulo 5, apresentam-se os trabalhos relacionados a esta tese, procedendo-se a uma revisão da literatura de trabalhos que buscam propor modelos de representação de histórias e narrativas. Ao final, faz-se a comparação entre esses modelos de representação.

No capítulo 6, destaca-se a solução proposta, construída a partir das demandas específicas a partir dos problemas citados e da revisão da literatura. A solução proposta contém um processo de trabalho, um conjunto de papéis, uma representação (ontologia) e uma ferramenta. 
No capítulo 7, procede-se à aplicação da solução proposta com base em um problema real. Mostra-se a situação atual e, em seguida, realiza-se a aplicação da solução proposta e mostra-se como ela facilita o processo de coleta e extração de conhecimento. No final, discutem-se os resultados de um conjunto de experimentos que buscam validar, principalmente, a representação proposta.

No capítulo 8, formulam-se as considerações finais e sugerem-se trabalhos futuros vislumbrados a partir dos resultados obtidos. 


\section{2 Metodologia}

Esta pesquisa pode ser classificada, com base na classificação de Creswell (2002), como:

- Concepção filosófica pós-positivista.

- Estratégia de investigação quantitativa, sendo utilizada pesquisa experimental (quase-experimentos) e pesquisa de levantamento.

- Método de pesquisa de questões baseadas no instrumento e análise estatística.

Como consequência dos problemas associados ao problema central deste trabalho, identificam-se algumas variáveis (conhecimentos gerados, tempo de resposta) que devem ser analisadas com base nos seguintes indicadores:

- Como melhorar a eficácia da coleta de conhecimento, no contexto de uma comunidade, a respeito de determinado evento?

a) Número de conhecimentos gerados a partir de conhecimentos preexistentes (indicador).

- Existe uma forma que represente o conhecimento que permita o seu posterior reaproveitamento de uma forma melhor do que a narrativa puramente textual?

a) Grau de acerto na utilização da representação proposta (indicador).

b) Tempo de resposta na utilização da representação proposta (indicador).

c) Tempo de resposta a determinada questão com um conteúdo na representação proposta (indicador).

d) Tempo de resposta a determinada questão com um conteúdo na representação antiga (indicador).

e) Número de acertos na representação proposta (indicador).

f) Número de acertos na representação antiga (indicador). 
Para a análise dos resultados do experimento, utilizaram-se algumas lentes teóricas, visando distinguir os resultados de alguns grupos considerados importantes:

a) Pertencimento do indivíduo à comunidade que trabalha o conteúdo do experimento.

b) Tempo de trabalho na empresa analisada.

Para realizar esta pesquisa, obedeceu-se a uma metodologia que envolveu as seguintes atividades:

- Primeiro, analisou-se um exemplo específico de uma aplicação real, que busca gerir conhecimentos, que estão na forma de histórias. A partir dessa análise, foram identificados os problemas que deveriam ser endereçados. Utilizou-se aqui a técnica de pesquisa documental (Neves, 1996). Foi preservada a identidade dos entrevistados e da empresa que forneceu o exemplo.

- Posteriormente, propôs-se uma solução para resolver os problemas identificados. Para tanto, procedeu-se à revisão de outros trabalhos na literatura que abordam modos de lidar com conhecimentos na forma de histórias. Esses trabalhos apresentam processos, formas de representação, ferramentas e papéis necessários para suportar essa dinâmica.

- Em seguida, implementou-se a solução.

- Elaborou-se um conjunto de experimentos (Apêndice III) que buscaram validar se a solução proposta traz efetivamente ganhos, facilitando a explicitação e a reutilização de conhecimentos. Esses experimentos contemplaram a utilização de técnicas de pesquisa de levantamento e de pesquisa experimental.

- Em seguida, identificou-se uma amostra de conveniência de vinte pessoas. Buscou-se estratificar tal amostra de forma a incluir representantes que cobrissem as lentes teóricas do interesse desta tese: o pertencimento do indivíduo à comunidade que trabalha o conteúdo do experimento e o tempo de trabalho na empresa analisada. 
- Posteriormente, aplicaram-se os experimentos e coletaram-se as respostas. A aplicação dos experimentos foi realizada de forma presencial com o mesmo facilitador, seguindo o mesmo roteiro para todos os respondentes.

- Por fim, a partir dos dados obtidos, analisaram-se os resultados.

A aplicação real utilizada é proveniente de uma empresa de energia que tem como principal produto o petróleo. Trata-se de uma empresa petrolífera integrada, que atua em todos os segmentos do negócio petróleo (upstream, downstream). Esta empresa atua em mais de 25 países e tem em torno de 75000 empregados, sendo que $10 \%$ deles estão dispersos nestes países.

Essa aplicação envolveu a elaboração de um estudo de caso da construção de uma refinaria de petróleo, selecionada por descrever um processo importante que faz parte do processo de negócio da empresa. 


\section{3 \\ Gestão do Conhecimento}

A Gestão do Conhecimento (GC) é um tema novo para as organizações. A literatura de referência começou a abordar sua aplicação de forma sistemática dentro das empresas por volta de 1995 (Nonaka \& Takeuchi, 1997; Oden et al., 1995).

A literatura oferece algumas definições de GC:

"A Gestão do Conhecimento (GC) é o conjunto de processos e meios para se criar, utilizar e disseminar conhecimento dentro de uma organização. A GC reconhece o conhecimento como o ativo de maior importância na organização. "6

"By KM, we mean the strategies and processes of identifying, capturing, and leveraging knowledge to help the firm compete. It is also tangible evidence of a "learning organization" one that can analyze, reflect, learn, and change based on experience."

Não existe uma definição única e consolidada do que é GC, porém surge uma convergência conceitual. Pode-se concluir que GC é uma forma sistemática de gerir os conhecimentos dentro de uma organização. Para alcançar esse intento, faz-se uso de uma série de práticas que abrangem uma ou mais etapas do framework de GC. São exemplos de práticas: brainstorm, comunidade de prática, coaching, shadowing.

É preciso caracterizar bem alguns conceitos que serão desenvolvidos ao longo deste trabalho. Uma discussão dentro da área de GC gira em torno do que seja seu objeto de estudo. Tendo como base as referências de Nonaka \& Takeuchi (1997) e Probst (2002), destacam-se as diferenças entre dado, informação e conhecimento:

- Dado - aplicação de uma sintaxe específica a um conjunto de símbolos.

${ }^{6}$ Silva, R. V.; Neves, A. Gestão de Empresas na Era do Conhecimento. Editora Serinews, 2003. 
- Informação - fluxo de mensagens; é um meio material necessário para extrair e construir conhecimento independente de contexto, simbólico.

- Conhecimento - "crença verdadeira justificada"; processo dinâmico de justificar a crença pessoal em relação a uma verdade; dependente de crenças e compromissos; está relacionado à ação; diz respeito ao significado; criado pelo próprio fluxo de informação.

A figura 4 resume e exemplifica as diferenças dos conceitos apresentados.

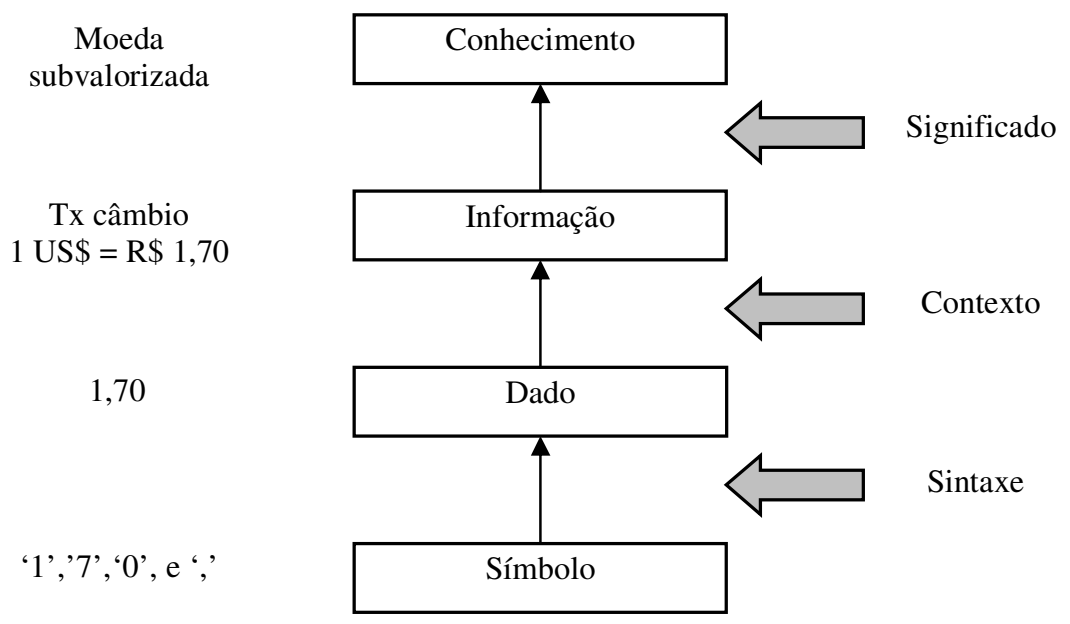

Figura 4 - Relação entre os conceitos de dado, informação e conhecimento. Fonte: Adaptado de Probst et al.(2002).

Esses conceitos se encontram em evolução, havendo ainda muita discussão sobre a relação e as fronteiras envolvendo informação e conhecimento (Styhre, 2003). O foco desta tese está nos conceitos de conhecimento e informação.

Em se tratando especificamente de conhecimento, Michael Polanyi (Nonaka \& Takeuchi, 1995) o divide em duas formas:

a) Conhecimento tácito - é altamente pessoal e dificilmente formalizado, sendo difícil comunicá-lo e compartilhá-lo com outros. Consiste de insights subjetivos, intuições e pressentimentos. Está profundamente enraizado nas ações e experiências dos indivíduos, tanto quanto em seus ideais, valores ou emoções que ele, ou ela, acalentam (Willians, 2006). 1995.

${ }^{7}$ APQC - Knowledge Management. APQC International Bechmarking Clearinghouse, 
b) Conhecimento explícito - é conhecimento codificado, que pode ser transmitido em uma linguagem formal e sistemática (Willians, 2006). É muito próximo do conceito de informação.

Nem tudo que é de difícil comunicação e compartilhamento com outros é necessariamente um conhecimento tácito. Questões como falta de incentivo e confiança são, muitas vezes, fatores mais relevantes do que a falta de meios para a comunicação de um conhecimento. O conhecimento tácito é aquele que é de difícil comunicação, devido a sua característica intrínseca. Alguns exemplos são: como andar de bicicleta, como surfar e como fazer uma análise de um mapa geológico.

$\mathrm{Na}$ perspectiva organizacional, o conhecimento explícito é tangibilizado por meio de patentes, modelos, relatórios etc. É um ativo de propriedade da empresa. Já o conhecimento tácito é mais fluido, pois está na "cabeça de seus empregados”. Dessa forma, é natural que as organizações tentem converter esse conhecimento tácito em explícito, dentro do possível. A ironia dessa questão é que por volta de $80 \%$ do conhecimento das empresas se encontra na forma de conhecimento tácito ${ }^{8}$.

\subsection{O framework de GC}

O framework, que permite essa sistematização, varia de autor para autor, devido tanto à imaturidade do tema como às diferenças culturais que cada autor percebe em seu contexto. Para fins práticos, será utilizado como referência neste trabalho o framework proposto pela American Productivity and Quality Center ${ }^{9}$ (APQC, 1998) (figura 1), que compõe-se dos processos necessários para a gestão do conhecimento. O framework é dinâmico, porém, normalmente, inicia-se pela criação, identificação e coleta de conhecimento interno da empresa. Posteriormente, organiza e compartilha o conhecimento coletado. À medida que surge a necessidade desse conhecimento, ele deve ser adaptado e usado, o que gerará novos conhecimentos a partir de sua reutilização.

\footnotetext{
${ }^{8}$ Information Management 101. Forrester Research, 2006.

${ }^{9}$ American Productivity \& Quality Center é uma entidade sem fins lucrativos, fundada em 1977, que tem como missão melhorar a produtividade e a qualidade nas empresas ao redor do mundo. A partir de 1993 a entidade se torna uma das referências em Gestão do Conhecimento.
} 
A seguir, descreve-se cada uma das etapas que compõem o framework (ver figura 1).

- Identificar - identificação de uma experiência importante para a empresa capaz de gerar conhecimento que justifique ser internalizado/discutido. Atrela-se à estratégia da empresa ou à identificação de algum problema que deve ser enfrentado.

- Coleta - identificação do grupo de pessoas que participaram, direta ou indiretamente, da experiência. O objetivo aqui é que o máximo de conhecimento dessa experiência vivida seja externalizado (de conhecimento tácito para conhecimento explícito).

- Organizar - busca organizar esse conhecimento explícito de forma a facilitar seu consumo posterior. Taxonomias são exemplos de ferramentas utilizadas nessa etapa.

- Compartilhar - uma vez organizado, o conhecimento explícito é difundido para quem possa interessar.

- Adaptação - uma vez identificado o potencial de reaproveitamento de um conhecimento explícito, há um processo de adaptação deste no novo contexto onde ele vai ser aplicado.

- Usar - aqui, reutiliza-se esse conhecimento adaptado em uma nova experiência prática.

- Criar - a partir dessa experiência prática, são criados conhecimentos, que podem ser absorvidos pela empresa, dependendo da importância que ela atribui a eles.

No escopo deste trabalho, observou-se que as etapas de coleta e adaptação apresentam algumas dificuldades em particular.

$\mathrm{Na}$ etapa de coleta, notou-se que, muitas vezes, os indivíduos têm dificuldade para externalizar seu conhecimento. Por exemplo, em uma comunidade de prática a reflexão sobre a experiência dos membros é um aspecto fundamental para sua dinâmica. Muito do aprendizado que ocorre dentro dessas comunidades se dá com base em um processo coletivo de análise das experiências vividas por seus membros. O processo de validação de conhecimentos, que é 
muito comum nesse tipo de prática, é um exemplo limitado ${ }^{10}$ de um processo coletivo de análise.

Em termos tecnológicos, conforme apresentado em Guimarães \& Souza (2008), são colocadas algumas dificuldades típicas das bases de conhecimento utilizadas em ambientes que suportam as comunidades de prática, sendo a principal delas dificuldade de representar a experiência de um membro em uma estrutura que exige rigidez de discurso. Devido a essa rigidez de discurso ${ }^{11}$, muitas vezes, o conhecimento coletado não traz uma boa informação de contexto para quem futuramente irá reutilizá-lo.

Uma forma de contornar essas questões é mediante a utilização de estruturas menos rígidas, mais adequadas à explicitação do discurso. Um exemplo da utilização desse tipo de estrutura são os sistemas baseados na notação Issue Based Information System - IBIS (Conklin, 2006). A ferramenta Compendium ${ }^{12}$ é um sistema desse tipo.

É interessante observar que "comunidade de prática" não é a única abordagem de Gestão do Conhecimento afetada por questões de rigidez do discurso. Outras abordagens também são afetadas, tais como group storytelling (Santoro et al., 2008; Nakasone \& Ishizuka, 2006) e design rationale (Medeiros, 2006). O trabalho de Carminatti (2006) propõe uma forma de estruturação dos fragmentos do discurso de um grupo para construir um relato preciso de um evento passado a partir da interação de um grupo que já tenha participado desse evento. Já o trabalho de Medeiros (2006) utiliza a estruturação do discurso para apoiar a representação de design rationale, de modo a registrar as decisões em designs baseados em modelos.

A etapa de adaptação do conhecimento compartilhado não é feita, muitas vezes, de maneira adequada, como ilustram os exemplos a seguir:

- Uma empresa brasileira que atua no segmento petrolífero importa tecnologia para a construção e utilização de plataformas de petróleo na costa brasileira. $\mathrm{O}$ projeto em questão foi importado de plataformas que atuam no mar do Norte, que é um ambiente muito

\footnotetext{
${ }^{10}$ Limitado, pois envolve apenas o publicador do conhecimento e o validador.

11 Entende-se por rigidez do discurso a necessidade de preencher os campos de um formulário com uma semântica muito bem definida, que, muitas vezes, restringe uma maior explicitação, por exemplo, do contexto da experiência.

$12 \mathrm{http} / / / \mathrm{kmi}$.open.ac.uk/projects/compendium/
} 
mais hostil e frio que a costa brasileira. Então, as primeiras plataformas construídas com essa tecnologia utilizadas no Brasil eram totalmente fechadas, pois o projeto importava as especificações para as rigorosas condições do mar do Norte, bastante diferentes da realidade brasileira.

- O telhado dos supermercados de uma multinacional americana que atua no Brasil, país onde não neva, é construído para resistir a uma carga de dois metros de neve, tal como nos Estado Unidos, país onde neva.

Esses exemplos mostram que, apesar de se reutilizar um conhecimento compartilhado, ele não é adaptado de forma adequada, uma vez que não traz consigo uma informação de contexto adequada à sua utilização.

\subsection{Os modos de conversão do conhecimento}

Segundo Nonaka \& Takeuchi (1995), a criação de conhecimento ocorre a partir da interação entre conhecimento tácito e conhecimento explícito. São quatro os modos de conversão de conhecimentos:

- Socialização (de conhecimento tácito para conhecimento tácito) trata-se de um processo de compartilhamento de experiências, e, a partir daí, da criação do conhecimento tácito, como modelos mentais ou habilidades técnicas compartilhadas. Um indivíduo pode adquirir conhecimento tácito diretamente de outros sem usar a linguagem. Os aprendizes trabalham com seus mestres e aprendem sua arte não por meio da linguagem, mas da observação, da imitação e da prática.

- Externalização (de conhecimento tácito para conhecimento explícito) - trata-se de um processo de criação do conhecimento perfeito, na medida em que o conhecimento tácito se torna explícito, expresso na forma de metáforas, analogias, conceitos, hipóteses ou modelos. Dentre os quatro modos de conversão do conhecimento, este é a chave para a criação do conhecimento, pois cria conceitos explícitos a partir do conhecimento tácito. Como se pode converter conhecimento tácito em explícito de forma eficiente e eficaz? A resposta está no uso de metáforas, de analogias e de modelos. 
- Combinação (de conhecimento explícito para conhecimento explícito) - este modo de conversão do conhecimento envolve a combinação de conjuntos diferentes de conhecimento explícito. Os indivíduos trocam e combinam conhecimentos por meio de documentos, reuniões, conversas ao telefone ou redes de comunicação computadorizadas. A reconfiguração das informações existentes por meio da classificação, do acréscimo, da combinação (por exemplo, através de inferências lógicas) e da categorização do conhecimento explícito (como o realizado em banco de dados de computadores) pode levar a novos conhecimentos.

- Internalização (de conhecimento explícito em conhecimento tácito) este processo está intimamente relacionado ao "aprender fazendo". Para que o conhecimento explícito se torne tácito, são necessárias a verbalização e a representação do conhecimento sob a forma de documentos, manuais ou histórias orais. Esses materiais ajudam os indivíduos a internalizarem suas experiências, aumentando, assim, seu conhecimento tácito. Além disso, também facilitam a transferência do conhecimento explícito a outras pessoas, ajudandoas a vivenciar, indiretamente, as experiências de terceiros.

Esses quatro modos de conversão compõem o modelo SECI (figura 5), em que o conhecimento da organização vai aumentando por meio da passagem entre os quatro quadrantes.

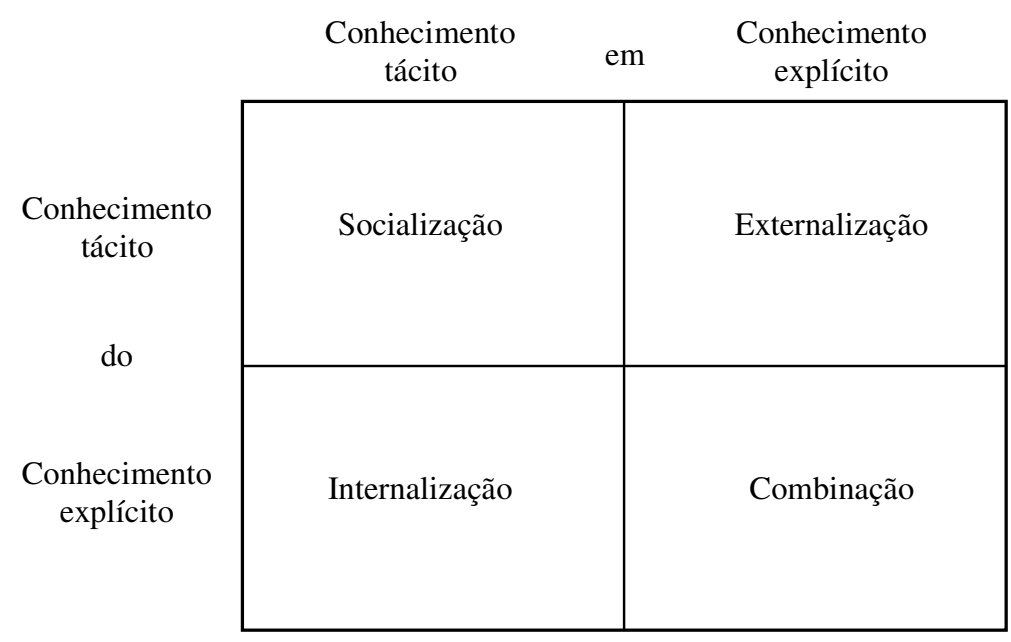

Figura 5 - O modelo SECI. Fonte: Nonaka \& Takeuchi (1995). 


\subsection{As práticas de GC}

As práticas de Gestão do Conhecimento têm por objetivo permitir a reutilização e a criação de conhecimentos dentro das empresas. Conforme discutido na Introdução, essas práticas podem suportar uma ou mais etapas do framework de GC. Apresentam-se a seguir, algumas práticas que serão mencionadas adiante neste trabalho e como elas se enquadram dentro deste framework.

\subsubsection{Comunidade de prática}

Etienne Wenger assim define comunidade de prática:

\footnotetext{
"Um grupo de indivíduos que compartilham uma preocupação, um conjunto de soluções, ou um entusiasmo sobre um assunto, e que aprofundam seus conhecimentos e experiências nesse assunto através de interação contínua" (Wenger et al., 2002).
}

$\mathrm{O}$ conceito em si não determina a necessidade de qualquer instrumento tecnológico para a existência da comunidade. O importante é ter um grupo de pessoas que lidam com uma mesma prática e que estejam dispostas a compartilhar suas experiências vividas dentro da comunidade, visando aperfeiçoar essa prática. Por exemplo, na Idade Média os grêmios de artesãos possuíam uma orientação semelhante, traduzida na existência da aprendizagem pela prática, em que a competência era transmitida na relação entre o aprendiz e o artesão no próprio decurso da atividade laboral (Souza-Silva, 2005).

Com a introdução da web e o desenvolvimento de ferramentas de tecnologia da informação, que auxiliam na dinâmica de colaboração entre as pessoas, permitiu-se a alavancagem não somente das comunidades de prática, como também de outros tipos de agrupamentos de pessoas voltadas para outros fins, tais como: comunidades de aprendizado (Cartelli, 2006), grupos virtuais (Wasko \& Teigland, 2006) e grupos de trabalho (Wasko \& Teigland, 2006).

\subsubsection{Taxonomias e ontologias}

O termo ontologia é originário da Filosofia. Ontologia é um ramo da Filosofia que lida com a natureza e a organização do ser. Esse termo foi 
introduzido por Aristóteles em Metafísica, IV, 1. No contexto da pesquisa em “ontologia", filósofos tentam responder às questões "O que é um ser?" e "Quais são as características comuns de todos os seres?” (Maedche, 2002).

Taxonomia (que é caso particular de uma ontologia) é um instrumento muito utilizado em GC para classificar os conteúdos que se deseja organizar. A ontologia é utilizada para construir representações de determinada área de conhecimento. Um exemplo é a realização de inferências automáticas, o que permite obter conclusões que não foram explicitamente inseridas pelo usuário em uma base.

Entre as várias definições de ontologia, uma muito interessante é a apresentada por Fensel (2001), proveniente de T. R. Gruber, em seu artigo " $A$ Translation Approach to Portable Ontology Specification":

"Uma ontologia é uma especificação formal explícita de uma conceitualização compartilhada."

Nesta definição é importante explicitar o significado de algumas palavras: "conceitualização" refere-se a um modelo abstrato de algum fenômeno que identifique suas características relevantes; "explícita" significa que os tipos de conceitos usados e as limitações do uso deles devem ser definidos de forma clara; "formal" refere-se ao fato de que a ontologia deve ter uma semântica não ambígua e, portanto, ser passível de processamento por uma máquina; e "compartilhada" reflete a noção de que a ontologia captura um conhecimento consensual, isto é, esse conhecimento não deve ser restrito a alguns indivíduos, mas aceito por um grupo de pessoas (Fensel, 2001).

Segundo Maedche (2002), os componentes de uma ontologia são:

- Um conjunto de conceitos e a hierarquia entre eles; ou seja, uma taxonomia. Os conceitos podem ser abstratos (por exemplo, força) ou concretos (por exemplo, carro), elementares (por exemplo, elétron) ou compostos (por exemplo, átomo), reais ou fictícios. Um exemplo de taxonomia: o conceito homem é um subconceito do conceito pessoa.

- Um conjunto de relacionamentos entre esses conceitos. Um exemplo de relacionamento entre os conceitos de pessoa e carro é o relacionamento de ser-dono. 
- Um conjunto de funções. Função é um caso especial de relacionamento em que um conjunto de elementos tem uma relação única com outro elemento. Um exemplo de função é ser_pais_biológicos, em que um conceito homem e um conceito mulher estão relacionados a um conceito pessoa.

- Um conjunto de axiomas; ou seja, regras que são sempre verdade. Um exemplo de axioma é afirmar que toda pessoa tem uma mãe.

- Um conjunto de instâncias que são um conhecimento prévio existente na ontologia.

Guimarães (2002), apresenta algumas metodologias de construção de ontologias. Grande parte das metodologias utilizadas para a construção de ontologias necessita da participação ativa de experts no tema da ontologia, em uma ou mais reuniões o que nem sempre é fácil se conseguir no ambiente empresarial.

\subsubsection{Análise de redes sociais}

Devido à dificuldade de explicitar o conhecimento tácito, a principal forma de transferência desse tipo de conhecimento é por meio do contato entre as pessoas. Assim, para que essa transferência ocorra de maneira eficiente, é importante entender como se dá a interação entre as pessoas. Uma forma de obter esse entendimento é com a ajuda da técnica de análise de rede social.

A análise de rede social é uma ferramenta de diagnóstico que permite, ao final de sua aplicação, compreender e identificar problemas no fluxo de informação e conhecimento entre as pessoas que compõem a rede analisada. É possível, por exemplo, encontrar gargalos no fluxo da rede, pessoas isoladas e pessoas que têm posição privilegiada de divulgação de informações na rede, entre outras análises.

Normalmente, a análise de rede social é realizada em um grupo fechado (grupo alvo). As seguintes etapas compõem o diagnóstico de uma rede social em um grupo fechado (Guimarães \& Melo, 2005):

a) Identificação do grupo que será analisado - grupos em que a colaboração entre seus membros proporciona grande diferencial para a empresa são fortes candidatos a serem analisados por essa técnica. 
b) Construção do questionário - o objetivo do questionário em uma análise de rede social é coletar informações sobre os relacionamentos de cada pessoa que compõe o grupo, de forma a entender a forma de trabalho do grupo que está sendo analisado.

c) Coleta das informações - as principais formas de coleta são: entrevista com os membros do grupo, resposta direta a um questionário ou algumas formas indiretas de obtenção das informações (por exemplo: análise de e-mails trocados).

d) Análise das informações - é possível tanto a análise visual das respostas obtidas como a análise qualitativa, por meio de indicadores, com o objetivo de identificar padrões nas redes (gargalos, pessoas isoladas etc.). A externalização desses padrões é um dos principais produtos dessa análise.

e) Apresentação do resultado - visa à proposição de ações de melhoria.

Conforme Guimarães \& Melo (2005), a forma de coleta das informações pela qual se obtém o maior número de respostas é aquela efetuada por meio de entrevista com cada um dos membros do grupo. Porém, sua desvantagem prendese ao grande custo de tempo e recursos, uma vez que cada membro do grupo deve ser entrevistado.

\subsubsection{Group storytelling}

O conceito básico de group storytelling é uma evolução do Storytelling (Schank, 2000). Dado um fenômeno, as pessoas que participaram dele podem se recordar de partes do conhecimento sobre ele e podem descrevê-lo com suas próprias palavras. Esse conhecimento é somente parcial, porém pode ser completado por meio da participação de outras pessoas (Santoro at el., 2008).

O uso de depoimentos como forma de coleta de informações de uma história é interessante, pois essa forma de representação (linguagem natural) é muito aderente ao processo de cognição humana (o processo de história oral data de 300.000 A.C.) (Levy, 2010). Isso ocorre da mesma forma que a representação numérica decimal está para a cognição humana (o sistema decimal para o número de dedos das mãos). 
Histórias reais em organizações são, geralmente, experiências de grupo. Dessa forma, alguns autores propõem técnicas de group storytelling, método mais apropriado que o Storytelling individual quando há várias pessoas envolvidas no cenário que está sendo construído. Um grupo constrói, conjuntamente, a história sobre um trabalho executado ou uma situação experimentada pelos seus membros. Uma vez que cada participante desempenha um papel nesse cenário, as histórias escritas por esse grupo irão, provavelmente, conter mais detalhes valiosos e todos terão a oportunidade de apresentar sua visão sobre o que ocorreu (Santoro \& Brézillon, 2005).

Essa dinâmica coletiva de depoimentos é interessante por permitir que todos, envolvidos ou não diretamente no fenômeno, possam publicar depoimentos sobre esse fenômeno específico. A experiência no Wikipedia revela a existência de um modelo de cauda longa (Anderson, 2006), em que poucas pessoas publicam muito e muitas publicam pouco. Ambos os grupos são importantes na construção desse conhecimento coletivo sobre o fenômeno (ver figura 6).

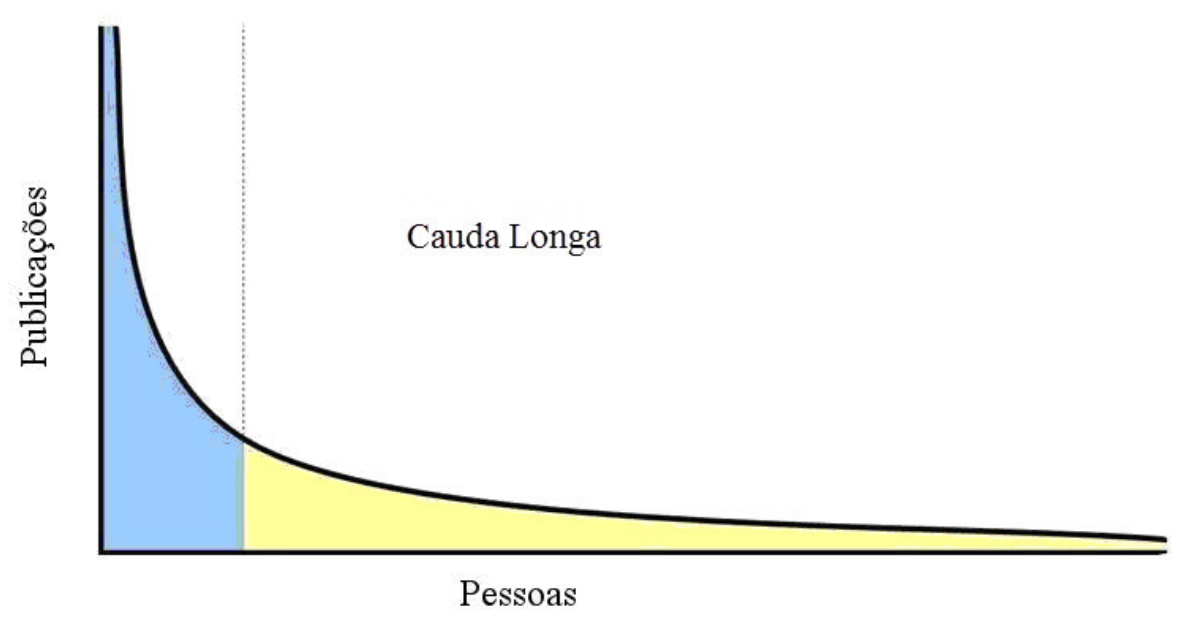

Figura 6 - O conceito de cauda longa exemplificado no Wikipedia. Fonte: Anderson (2006). 


\subsubsection{Práticas no framework de GC}

A tabela 1 ilustra como essas práticas se enquadram no framework GC.

\begin{tabular}{|c|c|c|c|c|c|c|c|c|}
\hline & \multicolumn{7}{|c|}{ Framework de GC } \\
\hline & & Identificar & Coletar & Organizar & Compartilhar & Adaptar & Usar & Criar \\
\hline \multirow{4}{*}{ 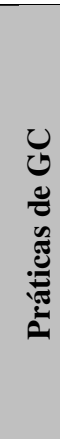 } & $\begin{array}{c}\text { Comunidades } \\
\text { de Prática }\end{array}$ & & Sim & Sim & Sim & & & \\
\hline & $\begin{array}{c}\text { Taxonomias e } \\
\text { Ontologias }\end{array}$ & & & Sim & & & & \\
\hline & $\begin{array}{c}\text { Análise de } \\
\text { Redes Sociais }\end{array}$ & Sim & Sim & Sim & & & & \\
\hline & $\begin{array}{c}\text { Group } \\
\text { Storytelling }\end{array}$ & & Sim & Sim & & & & \\
\hline
\end{tabular}

Tabela 1 - Práticas versus framework de GC.

\subsection{Exemplo de uso}

Como forma de melhorar a gestão do conhecimento produzido coletivamente, vê-se que é necessário suportar e combinar as práticas de GC citadas.

Deve-se facilitar a geração de conteúdo na execução de um group storytelling. Para isso, o uso de uma plataforma de wiki comum já seria suficiente para suportar essa prática dentro de uma comunidade. Cita-se, a seguir, um exemplo de material real fruto da aplicação de um group storytelling.

“... Veja bem, você pode usar o trabalho matricial para fazer pequenos projetos que não tem problema, funciona muito bem. Mas se você olhar a monta e a complexidade desse projeto você vai dizer: "Isso é um bando de loucos". E se você olha tudo o que o IPA fala pra você fazer, ele fala: "Não faça assim, não vai por aí. Se você quiser que dê tudo errado, faça multifuncional, vai dar tudo errado". Obviamente, que pro Fel 1 tudo isso deu para fazer. Foi duro, foi difícil, foi uma experiência inacreditável, coisa que a gente, em certos momentos, não acreditava que tivesse avançado... Se você fosse nos fundamentos, vendo a natureza e a complexidade do projeto, se você fosse nos fundamentos e ver como se gerencia um projeto. A primeira coisa que o cara faz: Monte uma estrutura sólida, competente, para tocar esse negócio, senão não vai dar certo, vai dar tudo errado. Mas funcionou, pro Fel 1, funcionou, inacreditavelmente. ...." (trecho do depoimento do Depoente 15)

“... A gente estava no Fel 1, e a gente precisava contar, então, com uma equipe matricial, que eram pessoas do CPLAM, pessoas da Área Industrial, pessoas da Área de Meio Ambiente, e tal... e éramos um grupo de pessoas de quase 30 
pessoas, mas que cada uma ficava nos seus locais de trabalho, nas suas atividades, e tínhamos as reuniões mensais, quinzenais, de acordo com a dinâmica do projeto. Bom, e, por essa característica da equipe matricial, o pessoal sentia que faltava algum instrumento tecnológico que permitisse compensar a dispersão geográfica, o comprometimento com o projeto para manter as pessoas atualizadas, e tal. Eu falei: "Eu acho que posso colaborar com vocês, nesse aspecto, porque eu utilizando tecnologias da informação, tal, tal, tal." E aí, tem um programa, um produto da Lotus, chamado QuickPlace, que você faz essas dinâmicas, mantém todo mundo atualizado, envia mensagens, recebe, faz arquivos, bibliotecas virtuais, tal, tal, tal. E na época, foi muito bem aceito, foi muito útil. ..." (trecho do depoimento de Depoente 14)

A partir desse material bruto, deve-se ter instrumentos que facilitem o agrupamento, a análise e a síntese desses conteúdos. O uso de taxonomias como forma de gerar agrupamentos, a elaboração da rede social subjacente aos depoimentos e a explicitação dos relacionamentos entre os fragmentos são instrumentos importantes para a realização dessas análises. O uso do wiki semântico (seção 6.4) busca contribuir para isso. 
4

\section{Fundamentos}

Este capítulo descreve os principais conceitos e linguagens associados ao desenvolvimento de aplicações que se encontram alinhadas com o conceito de web semântica. Isso é discutido aqui, pois a solução tecnológica proposta se utilizará desses conceitos. Neste capítulo apresenta-se também o conceito de semiótica, que será utilizado para a elaboração da representação proposta.

\subsection{Web semântica}

A web, tal como é conhecida atualmente, constitui um magnífico repositório de dados e informações. No entanto, as máquinas, nesse contexto, possuem, basicamente, as funções de armazenamento e de recuperação de dados, dependendo totalmente da cognição humana para o processamento e a transformação desses dados em informações e conhecimento úteis e relevantes. A web semântica tem por objetivo principal descrever, semanticamente, os dados na web, de forma que agentes de software (Nwana, 1996) possam, além de armazenar, recuperar e exibir tais dados, processar, aprender, inferir e tomar decisões baseadas na semântica das informações (Nunes, 2005).

Cita-se como exemplo o fato de as ferramentas de busca, que existem atualmente, não conseguirem descobrir o significado preciso sobre o que trata determinada página na web, tendo que contar com certas heurísticas para tentar compreender o significado do conteúdo. Por exemplo, uma heurística muito utilizada consiste em tentar classificar a página segundo a frequência de ocorrência das palavras.

A proposta da web semântica feita por Tim Bernes-Lee (Berners-Lee et al., 2001) vem resolver esse tipo de problema, adicionando semântica às páginas da web. Para isso, conta com três tecnologias principais: XML, RDF e ontologias. A tecnologia de ontologias entra para fornecer uma estrutura semântica para anotação das páginas da web. Espera-se que com a estrutura fornecida pela web semântica seja possível realizar buscas mais precisas (uma vez que a semântica 
estará colocada em linguagem formal) e dar maior capacidade aos agentes de software que utilizam conteúdo da web (Guimarães, 2002).

\subsection{RDF, RDFS e OWL}

RDF (Beckett, 2004), RDFS (Brickley, 2004) e OWL (McGuinness \& Harmelen, 2004) formam a infraestrutura básica para o desenvolvimento da web semântica. Por meio dessas linguagens, é possível adicionar semântica a uma página na web. Elas são padrões propostos pelo World Wide Web Consortium (W3C). Essas linguagens se organizam em camadas (figura 7). À medida que se sobe de camada, maior é o poder de expressão da linguagem.

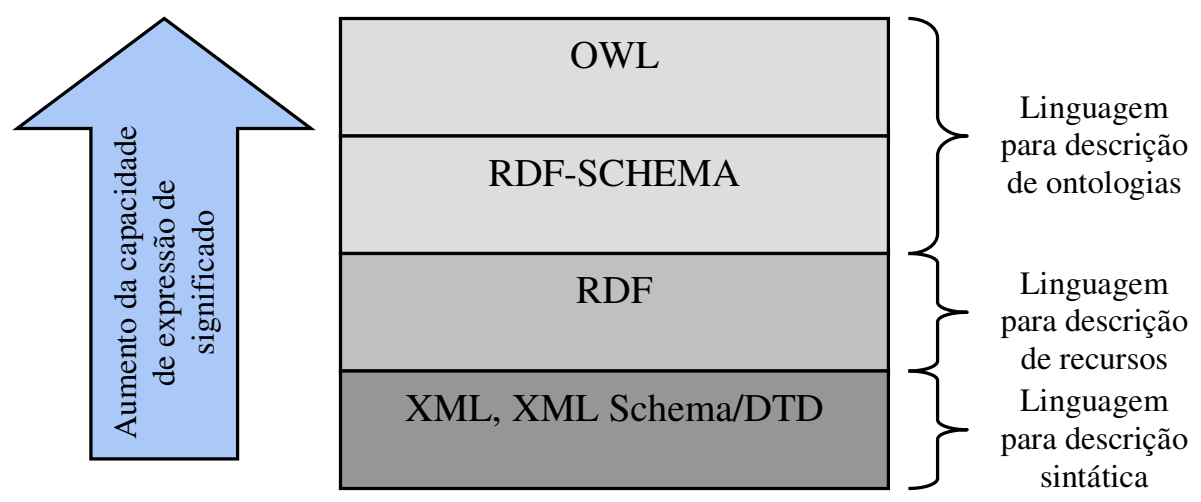

Figura 7 - Organização em camadas das linguagens.

O modelo de RDF (Resource Description Framework) proporciona uma forma de descrição de recursos existentes na WWW. Seu modelo de dados básico consiste na construção de declarações por meio de triplas.

Uma declaração, ou tripla, acontece quando um valor é atribuído a um recurso específico por meio de uma propriedade. Uma declaração é formada de três partes: sujeito, predicado e objeto. O sujeito da declaração é o recurso que está sendo descrito; o predicado é a propriedade que está sendo valorada; e o objeto é o valor do predicado específico para o sujeito descrito. O sujeito e o predicado da declaração são sempre recursos, porém o objeto da declaração pode ser tanto um recurso como um literal (string ou outro tipo de dado primitivo definido em XML) (Guimarães, 2002).

A figura 8 apresenta, de forma gráfica, um exemplo de declaração RDF (Brasília foi construída por Oscar Niemeyer). 


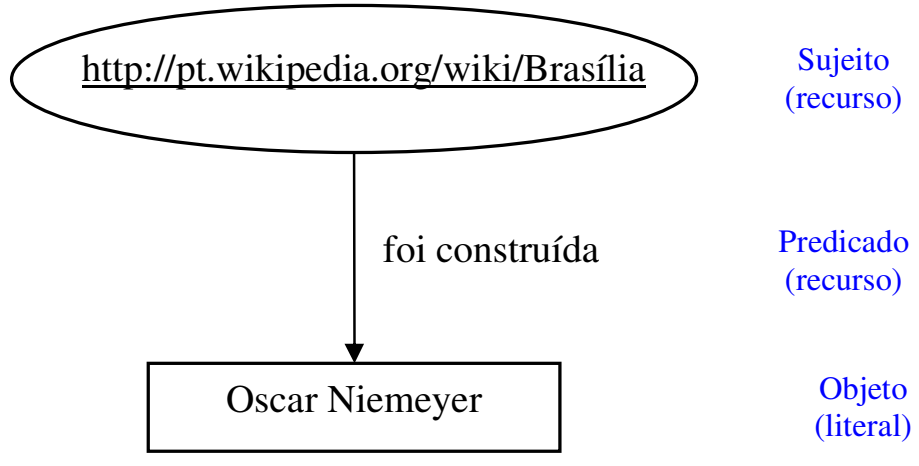

Figura 8 - Representação gráfica de uma declaração RDF.

O RDF, em formato textual serializável, é o primeiro nível de infraestrutura necessário para a construção de vocabulários de metadados para a web semântica. No entanto, o RDF é apenas um formato de dados que apresenta uma maneira genérica para representação de vocabulários, mas não indica como esses vocabulários devem ser descritos (Nunes, 2005).

O RDFS (RDF Schema) é uma linguagem por meio da qual é possível fornecer um sistema básico de tipos que pode ser usado nos modelos RDF. Por meio dele, é possível descrever classes, propriedades e outros recursos. É, ainda, utilizado para estruturar a informação contida nos modelos RDF, visando, assim, fornecer a capacidade de validação dos dados contidos no modelo. Com o uso de RDF Schema também é possível fazer inferências sobre as informações contidas em um modelo RDF. Apesar de o RDFS permitir certo nível de expressão semântica, seu poder de expressividade é baixo. A linguagem OWL (Web Ontology Language) busca solucionar essa questão.

O OWL é uma extensão semântica do formato RDF e da linguagem RDFS. O OWL fornece primitivas mais ricas para a descrição de classes, propriedades e relacionamentos entre grupos de recursos. Com o OWL é possível definir semanticamente termos de determinado vocabulário e seus inter-relacionamentos. Além de classes e propriedades, o OWL permite descrever conceitos lógicos, tais como cardinalidade, equivalência, disjunção e simetria, entre outros. OWL também pode ser descrito por meio do formato RDF e, portanto, possui uma representação e uma sintaxe em linguagem XML que pode ser processada e interpretada por máquinas (Nunes, 2005). 


\subsection{Wiki}

Fóruns de discussão, wikis e blogs são exemplos de algumas das ferramentas tecnológicas que poderiam ser usadas para suportar uma dinâmica de reflexão coletiva. Entre essas ferramentas, a mais flexível é o wiki, uma vez que as informações estão organizadas na forma de um grafo, enquanto, necessariamente, tanto no Fórum de discussão quanto no blog as informações estão organizadas em uma estrutura de árvore, o que nem sempre é o mais adequado para estruturar o desenvolvimento de um discurso.

O wiki tradicional é, essencialmente, uma coleção de páginas web conectada via elos hipertextuais. Apesar da existência de uma vasta gama de softwares desse tipo (por exemplo, MediaWiki, TikiWiki), todos eles possuem algumas características em comum, a saber (Schaffert et al., 2006):

a) Permitem a edição via browser, sendo, assim, muito acessíveis.

b) A sintaxe para a criação de conteúdo é mais simples do que a HTML.

c) Possuem mecanismo de controle de versão, viabilizando a restauração das informações (rollback).

d) É frequente uso de elos entre as páginas, devido à sintaxe simplificada para sua criação.

e) Apesar de ser possível, a maioria dos wikis não restringe o acesso para edição.

f) Permitem a edição colaborativa.

Apesar de o wiki facilitar a interação entre os envolvidos em uma dinâmica de reflexão coletiva, tanto ele quanto os Fóruns de discussão e os blogs apresentam algumas limitações:

a) Não permitem que os relacionamentos entre os depoimentos coletados tenham uma semântica formal definida. No wiki, é possível fazer relacionamentos entre depoimentos, porém esses relacionamentos não têm uma semântica formal.

b) Não há uma ontologia formal para a descrição do discurso que permita que relações subjacentes aos depoimentos sejam automaticamente concluídas. 
Essas duas limitações dificultam a atividade do facilitador responsável por consolidar o conteúdo presente nessas ferramentas. O uso de um wiki semântico, assunto discutido na seção 6.4, pode-se contornar essas limitações.

\subsection{Semiótica}

Semiótica é a ciência que estuda os signos. Por meio dela, é possível estudar o processo de atribuição de significado aos signos.

Nesta área, há duas linhas de pensamento em que os autores de referência são:

a) Ferdinand de Saussure (1857-1913), que desenvolveu os conceitos de semiótica para aplicação na área de Linguística.

b) Charles Sanders Peirce (1839-1914), que desenvolveu os conceitos de semiótica para estudar o conhecimento.

Neste trabalho, serão utilizados os conceitos desenvolvidos por este último autor.

\subsubsection{Signo}

Segundo Peirce, signo, ou representamen, é aquilo que, sob certo aspecto ou modo, representa algo para alguém. Qualquer coisa a que se consiga atribuir um significado é um signo.

O signo é um elemento ao qual se correlacionam três outros elementos: o representamen, o interpretante e o objeto.

a) Representamen é o signo; é a forma pela qual ele se acha representado. Por exemplo, a imagem que representa o Brasil "ㅇ.

b) Objeto é aquilo que o signo representa. Por exemplo, o Brasil.

c) Interpretante é o significado do signo na mente do intérprete. Em virtude de certa correspondência entre representamen e outros elementos vindos de experiências anteriores, é possível ao intérprete identificar não apenas o próprio representamen, mas também aquilo que nele se representa (o objeto), bem como a relação entre estes dois elementos (Prates, 1999). Por exemplo, a bandeira para alguém pode significar patriotismo.

O processo de atribuição de significado a um signo se chama "semiose". 
Cada signo dá origem a outro, uma vez que o interpretante também é um signo, o que acarreta um processo recursivo e teoricamente infinito. Peirce chama isso de "semiose ilimitada". Na prática, a semiose é finita, uma vez que os indivíduos não têm recursos (tempo) nem interesse de continuar esse processo, uma vez que tenham alcançado algum objetivo desejado. O que se pode concluir é que não se pode saber, exatamente, com quantas interações essa recursão parará.

\subsubsection{Tipos de raciocínio}

Caracterizam-se aqui as três espécies de raciocínio:

a) Dedução - é o modo de raciocínio que examina o estado das coisas colocado nas premissas, que elabora um diagrama desse estado de coisas, que percebe nas partes desse diagrama relações não explicitamente mencionadas, que se assegura, por meio de elaborações mentais sobre o diagrama, de que essas relações sempre subsistiriam ou, pelo menos, subsistiriam num certo número de casos, e conclui pela necessária, ou provável, verdade dessas relações (Peirce, 2005). Por exemplo, se tenho como premissas que "todo homem é mortal" e que "João é homem", por meio do processo dedutivo, concluo que "João é mortal".

b) Indução - é o modo de raciocínio que adota uma conclusão como aproximada por resultar de um método de inferência que, de modo geral, deve no final conduzir à verdade (Peirce, 2005). Por exemplo, obtenho um conjunto de amostras representativas de determinado carregamento e elas são de boa qualidade. Por indução, posso concluir que o carregamento é de boa qualidade.

c) Abdução (retrodução) - é o modo de raciocínio em que há a adoção provisória de uma hipótese em virtude de serem passíveis de verificação experimental todas suas possíveis consequências, de tal modo que se pode esperar que a persistência na aplicação do mesmo método acabe por revelar seu desacordo com os fatos se desacordo houver (Peirce, 2005). Um exemplo de aplicação deste tipo de raciocínio é quando se trabalha na fronteira de determinada ciência, em que ainda não há embasamento teórico forte (premissas). 


\subsubsection{O papel do pragmatismo}

Dado o que foi exposto, tem-se o seguinte dilema: se qualquer coisa que tenha um significado para alguém é um signo e o processo de interpretação de um signo (semiose) é recursivamente arbitrário, como é possível ocorrer o entendimento comum a respeito de algo por meio da comunicação entre dois indivíduos, sendo que essa comunicação nada mais é do que a troca de signos (no caso símbolos)?

O papel do pragmatismo vem a ser justamente o de "resolver" essa questão. O principal objetivo do pragmatismo é considerar a relação entre duas partes constituintes do signo: a representação (representamen) e o significado (interpretante). Segundo essa teoria, os interpretantes são um hábito; ou seja, uma resposta habitual para a presença das representações (representamen) mais ou menos próxima relativamente a seu objeto.

Assim, na prática, duas pessoas imersas em uma mesma cultura conseguem se comunicar com relativa facilidade. O que o pragmatismo diz é que o processo da semiose dos indivíduos é fortemente orientado por questões culturais e de contexto, o que possibilita a comunicação entre eles. Dessa forma, em uma comunidade de prática seus membros comungam esse contexto comum, o que facilita a comunicação entre eles. 


\section{5 \\ Trabalhos relacionados}

Este capítulo realiza uma revisão da literatura de trabalhos que buscam propor modelos de representação de histórias e narrativas. Isso é discutido aqui, pois servirá como uma das bases para elaboração da representação proposta.

Inicialmente, é importante distinguir o trabalho com histórias do trabalho relativo a design rationale e com cenários.

Segundo Jarke et al. (1998), um cenário é uma descrição do mundo, em um contexto e para um propósito, focando a interação de tarefas. Tem por fim ser um meio de comunicação entre stakeholders, servindo também, para limitar a engenharia de requisitos de um ou mais pontos de vista (usualmente, não completos, não consistentes e não formais). Já segundo Laporti et al. (2007), cenários são descrições narrativas de uma sequência de ações em que o usuário está envolvido quando executa uma tarefa específica.

A construção de cenários é usada por disciplinas como: Gerenciamento estratégico, Interação humano-computador e Engenharia de software e sistemas (Jarke et al., 1998). Pode-se observar que em todos esses usos a etapa de coleta de informações para a elaboração dos cenários se dá por meio de linguagem natural (da mesma forma que com histórias). Porém, mais agudamente que no uso de histórias, busca-se transformar essa descrição em linguagem natural em uma representação formal. Sampaio et al. (2000) e Sun et al. (2003) são alguns exemplos disso.

Em Sampaio et al. (2000); Sutcliffe (2003) e Laporti et al. (2007), a coleta de informações para a construção dos cenários requer a presença de um facilitador que conheça o método (por exemplo, realização de entrevistas estruturadas, leitura de documentação e observações). Em outras palavras, na forma tradicional, é necessário um analista para tentar extrair o conhecimento dos usuários. Em Laporti et al. (2007), é proposto que, a partir de uma dinâmica de group storytelling, se explicitem histórias, que, posteriormente, virarão cenários, os quais, por fim virarão casos de uso para o desenvolvimento de sistemas. Outro 
exemplo é o sistema Athena, que propõe uma forma colaborativa para o levantamento de requisitos, em que os stakeholders contam suas histórias sobre sistemas atuais e anteriores que apoiam determinada atividade. Essas histórias serão posteriormente transformadas em cenários e, então em casos de uso.

Outra distinção importante entre o uso de cenários e o uso de histórias se dá por meio do escopo de conteúdo que cada um deles busca alcançar. O relato de uma história pode se desdobrar em outras histórias, sendo isso um resultado interessante, pois propicia maior diversidade de pontos de vista. Já no uso de cenários esse escopo é limitado, uma vez que a partir deles constroem-se requisitos para o desenvolvimento de um sistema que necessita de um escopo bem definido. A tabela 2 resume as diferenças observadas.

\begin{tabular}{|l|c|c|}
\hline \multicolumn{1}{|c|}{ Características } & Histórias & Cenários \\
\hline Representação do conteúdo & Menos formal & Mais formal \\
\hline $\begin{array}{l}\text { Necessidade de facilitador } \\
\text { para coleta de informações }\end{array}$ & Menos necessário & Mais necessário \\
\hline Escopo do conteúdo & Mais abrangente & Mais limitado \\
\hline
\end{tabular}

Tabela 2 - Diferenças entre histórias e cenários.

O objetivo do design rationale é registrar as decisões de projeto, visando a sua adaptação e reutilização em situações semelhantes. Essas decisões são registradas durante o desenrolar do projeto ou posteriormente.

Já o trabalho com histórias tem por objetivo coletar depoimentos de pessoas que participaram de situações ou projetos já realizados (tempo passado), para que, posteriormente, esses conhecimentos também possam ser reutilizados. As pessoas descrevem os eventos e as informações de contexto deles. A tabela 3 apresenta as diferenças observadas.

\begin{tabular}{|l|c|c|}
\hline \multicolumn{1}{|c|}{ Características } & Histórias & Design Rationale \\
\hline O que é discutido & Projetos, Situações & Projetos \\
\hline $\begin{array}{l}\text { Tempo do que está sendo } \\
\text { discutido }\end{array}$ & Passado & Questões \\
\hline Elemento central & Eventos & $\begin{array}{c}\text { Grafo com as alternativas de } \\
\text { solução e decisões }\end{array}$ \\
\hline Resultados obtidos & $\begin{array}{c}\text { Conjunto de eventos que } \\
\text { compõem histórias }\end{array}$ & \multicolumn{2}{|c|}{} \\
\hline
\end{tabular}

Tabela 3 - Diferenças entre histórias e design rationale.

Em se tratando de sistemas que lidam com histórias, têm-se as seguintes linhas de trabalho:

- Sistemas que têm por objetivo promover a geração automática de narrativas a partir de padrões previamente especificados. O Virtual Storyteller (Oinonen, 2006) é um exemplo. 
- Sistemas que têm por objetivo permitir a modelagem das narrativas de vários atores para possibilitar a sua análise posterior. É um exemplo o Scenario Content Ontology (Sanfilippo, 2005).

- Sistemas que têm extração automática de conteúdos para a construção das narrativas. É um exemplo deste tipo o Scenario Content Ontology (Sanfilippo, 2005).

- Sistemas que lidam com narrativas de ficção, por exemplo, Ontomedia (Lawrence \& Schraefel, 2005), e outros que lidam com narrativas reais.

- O nível de granularidade da representação dos depoimentos que constroem uma fábula. Sistemas como Scenario Content Ontology (Sanfilippo, 2005) têm uma granularidade da representação dos depoimentos muito fina (detalhada), trabalhando no nível de montagem das frases (sujeito, verbo e predicado).

Têm-se aqui por objetivo concreto modelar a estrutura da história, visando facilitar tanto a coleta quanto a análise dos depoimentos que compõem essa história. Para isso, analisou-se a literatura sobre o tema "Histórias e Narrativas". Apresentam-se, a seguir, alguns trabalhos que orientaram a construção do modelo de ontologia.

\subsection{Níveis de representação}

A forma básica de representação escolhida, que orientou a construção da ontologia para o manuseio das histórias, é o uso de linguagem natural, pois esta forma é muito aderente ao processo de cognição humana (o processo de história oral data de 300.000 A.C.) (Levy, 2010).

Com o objetivo de representar o contexto específico da construção de histórias, é necessário, inicialmente, entender em que aspectos a história está sendo modelada. Os trabalhos de Tuffield (2005) e Oinonen (2006) discutem essa questão, apresentando uma organização em níveis.

Tuffield (2005) utiliza a visualização proposta por Bal (1997) com o objetivo de explicitar o que está sendo modelado em ontologias que estruturam narrativas. Ele propõe que a narrativa pode ser vista considerando três níveis: 
$1^{\circ}$.) A fábula (fabula), que representa a cronologia básica dos eventos que estão sendo descritos. A modelagem neste nível é vantajosa, pois provê uma base a partir da qual novas histórias podem ser geradas ou as existentes podem ser analisadas (como é o caso deste trabalho). É interessante também porque neste nível a informação básica pode ser expressa sem que seja "poluída" pela intenção do autor.

$2^{\circ}$.) A história (story), que é um subconjunto da fábula, reorganizado em uma sequência, visando a um efeito em particular - por exemplo, criar linhas de enredos (plot), instigar tensão ou expectativa ou informar ao usuário sobre o contexto de um tópico. Para uma dada fábula, é possível derivar uma série de histórias diferentes.

$3^{\circ}$.) A narrativa (narrative), que é uma forma de história, com toda a sua semântica. Qualquer história pode se transformar em diversas narrativas - por exemplo, um monólogo, um romance, um filme ou uma apresentação multimídia. Há a preocupação com os efeitos semânticos resultantes da forma de apresentação escolhida.

Conforme o autor, há sistemas diversos para cada um desses níveis: sistemas que trabalham com objetos e evento (nível da fábula), outros que lidam com a estrutura e organização do conteúdo (nível da história) e, ainda, outros que tentam modelar o efeito e o impacto do texto final no usuário (nível de narrativa).

Oinonen (2006) propõe um modelo que representa diferentes aspectos da narrativa. É importante observar que o autor desse trabalho tem por objetivo promover a geração automatizada de narrativas. É proposto, então, que a narrativa seja vista com base em cinco níveis:

$1^{\circ}$.) Rede semântica para o conhecimento do contexto da história constrói-se uma ontologia geral básica, capaz de descrever conceitos e possíveis relações dentro do domínio da história. São exemplos de construções neste nível: descrição do contexto do domínio da história e instanciação de alguns conceitos da ontologia geral em certo ponto no tempo, juntamente com seus valores correntes de propriedades e relacionamento.

$2^{\circ}$.) Representação dos personagens - constrói-se uma representação complexa e extensa dos personagens inteligentes que atuarão nos 
papéis da história. São exemplos informações acerca do estado físico dos personagens, suas percepções e crenças.

$3^{\circ}$.) Estrutura do enredo, como também as relações de causa efeito e temporalidade - as histórias e fragmentos de história são representados como uma rede causal ou um modelo de grafo de ações e eventos, ligados aos personagens e aos objetos relativos a ela. Aqui também há o registro temporal dos eventos.

$4^{\circ}$.) Representação dos conceitos de narratologias - para permitir a um sistema computadorizado raciocinar sobre os ingredientes que compõem um enredo dramático, é necessário que o modelo de representação da história inclua conceitos de narratologia: metaconhecimento sobre as estruturas de história e as propriedades de suas narrativas. Conceitos relevantes nesta questão incluem coerência $^{13}$, relevância ${ }^{14}$ e conflito ${ }^{15}$. Esses conceitos podem ser representados como uma relação n-aria, ligando elementos provenientes da representação da rede de um enredo. O conhecimento dessas relações pode ser usado por algoritmos de busca de padrões, visando detectar estruturas emocionalmente dramáticas da história e criar histórias mediante a manipulação de estruturas localizadas em história anteriores.

$5^{\circ}$.) Representação da emoção cognitiva da interação - o modelo de representação da história deve também incluir informação sobre os potenciais efeitos da história ou dos fragmentos de história, sobre o usuário (por exemplo: suspense), com base em seu feedback.

Pode-se observar na organização proposta por Oinonen (2006) que o primeiro e o segundo níveis são específicos para a geração automática de histórias. O terceiro nível compreende o da fábula e o da história do modelo de Bal (1997). O quinto nível compreende o da narrativa nesse mesmo modelo.

Neste trabalho, utiliza-se o nível da fábula.

\footnotetext{
${ }^{13}$ Grau de coerência de uma história é o número de objetos e eventos relatados cobertos em uma representação consistente de todo o enredo.

${ }^{14}$ A relevância de uma ação, ou evento, em uma história pode ser medida da perspectiva de um personagem na comunidade que compõe o mundo da história, ou um usuário.

${ }^{15}$ Conflito se dá quando pelo menos dois sujeitos compartilham um desejo contraditório sobre o estado de um mesmo objeto ou sobre as relações com esse objeto.
} 


\subsection{Ontologias para a representação de histórias e narrativas}

Apresentam-se nesta seção os principais trabalhos que lidam com histórias narrativas e fábulas. Busca-se aqui compreender a sua ontologia, ou estrutura de dados, utilizada nesses trabalhos, assim como outras ontologias que lidam com evento, conceito chave para os propósitos deste trabalho.

\subsubsection{ISRST: An Interest based on Storytelling Model using Rhetorical Relations}

O trabalho de Nakasone \& Ishizuka (2007) propõe um modelo de ontologia genérico para storytelling, que tem como base a organização dos eventos usando um subconjunto significativo de relações propostas pela Rhetorical Structure Theory (RST). O Interactive Storytelling RST (ISRST) é uma evolução do Storytelling RST (SRST) (Nakasone \& Ishizuka; 2006).

O objetivo da ontologia definida neste trabalho é a modelagem de histórias a partir de um conjunto de eventos, os quais serão processados por uma narrative engine, em que o usuário pode interagir com eles por meio da indicação do grau de interesse ao longo da apresentação de uma história, influenciando, assim, a sua trajetória (Nakasome, 2009). A figura 9 apresenta um exemplo de aplicação dessa ferramenta. 


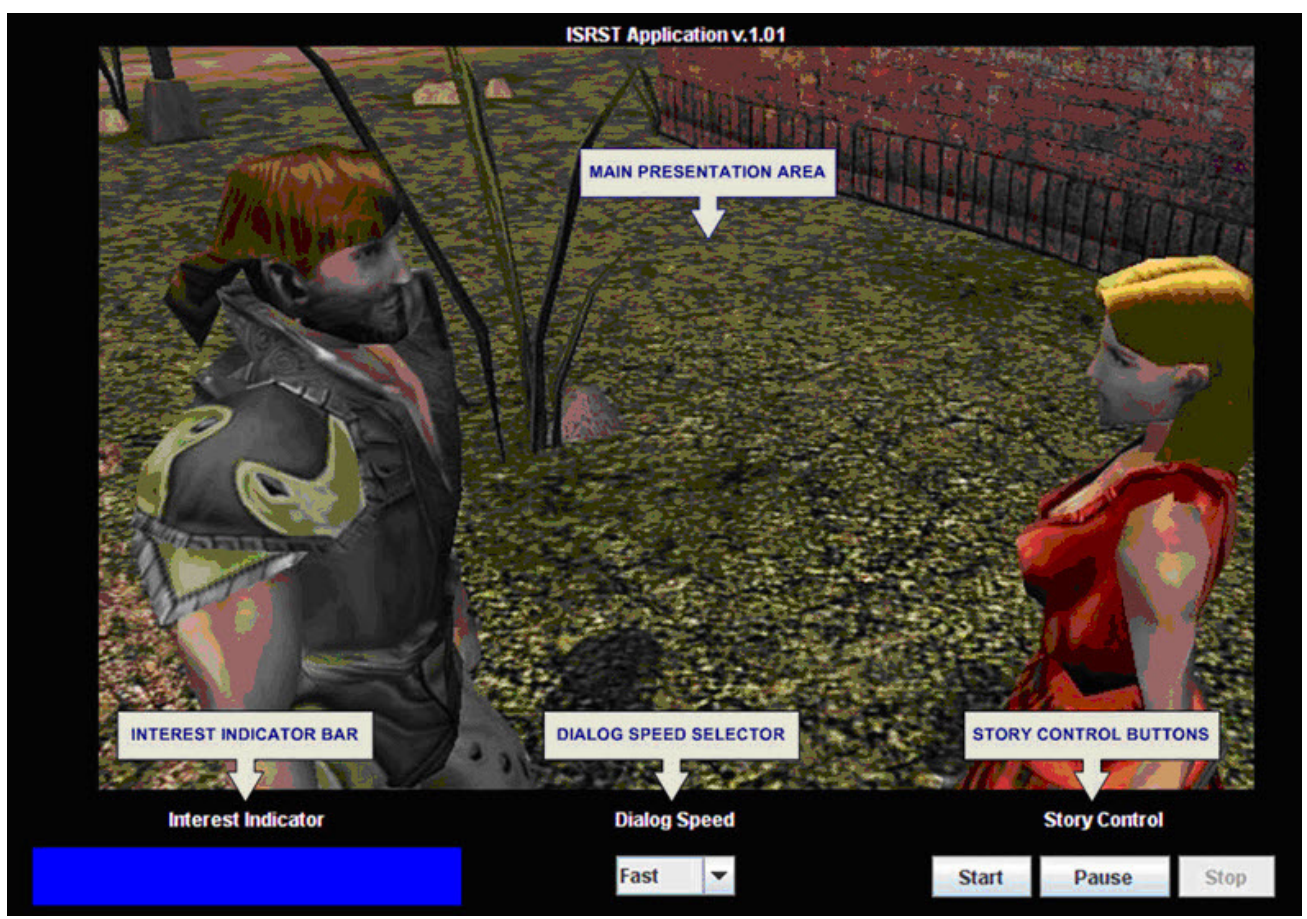

Figura 9 - Aplicação ISRST - tela principal. Fonte: Nakasone \& Ishizuka (2007).

As principais classes definidas na ontologia ISRST são:

- Conceito (Concept) - define um tópico específico a que uma apresentação, ou parte dela, pode se referir.

- Evento (Event) - é definido como um único pedaço de informação significativa que vale a pena ser apresentado. Devido à propriedade genérica do modelo, um evento pode se referir a uma parte de texto, um vídeo, uma imagem etc.

- Relação (Relation) - é uma ligação retórica entre duas entidades, que se refere a uma função retórica específica. A representação da relação entre dois eventos é dada pela seguinte construção: $(\mathrm{A} \rightarrow \mathrm{R}(\mathrm{X}) \rightarrow \mathrm{B})$, em que o evento $\mathrm{A}$ é a relação $\mathrm{R}$ do evento $\mathrm{B}$ aplicado com respeito ao agente $X$. Estas relações são um subgrupo do RST. A seguir, explica-se quais relações compõem esta classe.

- Agente (Agent) - é um ator que faz parte de uma relação e é afetado por ela.

- Origem e Destino - estas classes definem a posição de determinada entidade em uma relação. Uma entidade pode ser tanto um evento como uma cena. 
- Cena (Scene) - é definida por meio de um grafo composto de relações. Esta classe define o nível mínimo de organização na qual as histórias surgem. É uma estrutura recursiva, que identifica qual evento, ou outra cena, pode-se referenciar a uma origem e/ou destino.

- Episódio (Episode) - é definido como um conjunto de cenas, que são agrupadas em um contexto de um único conceito. Todavia, para esta versão da ontologia somente uma cena por episódio foi considerada.

- História (Story) - molda a história como um todo e é composta de um ou mais episódios.

A classe relações é composta pelos seguintes tipos:

- Background - um evento A é referido como o contexto em que outro evento $\mathrm{B}$, acontece. $\mathrm{O}$ evento $\mathrm{A}$ acontece antes do evento $\mathrm{B}$, porém ele não tem, necessariamente, uma relação de causa e efeito.

- Causa - quando um evento é identificado como a origem de outro. A causa é uma das principais relações na ontologia, porque é a que as pessoas distinguem mais claramente.

- Propósito - reflete que um evento deve ser apresentado antes que algum outro possa sê-lo. Embora tenha uma relação direta com a causa, seu uso é diferente, dado que indica uma condição para avançar na história.

- Resultado - indica que um evento é apresentado como uma consequiência direta de outro. Tem relação com o propósito, porém com mais conotações imediatas e finais. Esta relação é usada principalmente para indicar a apresentação de eventos finais durante a história.

- Contraste - para que qualquer história tenha qualidade narrativa, ela deve apresentar algum tipo de conflito entre dois ou mais eventos. Conflitos introduzidos como contrastes dão às histórias a oportunidade de aumentar a compreensão e o interesse da sua audiência, por meio da criação de uma tensão narrativa.

- Solução - fornece um caminho para definir como uma relação de contraste será resolvida. 
- Elaboração - um evento é apresentado para dar mais detalhes sobre outro.

- Avaliação - fornece um caminho para declarar uma conclusão final sobre um evento. É útil para os autores comunicarem uma mensagem, ou pensamento final, para a história como um todo.

- Sequência - estabelece uma ligação temporal linear entre os acontecimentos. É útil para forçar uma sequência na história, porém não deve ser usada como a principal forma de ligação entre os eventos.

Pode-se observar que a maioria das relações modeladas tem uma conotação temporal associada. A figura 10 apresenta o modelo da ontologia ISRST.

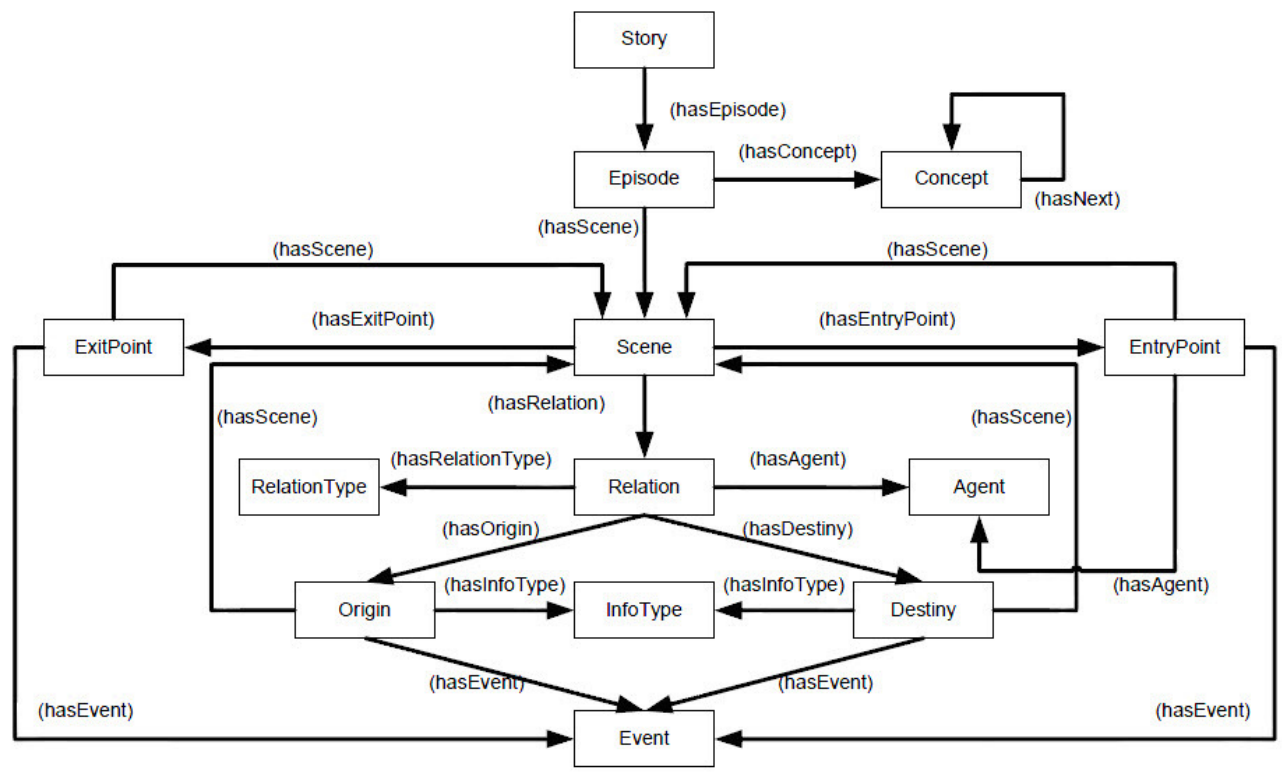

Figura 10 - O modelo da ontologia de ISRST. Fonte: Nakasone \& Ishizuka (2007).

\subsubsection{Virtual Storyteller}

O Virtual Storyteller é um framework multiagente utilizado para gerar histórias, as quais emergem a partir de simulações de personagens virtuais no ambiente. A geração da história acontece em duas fases: simulação; e apresentação.

$\mathrm{Na}$ fase de simulação, os agentes que representam os personagens trabalham, junto com o agente de enredo, para produzir uma sequência de eventos 
interessante. Os agentes, que representam os personagens, simulam a vida dos mesmos no ambiente da história. Eles possuem objetivos e razão sobre sua percepção, emoções experimentadas e tomam decisões no contexto desse ambiente. $\mathrm{O}$ agente de enredo possibilita a simulação por meio da inicialização de cenas, que especificam o estado inicial dos personagens e do ambiente da história para uma cena em particular. A sequência de eventos resultante da interação dos agentes dos personagens é capturada pelo agente de enredo, em uma representação formal (a fábula), que é o insumo para a fase de apresentação. $O$ agente do ambiente gerencia uma representação do mundo virtual, executando ações e eventos à medida em que eles ocorrem e enviando os resultados para o agente de enredo (Swartjes \& Theune, 2008).

$\mathrm{Na}$ fase de apresentação, o componente de narração transforma a fábula formal em uma história real, selecionando o conteúdo a ser narrado proveniente da fábula e aplicando técnicas de geração de linguagem nesse conteúdo, com o objetivo de produzir um texto (Swartjes \& Theune, 2008).

Apesar de esse trabalho focar a geração automática de histórias, foco este diferente do adotado nesta tese, ele apresenta um formato de representação da fábula que pode ser útil para os propósitos aqui pretendidos.

A figura 11 mostra a representação da fábula. As seguintes classes são utilizadas (Swartjes \& Theune, 2008):

- Elemento de inicialização (setting element) - descreve um aspecto do ambiente da história que todos os personagens compartilham e consideram como verdade.

- Objetivo (goal) - é o principal direcionador da ação dos personagens. Neste contexto, ele descreve o desejo de atingir, manter, deixar ou evitar certos estados, atividades ou objetos.

- Ações (actions) - é usado para indicar uma modificação do estado do ambiente realizado de forma intencional por um personagem.

- Resultados (outcomes) - é um conceito mental, o qual relaciona um objetivo ao seu alcance ou não. Quando um personagem acredita que um de seus objetivos foi cumprido, este é dado como alcançado. Caso esse personagem acredite que as ações executadas não permitiram alcançar o objetivo, o resultado é dado como negativo. 
- Eventos (events) - modificam o estado do ambiente da história, independente da ação de qualquer personagem.

- Percepções (perceptions) - descrevem as propriedades do ambiente que um personagem pode presenciar.

- Elementos internos (internal elements) - são questões internas do personagem, tais como cognição, emoções, sentimento e crenças.

Em uma fábula, essas classes são conectadas por quatro tipos de relações (Swartjes \& Theune, 2006):

- Causalidade física (physical causality) - quando um evento ou ação acontece no ambiente da história e provoca o acontecimento de qualquer outra coisa (por exemplo, quando o cavaleiro apunhala o dragão com sua espada, isso pode causar fisicamente a morte do dragão).

- Motivação (motivation) - é uma causa intencional, originada dentro da mente do personagem (por exemplo, o desejo de matar um monstro pode motivar o rei a apunhalar o dragão com a espada).

- Causalidade psicológica (psychological causality) - é quando ocorre dentro da mente do personagem (por exemplo, se o rei acredita que o dragão irá matá-lo, isso, psicologicamente, provoca medo nele).

- Possibilidade (enable) - é a forma mais fraca de relação de causa. Se um elemento A da fábula possibilita outro elemento $\mathrm{B}$, isso significa que B é possível por causa de A, e nada mais que isso. 


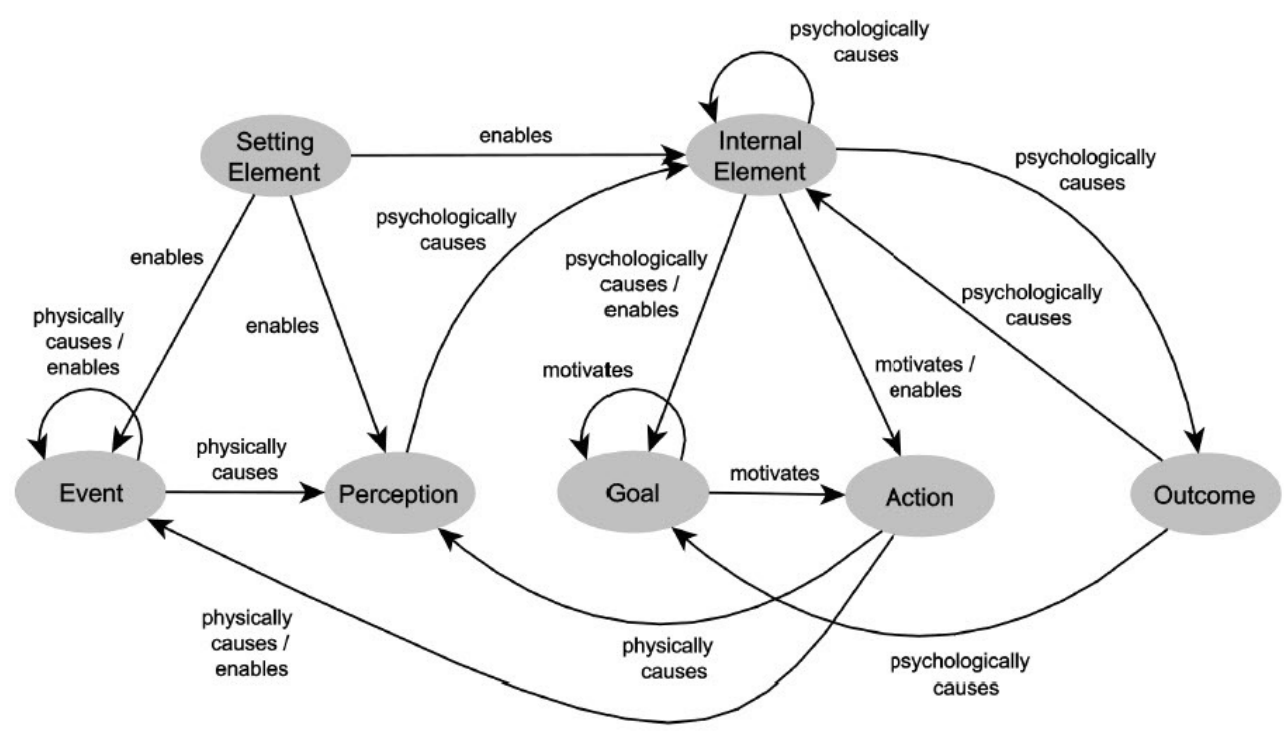

Figura 11 - Modelo da fábula. Fonte: Swartjes \& Theune (2008).

\subsubsection{StoryMapper}

StoryMapper é uma ferramenta que utiliza mapas conceituais ${ }^{16}$ para representar o conhecimento, visando facilitar sua captura, organização e compartilhamento. O objetivo desta ferramenta é externalizar o conhecimento tácito de um grupo por meio da técnica colaborativa de group storytelling. No trabalho de Acosta (2004), o uso do StoryMapper é apresentado juntamente com a técnica de group storytelling, com o objetivo de externalizar os conhecimentos tácitos de projetos já realizados. A figura 12 apresenta a interface do StoryMapper.

No processo de group storytelling, os seguintes papéis são necessários (Valle, 2003):

- Narrador (StoryTeller) - deve ser capaz de usar uma vasta gama de expressões e histórias organizacionais, de forma a permitir que os conhecimentos, tácitos e explícitos, possam ser bem representados.

- Organizador (Organizer) - uma vez que a história está registrada, é necessário verificar a qualidade de seu conteúdo e observar se todas as partes estão relacionadas entre si e se a história como um todo faz

${ }^{16}$ Os mapas conceituais são estruturas compostas por conceitos, que, usualmente, aparecem dentro de círculos ou quadrados. O relacionamento entre esses conceitos deve ser indicado por meio de linhas que conectam dois conceitos. As palavras sobre a linha, conhecidas como "palavras 
sentido. Ele pode organizar, editar e dar o formato final à história, depois que os narradores tenham participado.

- Associador / Indexador (Associator / Indexer) - é responsável por ligar os itens relacionados na história registrada. Podem ser armazenados em qualquer mídia (texto, imagens, vídeos etc.).

- Ouvinte da história (Story listener) - deve ser capaz de entender as várias perspectivas da história, considerando o que é implícito e explícito, como também o que é emocional e o que é factual nos eventos da narração.

Além desses papéis, há o coordenador, que é responsável pelas seguintes tarefas:

a) definir os membros do grupo;

b) fazer a atribuição de papéis para cada membro (atribuir uma cor para cada pessoa);

c) definir a semântica dos relacionamentos, associando uma cor para cada tipo;

d) declarar o assunto principal da história que será relatada;

e) definir a janela de tempo da atividade do grupo;

f) definir a janela de tempo da história que está sendo contada; e

g) definir o formulário de entrada dos nós mais adequado ao contexto discutido.

Uma vez que o coordenador atribui os itens "c" e "g", pode-se concluir que o modelo de dados do StoryMapper é composto por relacionamento e nós, que são configurados pelo coordenador. Dessa forma, não há uma ontologia formal que permita a realização de inferências a partir dos conteúdos publicados. 


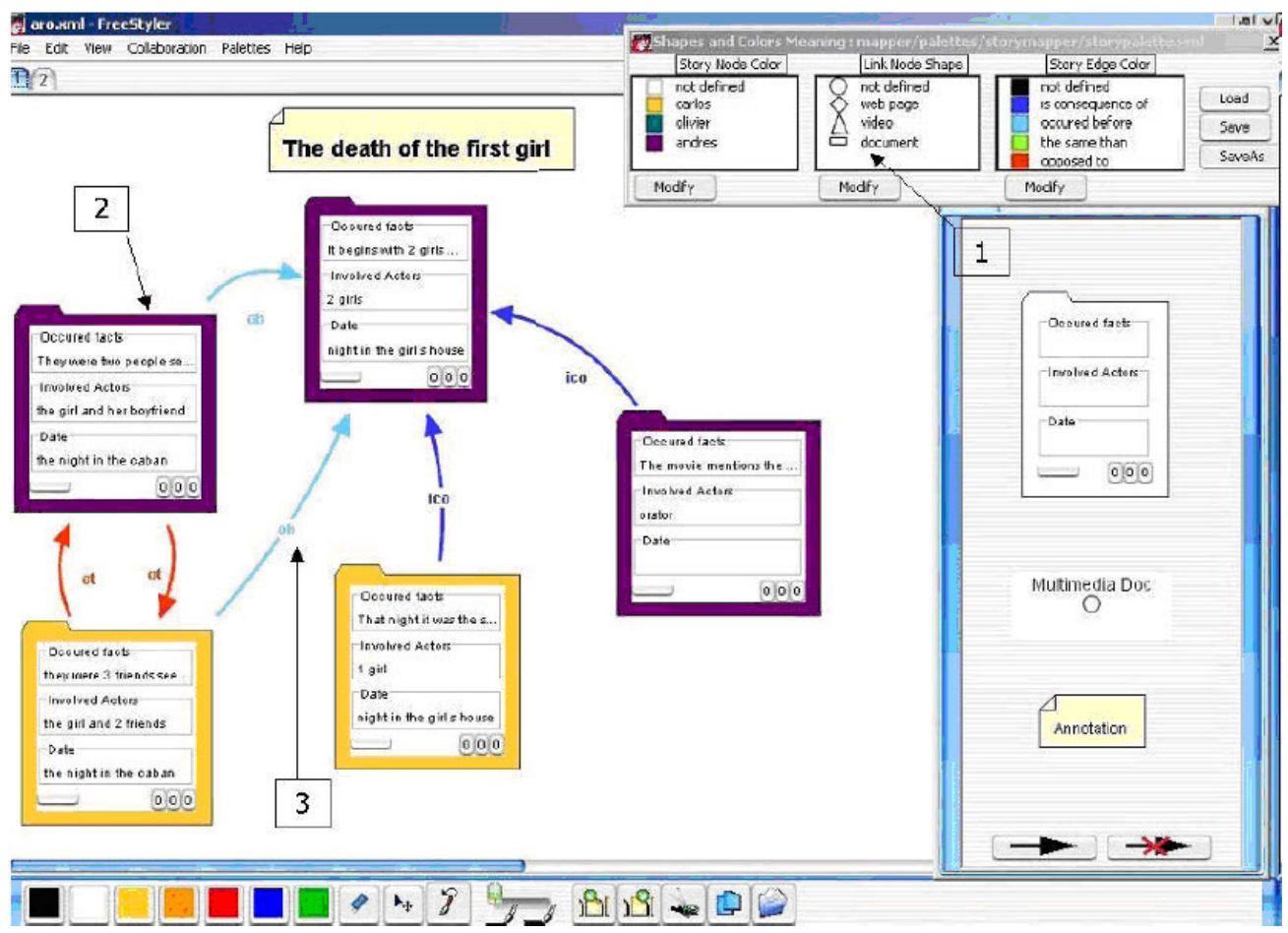

Figura 12 - Interface do StoryMapper. Fonte: Valle (2003).

\subsubsection{Tellstory}

Tellstory (Santoro \& Brézillon, 2005) é uma ferramenta voltada para auxiliar a explicitação do conhecimento tácito, visando a sua reutilização no contexto empresarial. Visa apoiar a dinâmica de group storytelling. Exemplo de aplicação prática desta ferramenta: sua utilização para modelagem de processos de uma empresa (Santoro et al., 2008).

A maioria dos processos de storytelling aplicados em empresas baseia-se em entrevistas individuais, realizadas por um profissional de storytelling, que sintetiza os eventos coletados e escreve sua própria interpretação em um único texto. Neste caso, a história representa uma fração daquilo que cada indivíduo percebe, agrupada de acordo com o ponto de vista do narrador (Santoro \& Brézillon, 2005).

Contudo, histórias reais em organizações são, geralmente, experiências de grupo. Dessa forma, alguns autores propõem técnicas de group storytelling (Santoro et al., 2008; Nakasone \& Ishizuka, 2006). Este método é mais apropriado que o storytelling individual quando existem várias pessoas envolvidas no cenário que está sendo construído. Um grupo constrói, conjuntamente, uma história sobre 
um trabalho executado, ou uma situação experimentada pelos seus membros. Uma vez que cada participante desempenha um papel neste cenário, as histórias escritas por esse grupo irão conter mais detalhes valiosos, e todos terão a oportunidade de apresentar suas visões sobre aquilo que ocorreu (Santoro \& Brézillon, 2005).

Os indivíduos podem participar da construção da narrativa, desempenhando um dos seguintes papéis, segundo a forma de uso da ferramenta (Santoro \& Brézillon, 2005):

- Moderador - criador e responsável pela coordenação das atividades sobre a história.

- Narrador - membro que tem a permissão de contribuir com eventos.

- Editor - pessoa que irá escrever o texto final.

- Comentarista - responsável pela identificação de conhecimento tácito externalizado na história.

Esses papéis são responsáveis por cada passo no processo de group storytelling. Quando o grupo de narradores compreende que a história já apresenta um fluxo de eventos suficiente, o moderador pode concluí-la, ocasião em que o editor coleta os eventos e escreve um texto final com base na sequência. Finalmente, o comentarista busca por conhecimentos tácitos que podem ser identificados na história e que estão registrados dentro do texto final.

Apesar de este sistema não ter como base uma ontologia formal, que permita que se façam inferências, alguns conceitos são utilizados no modelo do sistema:

- História - sequência de eventos ligados entre si por uma linha de mesmo significado, construída por relacionamentos de causa e efeito entre um fato e seu sucessor.

- Evento - conjunto de fatos lembrados pelos usuários que acontecem ao longo da história. Devem ser interligados em um fluxo temporal (a figura 13 apresenta um exemplo de fluxo temporal de eventos). Eventos podem ser aglutinados ou separados conforme o seu conteúdo.

- Comentários - observações sobre um evento em formato de fórum.

- Informações de contexto - informações sobre um evento que visam explicitar o contexto deste. 


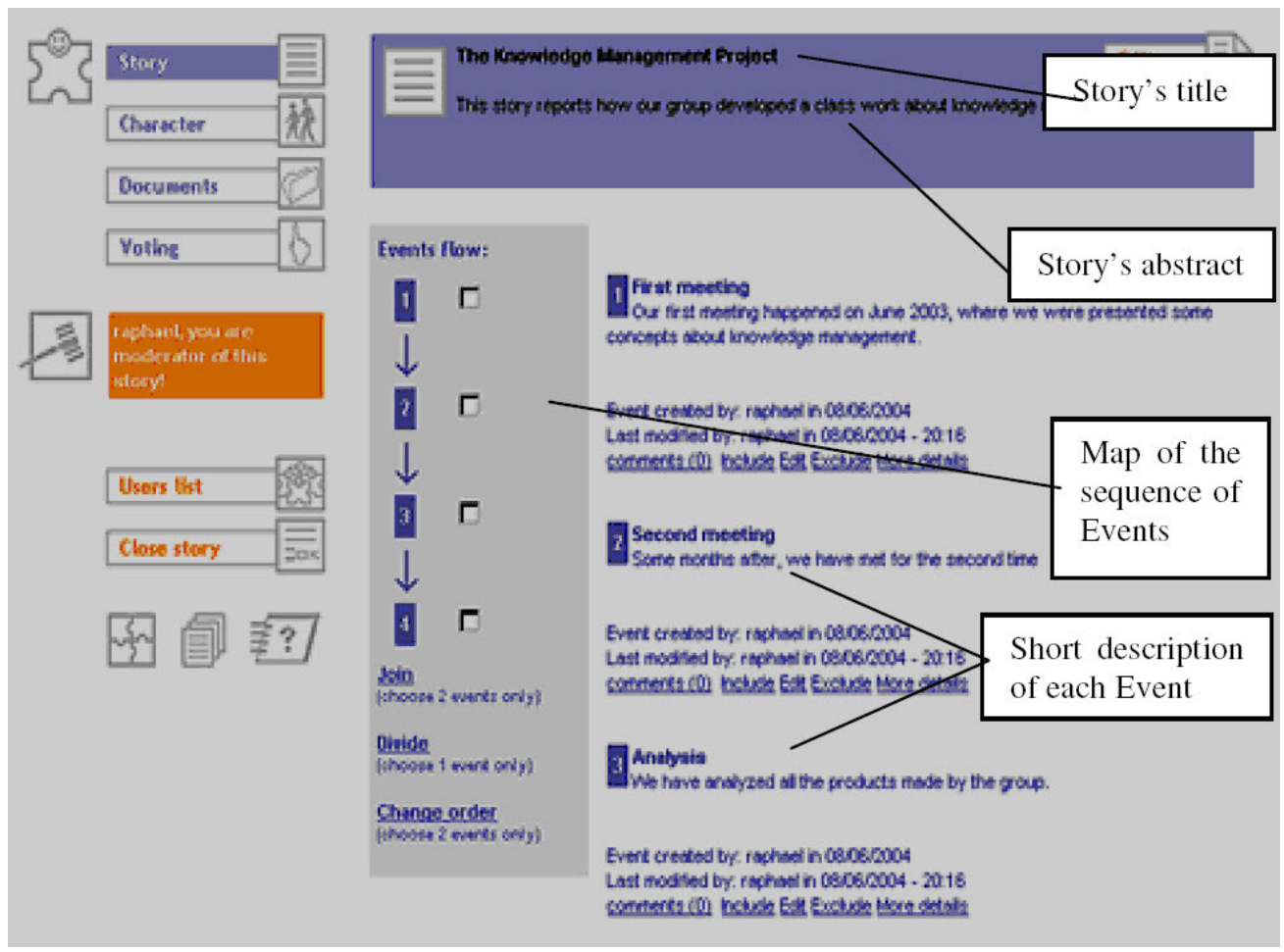

Figura 13 - Fluxo de uma história no sistema Tellstory. Fonte: Santoro \& Brézillon (2005).

As informações de contexto (tabela 4) funcionam como um guia para os narradores, estimulando sua memória, auxiliando-os a melhor estruturar seus pensamentos e expandindo sua contribuição, proporcionando mais detalhes sobre o evento que estão relatando.

\begin{tabular}{|c|c|c|}
\hline Assunto & Pergunta feita ao narrador & Endereça \\
\hline Personagem & $\begin{array}{l}\text { Detalhe os personagens e seus papéis na história } \\
\text { (descrição geral, contexto profissional, } \\
\text { habilidades técnicas, relacionamento interpessoal } \\
\text { com o grupo, envolvimento nas tarefas). A figura } \\
14 \text { apresenta a descrição do personagem no } \\
\text { sistema Tellstory. }\end{array}$ & Quem? (Who?) \\
\hline Período & $\begin{array}{l}\text { Escreva a data ou o período onde o evento } \\
\text { ocorreu. }\end{array}$ & Quando? (When?) \\
\hline Classificação & $\begin{array}{l}\text { Indique em que parte da história esse evento } \\
\text { pertence (exposição, complicação, clímax ou } \\
\text { resultado). }\end{array}$ & Quando? (When?) \\
\hline Local & $\begin{array}{l}\text { Descreva o local e o cenário onde esse evento } \\
\text { ocorreu. }\end{array}$ & Onde? (Where?) \\
\hline Causas & $\begin{array}{l}\text { Discuta o que causou esse evento (eventos } \\
\text { podem ser relacionados a eventos prévios) }\end{array}$ & Por quê? (Why?) \\
\hline Efeitos & $\begin{array}{l}\text { Indique as consequiências desse evento (eventos } \\
\text { podem ser relacionados a eventos que se } \\
\text { sucederam). }\end{array}$ & O que? (What?) \\
\hline Emoções & $\begin{array}{l}\text { Descreva sentimentos percebidos enquanto esse } \\
\text { evento estava ocorrendo }\end{array}$ & Como? (How?) \\
\hline
\end{tabular}

Tabela 4 - Assuntos do framework de contexto. Fonte: Santoro \& Brézillon (2005). 


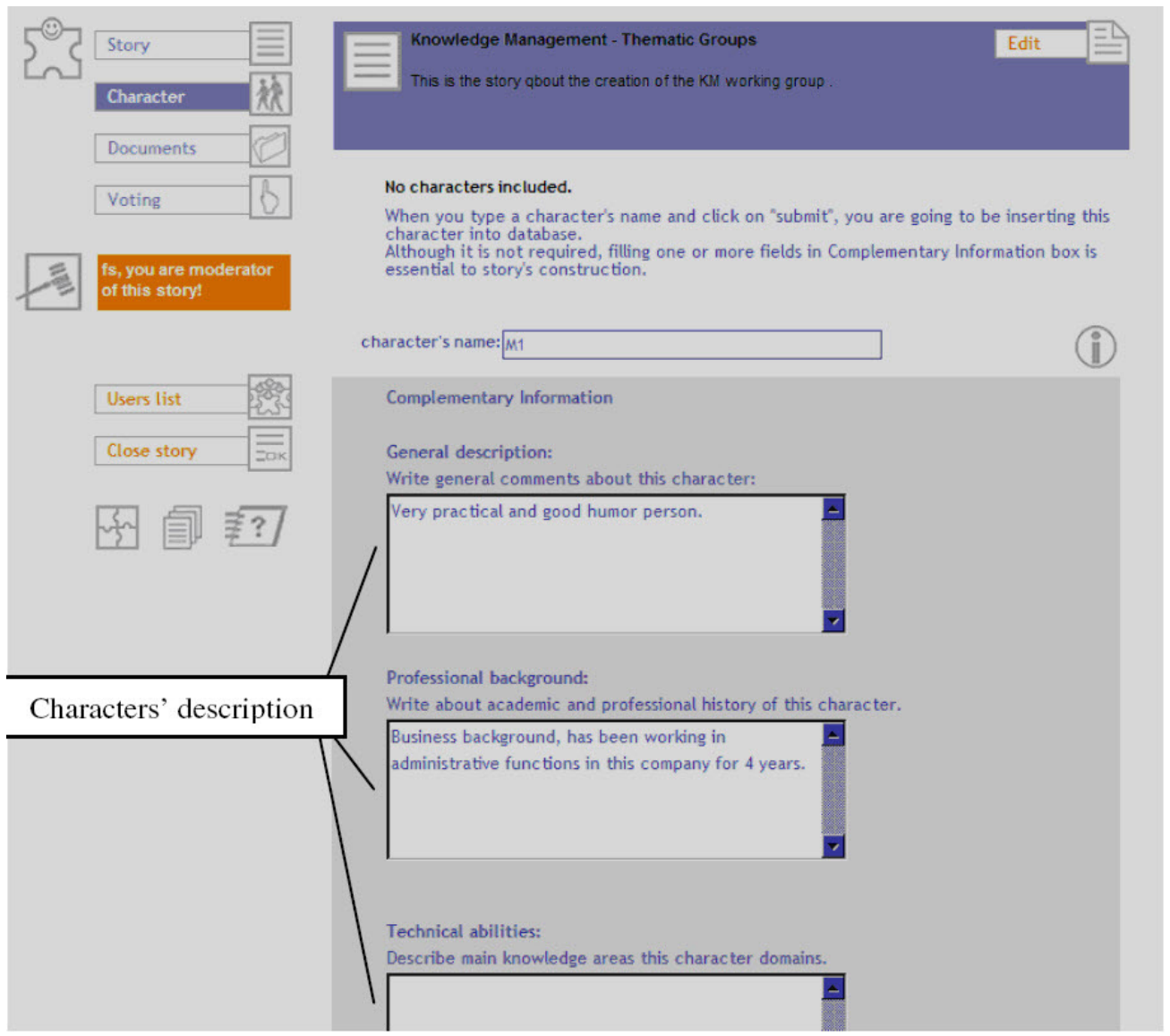

Figura 14 - Descrição do personagem no sistema Tellstory. Fonte: Santoro \& Brézillon (2005).

\subsubsection{The Event Ontology}

Esta ontologia foi desenvolvida no Centro de Música Digital da Universidade de Londres (Raimond \& Abdallah, 2007). Seu foco prende-se à noção de evento, sendo esta a forma pela qual os agentes cognitivos classificam, arbitrariamente, tempo e espaço, sendo esta a visão expressa por Allen \& Fergusson (1994):

"Eventos têm, principalmente, uma natureza lingüística ou cognitiva. Isto é, o mundo na realidade não contém eventos. Os eventos são uma forma na qual os agentes classificam certos padrões de mudança úteis e relevantes."

A figura 15 apresenta a ontologia em discussão. Pode-se ver que ela utiliza duas outras: a ontologia OWL-Time ${ }^{17}$ (para registrar a dimensão tempo) e a The

\footnotetext{
${ }^{17}$ http://www.w3.org/2006/time\#
} 
WGS84 Geo Positioning Ontology ${ }^{18}$ (para registrar a dimensão espaço). O namespace XML dessa ontologia é http://purl.org/NET/c4dm/event.owl\# e tem o prefixo event.

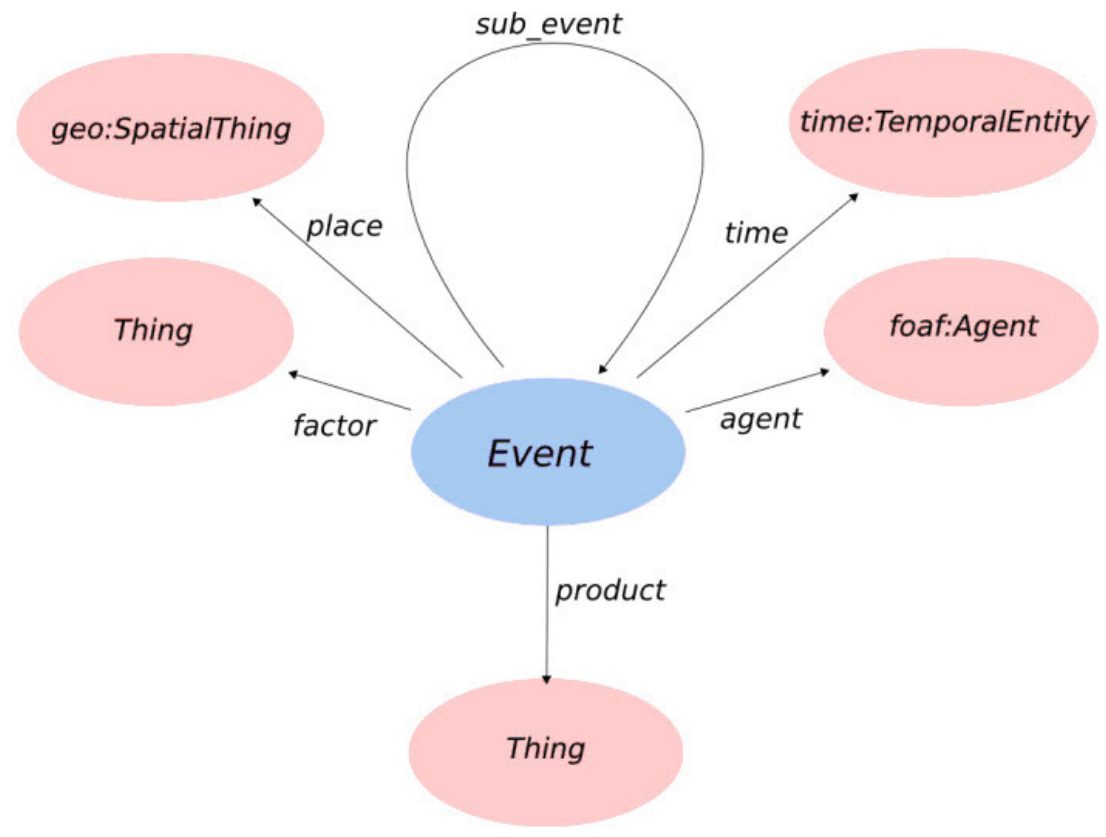

Figura 15 - Ontologia de evento. Fonte: Raimond \& Abdallah (2007).

As tabelas 5 e 6 apresentam as classes e propriedades dessa ontologia.

\begin{tabular}{|c|l|}
\hline Classe & \multicolumn{1}{c|}{ Definição } \\
\hline Event & $\begin{array}{l}\text { Uma classificação arbitrária de uma região de espaço/tempo, realizada pelos agentes } \\
\text { cognitivos. Um evento pode ter agentes participando ativamente, fatores passivos, } \\
\text { produtos, e a localização no espaço/tempo. }\end{array}$ \\
\hline Factor & Qualquer coisa usada como fator em um evento. \\
\hline Product & Qualquer coisa produzida pelo evento. \\
\hline
\end{tabular}

18 http://www.w3.org/2003/01/geo/wgs84_pos\# 


\begin{tabular}{|c|c|c|c|c|}
\hline Propriedade & Definição & $\begin{array}{l}\text { Domínio } \\
\text { (domain) }\end{array}$ & Extensão (range) & $\begin{array}{l}\text { Inverso de } \\
\text { (inverse-of) }\end{array}$ \\
\hline Agent & $\begin{array}{l}\text { Relaciona um evento a } \\
\text { um agente ativo (uma } \\
\text { pessoa, um computador } \\
\text { etc.) }\end{array}$ & Event & foaf:Agent & event:isAgentIn \\
\hline Factor & $\begin{array}{l}\text { Relaciona um evento a } \\
\text { um fator passivo (uma } \\
\text { ferramenta, um } \\
\text { instrumento, uma causa } \\
\text { abstrata etc.) }\end{array}$ & Event & & event:isFactorOf \\
\hline Literal_factor & $\begin{array}{l}\text { Relaciona um evento a } \\
\text { um fator que pode ser } \\
\text { descrito como um } \\
\text { literal. Essa propriedade } \\
\text { não deve ser usada } \\
\text { dessa forma bruta, } \\
\text { porém deve rer } \\
\text { utilizada por outras } \\
\text { propriedades } \\
\text { específicas (tal como } \\
\text { temperatura, ligando } \\
\text { um evento a uma } \\
\text { temperatura) }\end{array}$ & Event & & \\
\hline Place & $\begin{array}{l}\text { Relaciona um evento a } \\
\text { um objeto espacial }\end{array}$ & Event & geo:SpatialThing & \\
\hline Product & $\begin{array}{l}\text { Relaciona um evento a } \\
\text { alguma coisa produzida } \\
\text { durante o evento (por } \\
\text { exemplo, um som, uma } \\
\text { torta, ou qualquer outra } \\
\text { coisa) }\end{array}$ & Event & & event:producedIn \\
\hline Sub-event & \begin{tabular}{l}
\multicolumn{3}{l}{ Essa propriedade é uma } \\
forma de dividir um \\
evento complexo (por \\
exemplo, o desempenho \\
de vários músicos) em \\
vários menores (um \\
evento para cada \\
músico)
\end{tabular} & Event & Event & \\
\hline Time & $\begin{array}{l}\text { Relaciona um evento a } \\
\text { um objeto temporal, } \\
\text { classificando a região } \\
\text { temporal (tanto } \\
\text { instantaneamente ou } \\
\text { tendo uma extensão) }\end{array}$ & Event & time:TemporalEntity & \\
\hline
\end{tabular}

Tabela 6 - Propriedade da ontologia de evento. Fonte: Raimond \& Abdallah (2007).

Devido a sua simplicidade, esta ontologia é largamente utilizada como base na elaboração de outras. Exemplos de sua utilização: Music Ontology Specification $^{19}$ e The OMRAS2 Chord Ontology ${ }^{20}$.

${ }^{19}$ http://musicontology.com/

$20 \underline{\text { http://motools.sourceforge.net/chord_draft_1/chord.html }}$ 


\subsubsection{LODE: An ontology for Linking Open Descriptions of Events}

Esta ontologia tem por objetivo permitir a descrição de eventos históricos, a interligação entre eles e o mapeamento entre outros vocabulários e ontologias relacionadas a eventos. Não é seu objetivo descrever eventos em uma perspectiva científica, tal como um processo bem definido ou como parte de um mecanismo causal. É um mínimo múltiplo comum entre diversas outras, tais como CIDOC, DUL, F-Event-Model, Event Ontology, ABC Ontology e OpenCYC Ontology.

Ela trata o conceito de evento de uma maneira objetiva; ou seja, não trata de questões subjetivas provenientes da perspectiva do observador. Segundo o autor, a subjetividade seria tratada em uma ontologia que poderia ser sobreposta aos conceitos desta.

As tabelas 7 e 8 apresentam as classes e propriedades desta ontologia.

\begin{tabular}{|l|l|l|l|}
\hline Classe & \multicolumn{1}{|c|}{ Definição } & \multicolumn{1}{|c|}{ Subclasse de } & \multicolumn{1}{|c|}{ Equivalente a } \\
\hline Event & "É alguma coisa que & dctype:Event & event:Event \\
& $\begin{array}{l}\text { aconteceu" que pode ser } \\
\text { relatado como uma notícia ou }\end{array}$ & cidoc:E2.Temporal_Entity & dul:Event \\
& $\begin{array}{l}\text { ser explicado por um } \\
\text { historiador. }\end{array}$ & & \\
\hline
\end{tabular}

Tabela 7 - Classes da ontologia de evento. Fonte: Shaw (2009).

\begin{tabular}{|c|c|c|c|c|}
\hline Propriedade & Definição & $\begin{array}{l}\text { Domínio } \\
\text { (domain) }\end{array}$ & $\begin{array}{c}\text { Extensão } \\
\text { (range })\end{array}$ & $\begin{array}{c}\text { Subpropriedade } \\
\text { de }\end{array}$ \\
\hline atPlace & $\begin{array}{l}\text { É o local onde o } \\
\text { evento aconteceu. }\end{array}$ & Event & dul:Place & dul:hasLocation \\
\hline atTime & $\begin{array}{l}\text { E o instante } \text { ou o } \\
\text { intervalo de tempo em } \\
\text { que } \quad \text { o } \\
\text { aconteceu. }\end{array}$ & Event & $\begin{array}{l}\text { owltime:Temp } \\
\text { oralEntity }\end{array}$ & $\begin{array}{l}\text { dul:isObservable } \\
\text { At } \\
\text { cidoc:P4.has_tim } \\
\text { e-span }\end{array}$ \\
\hline circa & $\begin{array}{l}\text { É o intervalo de tempo } \\
\text { que pode ser } \\
\text { precisamente descrito } \\
\text { usando data e hora. }\end{array}$ & $\begin{array}{l}\text { owltime:Tempo } \\
\text { ralEntity }\end{array}$ & $\begin{array}{l}\text { owltime:DateT } \\
\text { imeInterval }\end{array}$ & \\
\hline inSpace & $\begin{array}{l}\text { É uma região abstrata } \\
\text { do espaço (por } \\
\text { exemplo, uma região } \\
\text { ou ponto geospacial) } \\
\text { que é onde um evento } \\
\text { aconteceu. }\end{array}$ & Event & $\begin{array}{l}\text { geo:SpatialThi } \\
\text { ng }\end{array}$ & dul:hasRegion \\
\hline involved & $\begin{array}{l}\text { É um objeto (físico, } \\
\text { social, ou mental) } \\
\text { envolvido em } \quad \text { um } \\
\text { evento. }\end{array}$ & Event & dul:Object & \\
\hline involverAgent & $\begin{array}{l}\text { É um agente envolvido } \\
\text { em um evento. }\end{array}$ & Event & dul:Agent & Involved \\
\hline
\end{tabular}

Tabela 8 - Propriedades da ontologia de evento. Fonte: Shaw (2009). 


\subsubsection{Event-Model-F}

Esta ontologia baseia-se na ontologia básica DOLCE+DnS Ultralite (Masolo et al., 2003), que oferece suporte para representar tempo, espaço, objetos e pessoas, assim como relações de composição, causal e de correlação entre eventos.

Adicionalmente, a Event-Model-F (Scherp et al., 2009) fornece uma forma flexível para a composição, modelagem da causalidade e correlação dos eventos, além de representar interpretações diferentes do mesmo modelo.

Esta ontologia utiliza o conceito de evento como forma de capturar e representar uma experiência humana; isto é, para descrever, em alto nível, as ocorrências nas quais as pessoas participam. Estes eventos podem ser bem complexos e precisam levar em consideração uma variedade de aspectos, tais como: tempo, espaço, objetos e pessoas envolvidas. Os relacionamentos de composição, causais e de correlação entre os eventos também devem ser considerados.

Para a elaboração desta ontologia, os seguintes requisitos funcionais foram considerados:

a) Representar a participação de objetos no evento, sendo estes vivos ou não - por exemplo: pessoas, animais ou materiais.

b) Representar a duração temporal de um evento.

c) Representar a extensão espacial de um objeto.

d) Representar relacionamentos estruturais entre os acontecimentos: de composição, causais e de correlação.

e) Propiciar suporte documental para eventos e objetos.

f) Permitir a representação da interpretação de eventos; ou seja, fornecer diferentes pontos de vista para a mesma ocorrência no mundo real.

Esta ontologia também propõe os seguintes requisitos não funcionais:

a) O núcleo do modelo para representação do conhecimento precisa suportar a evolução do sistema, sendo extensível a novos desenvolvimentos e requisitos funcionais. 
b) Ter precisão formal e ser capaz de lidar com axiomas, de forma que o sistema possa inferir sobre o conhecimento representado e executar checagens semânticas da sua validade.

c) Modularidade, visando permitir a utilização de somente uma parte do modelo, uma vez que este, como um todo, busca capturar diferentes estruturas de conhecimento.

d) Deve ser reutilizável, uma vez que diferentes sistemas baseados em eventos podem ser construídos para diferentes tarefas e utilizados em diferentes domínios.

e) O modelo central deve ser aplicável a qualquer domínio de aplicação. Para isso, o conhecimento independente do domínio, presente no modelo central, precisa ser, claramente, separado do conhecimento de um domínio especifico de uma aplicação que está sendo modelada.

Devido ao requisito funcional "f", a ontologia Event-Model-F é muito extensa, tendo no modelo central ${ }^{21} 105$ classes e 109 propriedades. Ela também apresenta maior dificuldade de compreensão do que as anteriormente apresentadas, que lidam com evento. O requisito não funcional "c" busca diminuir a complexidade por meio da utilização de padrões de ontologia (ontology patterns).

A tabela 9 apresenta as principais classes da ontologia Event-Model-F.

\begin{tabular}{|l|l|l|}
\hline \multicolumn{1}{|c|}{ Classe } & \multicolumn{1}{|c|}{ Definição } & Subclasse de \\
\hline Abstract & $\begin{array}{l}\text { Qualquer entidade que não pode ser localizada em } \\
\text { relação a espaço e tempo. }\end{array}$ & Entity \\
\hline Event & $\begin{array}{l}\text { Eventos são relacionados a situações observáveis, que } \\
\text { podem ter diferentes visões no mesmo tempo. }\end{array}$ & Entity \\
\hline InformationEntity & $\begin{array}{l}\text { Um pedaço de informação, sendo ele concretamente } \\
\text { compreendido ou não. }\end{array}$ & Entity \\
\hline Object & $\begin{array}{l}\text { Qualquer objeto físico, social ou mental, ou uma } \\
\text { substância. }\end{array}$ & Entity \\
\hline Quality & É a característica de um Objeto ou Evento. & Entity \\
\hline
\end{tabular}

Tabela 9 - Classes principais da ontologia Event-Model-F. Fonte: Scherp et al. (2009).

${ }^{21}$ http://www.uni-koblenz-landau.de/koblenz/fb4/institute/IFI/AGStaab/Research/ ontologies/events/model.owl 


\subsubsection{Unified Foundational Ontology (UFO)}

A ontologia UFO (Guizzardi \& Wagner, 2005; Guizzardi et al., 2008) é uma ontologia fundacional ${ }^{22}$. Tem por objetivos permitir a avaliação de linguagens de modelagem conceitual e elaborar orientações para uso dessas linguagens. Consiste na combinação de duas outras: a general formal ontology (GFO) (Herre, 2007) e a OntoClean (Guarino \& Welty, 2004), que apresentam maior número de constructos relevantes para a modelagem conceitual em comparação com outras ontologias fundacionais. Além disso, foram adicionadas outras categorias, tendo por base a sua relevância para a modelagem conceitual, de acordo com a experiência dos autores.

A UFO é dividida em três níveis incrementais:

$1^{\circ}$.) UFO-A - que define o núcleo da ontologia

$2^{\circ}$.) UFO-B - adiciona à UFO-A termos relativos a perdurants ${ }^{23}$

$3^{\circ}$.) UFO-C - adiciona à UFO-B termos relativos a questões sociais e intencionais, incluindo questões lingüísticas.

A partir dessa descrição, pode-se ver que o foco de estudo desta tese está em UFO-B e UFO-C.

A figura 16 apresenta a parte da UFO-B que mostra o tipo básico de perdurant (evento). Vale salientar sobre esta ontologia:

a) Eventos transformam a realidade de uma situação atual (pre-state) para uma situação posterior (post-state).

b) Eventos dependem de participantes para acontecer.

c) Um evento acontece em determinado intervalo de tempo (framed by).

d) Diferente da relação temporal, a relação espacial dos eventos é definida em termos das relações espaciais de seus participantes.

\footnotetext{
${ }^{22}$ As ontologias fundacionais têm por objetivo ser uma plataforma para a construção de ontologias de domínios específicos.

${ }^{23}$ Perdurants são aquelas entidades em que somente parte dela existe se olhamos para elas em um dado instante do tempo. Quando as congelamos no tempo, só se pode perceber apenas parte de um perdurant (Bittner et al., 2004).
} 


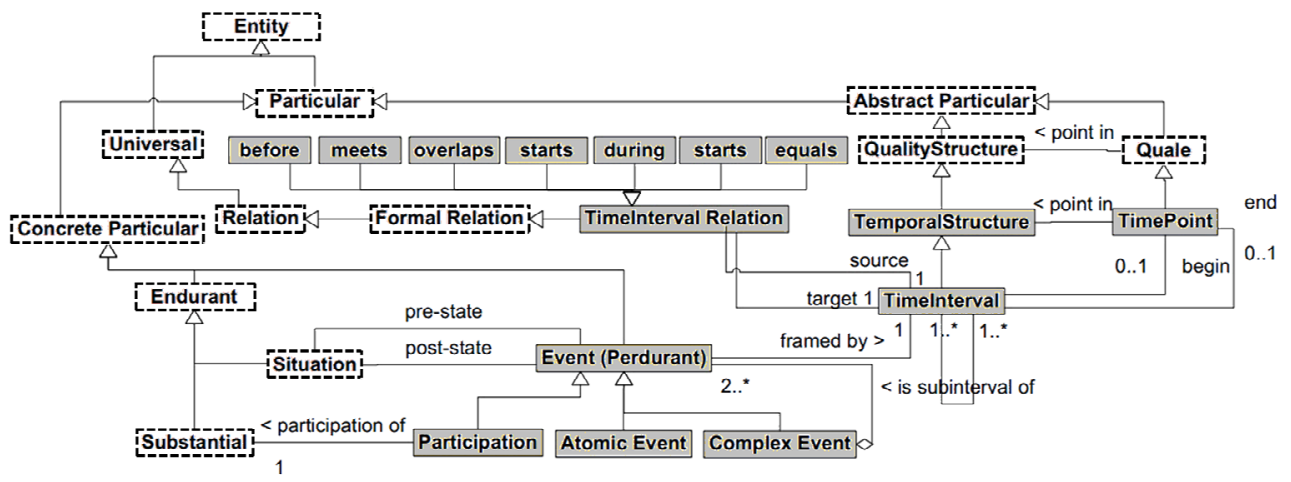

Figura 16 - Fragmento de UFO-B (conceitos reutilizados de UFO-A em caixa tracejada de fundo branco, conceitos UFO-B em caixa de fundo cinza). Fonte: Adaptada de Guizzardi (2008).

A figura 17 apresenta a parte da UFO-C que mostra as questões sociais e intencionais, incluindo questões lingüísticas. Vale salientar sobre esta ontologia:

a) O agente pode ser físico (por exemplo, uma pessoa) ou social (por exemplo, uma organização).

b) O objeto pode ser físico (por exemplo, um livro) ou social (por exemplo, dinheiro, linguagem).

c) Os agentes podem prover suporte a momentos ${ }^{24}$ intencionais (por intencionais deve-se entender a capacidade para se referir a possíveis situações de realidade). O momento intencional pode ser do tipo crença (belief), desejo (desire) ou intenção (intention).

d) A intenção (intention) é a proposição de um objetivo (goal).

e) Crenças (beliefs) podem ser justificadas por situações na realidade (por exemplo, a Lua orbita a Terra). Já desejos (desire) e intenções (intentions) podem ser alcançados ou não.

${ }^{24}$ Um momento é um indivíduo que só pode existir em outro indivíduo. Por exemplo, uma carga elétrica (o momento) só pode existir em algum condutor. Nesse contexto, não há qualquer relação entre momento e instante temporal. 


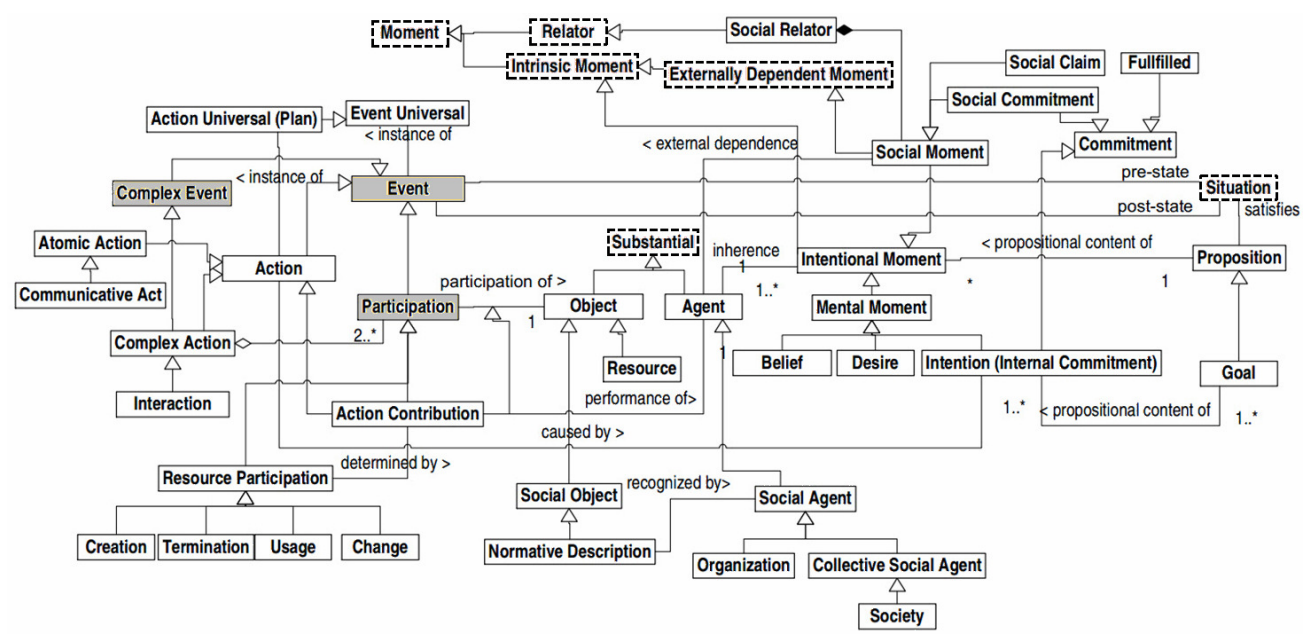

Figura 17 - Fragmento de UFO-C (conceitos reutilizados de UFO-A em caixa tracejada de fundo branco, conceitos reutilizados de UFO-B em caixa de fundo cinza, conceitos UFO-C em caixa de fundo branco). Fonte: Adaptada de Guizzardi (2008).

Apesar de o conceito de crença (belief) ser conhecido, na UFO-C ele é diferente do conceito de interpretação de eventos da forma como a ontologia Event-Model-F coloca.

\subsection{Comparação entre as ontologias}

Scherp (2009) e Shaw (2009) apresentam um trabalho de comparação entre algumas ontologias que lidam com o conceito de evento. As seguintes ontologias foram analisadas:

- International Committee for Documentation on a Conceptual Reference Model (CIDOC CRM) (http://cidoc.ics.forth.gr/ index.html) - tem por objetivo permitir melhor interoperabilidade entre padrões de metadados que descrevem objetos multimídia complexos presentes em museus e bibliotecas. Os eventos buscam descrever tanto os históricos (por exemplo, guerras e nascimentos) como os da história dos objetos que estão sendo descritos (por exemplo, trocas de posse, ou restauração) (Shaw, 2009).

- $\mathrm{ABC}$ Ontology (http://metadata.net/harmony/Results.htm) - tem o mesmo objetivo da ontologia CIDOC CRM (Shaw, 2009).

- Event Ontology (http://motools.sourceforge.net/event/event.html\#) desenvolvida pelo Centro para Música Digital para ser usada juntamente com outras relacionadas à música. Apesar de seu 
objetivo ser descrever eventos tais como composições, gravações ou geração de som, não há nada específico ao domínio musical nesta ontologia de eventos, o que a torna muito flexível (Shaw, 2009).

- EventsML-G2

(http://www.iptc.org/cms/site/index.html?channel=CH0112) desenvolvida pelo International Press Telecommunications Council (IPTC) para a troca de informações estruturada sobre eventos entre provedores de notícias e seus parceiros. Busca representar tanto eventos planejados, passados ou novos, como reportados em noticiários, adotando, assim, um ponto de vista jornalístico (Shaw, 2009).

- Event-Model-F (http://isweb.uni-koblenz.de/eventmodel/) - um modelo formal de eventos elaborado sobre a ontologia (DUL). Provêm classes e propriedades adicionais para modelar a participação em eventos, relações de composição e de causa e correlações entre os eventos. Também permite representar as múltiplas interpretações de um mesmo evento (Shaw, 2009).

- Linking Open Descriptions of Events (LODE) - tem por objetivo permitir a descrição de eventos históricos e a interligação entre eles, além de permitir o mapeamento entre outros vocabulários e ontologias relacionadas a eventos.

- Eventory $^{25}$ - utilizada no domínio jornalístico (Scherp, 2009).

- Semantic-syntactic Video Model $\left(\mathrm{SsVM}^{26}\right)$ - usada para conteúdo em vídeo (Scherp, 2009).

- Video Event Representation Language (VERL ${ }^{27}$ ) - elaborada para lidar com conteúdo em vídeo (Scherp, 2009).

- Event Calculus $^{28}$ - utilizada para a representação do conhecimento (Scherp, 2009).

${ }^{25}$ X. Wang, S. Mamadgi, A. Thekdi, A. Kelliher, and H. Sundaram. Eventory an event based media repository. In Semantic Computing. IEEE, 2007.

${ }^{26}$ A. Ekin, A. M. Tekalp, and R. Mehrotra. Integrated semantic-syntactic video modeling for search and browsing. IEEE Transactions on Multimedia, 6(6), 2004.

${ }^{27}$ R. Nevatia, J. Hobbs, and B. Bolles. An ontology for video event representation. In Computer Vision and Pattern Recognition. IEEE, 2004.

${ }^{28}$ I. Cervesato, M. Franceschet, and A. Montanari. A guided tour through some extensions of the event calculus. Computational Intelligence, 16:2000, 1999. 
- Unified Foundational Ontology (UFO) - ontologia fundacional que tem por objetivos permitir a avaliação de linguagens de modelagem conceitual e elaborar orientações para uso dessas linguagens (Guizzardi \& Wagner, 2005; Guizzardi et al., 2008).

A partir do framework proposto por Scherp (2009) e Shaw (2009), tem-se a tabela 10. As colunas são os requisitos funcionais apresentados na seção 5.2.7 (Event-Model-F). O termo "Abs." (absoluto) diz respeito ao momento ou local preciso, enquanto o termo "Rel." (relativo) diz respeito a uma relação temporal ou espacial com referência a outro evento.

\begin{tabular}{|c|c|c|c|c|c|c|c|c|c|c|c|}
\hline \multirow{2}{*}{ Ontologia } & \multirow{2}{*}{ Participação } & \multicolumn{2}{|c|}{ Tempo } & \multicolumn{2}{|c|}{ Espaço } & \multirow{2}{*}{\multicolumn{3}{|c|}{ Relacionamento entre eventos }} & \multirow{2}{*}{ Documentação } & \multirow{2}{*}{ Interpretação } & \multirow{2}{*}{$\begin{array}{c}\begin{array}{c}\text { Ontologia } \\
\text { formal }\end{array} \\
\end{array}$} \\
\hline & & \begin{tabular}{|l|} 
Rel. \\
\end{tabular} & Abs. & Rel. & Abs. & Composição & & Correlação & & & \\
\hline $\mathrm{ABC}$ & Sim & Sim & Sim & Não & Sim & Sim & Não & Limitado & Sim & Não & Sim \\
\hline CIDOC CRM & Sim & Sim & Sim & Sim & Sim & Limitado & \begin{tabular}{|l|} 
Limitado \\
\end{tabular} & Não & Sim & Não & Sim \\
\hline Event Calculus & Não & Sim & Sim & \begin{tabular}{|l|} 
Não \\
\end{tabular} & Não & Sim & Sim & Sim & Não & Não & Sim \\
\hline Event Ontology & Sim & Sim & Sim & \begin{tabular}{|l|} 
Não \\
\end{tabular} & Sim & Limitado & \begin{tabular}{|l|} 
Limitado \\
\end{tabular} & Não & Não & Não & Sim \\
\hline Event-Model-F & Sim & Sim & Sim & Sim & Sim & Sim & \begin{tabular}{|l|}
$\operatorname{Sim}$ \\
\end{tabular} & Sim & Sim & Sim & Sim \\
\hline Eventory & Sim & Sim & Sim & Sim & Sim & Limitado & Limitado & Não & Sim & Não & Sim \\
\hline EventsML-G2 & Sim & Não & Sim & Não & Sim & Sim & Não & Não & Sim & Limitado & Sim \\
\hline LODE & Sim & Não & Sim & \begin{tabular}{|l|} 
Não \\
\end{tabular} & Sim & Não & Não & Não & Sim & Não & Sim \\
\hline Ontologia ISRST & Sim & Sim & \begin{tabular}{|l|} 
Não \\
\end{tabular} & Não & Não & Sim & Sim & Sim & Sim & Não & Não \\
\hline $\begin{array}{c}\text { Ontologia } \\
\text { StoryMapper }\end{array}$ & Não & Não & Não & Não & Não & Não & Não & Não & Sim & Não & Não \\
\hline Ontologia TellStory & Sim & Sim & Sim & Sim & Sim & Não & Sim & Não & Sim & Sim & Não \\
\hline SsVM & Sim & Sim & Sim & Sim & Sim & Sim & Limitado & Não & Sim & Não & Sim \\
\hline UFO & Sim & Sim & Sim & \begin{tabular}{|l|}
$\operatorname{Sim}$ \\
\end{tabular} & Sim & Sim & Não & Não & Sim & Limitado & Sim \\
\hline VERL & Sim & Sim & Sim & \begin{tabular}{|l|} 
Sim \\
\end{tabular} & Sim & Limitado & Limitado & Não & Sim & Não & Sim \\
\hline
\end{tabular}

Tabela 10 - Comparação entre ontologias de eventos. Fonte: Adaptado a partir de Scherp (2009) e Shaw (2009). 


\section{6 \\ Solução proposta}

Apresenta-se neste capítulo a solução proposta por esta tese, composta de papéis envolvidos, processo de trabalho, tecnologia e ontologia a ser utilizada.

A figura 18 apresenta a visão geral da solução proposta. A forma de leitura dessa figura é a seguinte:

a) O Patrocinador identifica um evento relevante.

b) O Analista de GC identifica os participantes da história.

c) Os Depoentes falam sobre sua participação no evento, usando ou não um entrevistador.

d) O Curador busca garantir a consistência dos conteúdos registrados.

e) O Reutilizador busca na representação semi-formal conteúdos que ele possa reutilizar.

$\mathrm{Na}$ solução proposta, a representação semi-estruturada apresentada na figura 18 é fornecida por meio de uma ontologia do domínio e pelo uso de um wiki semântico como ferramenta de colaboração. 


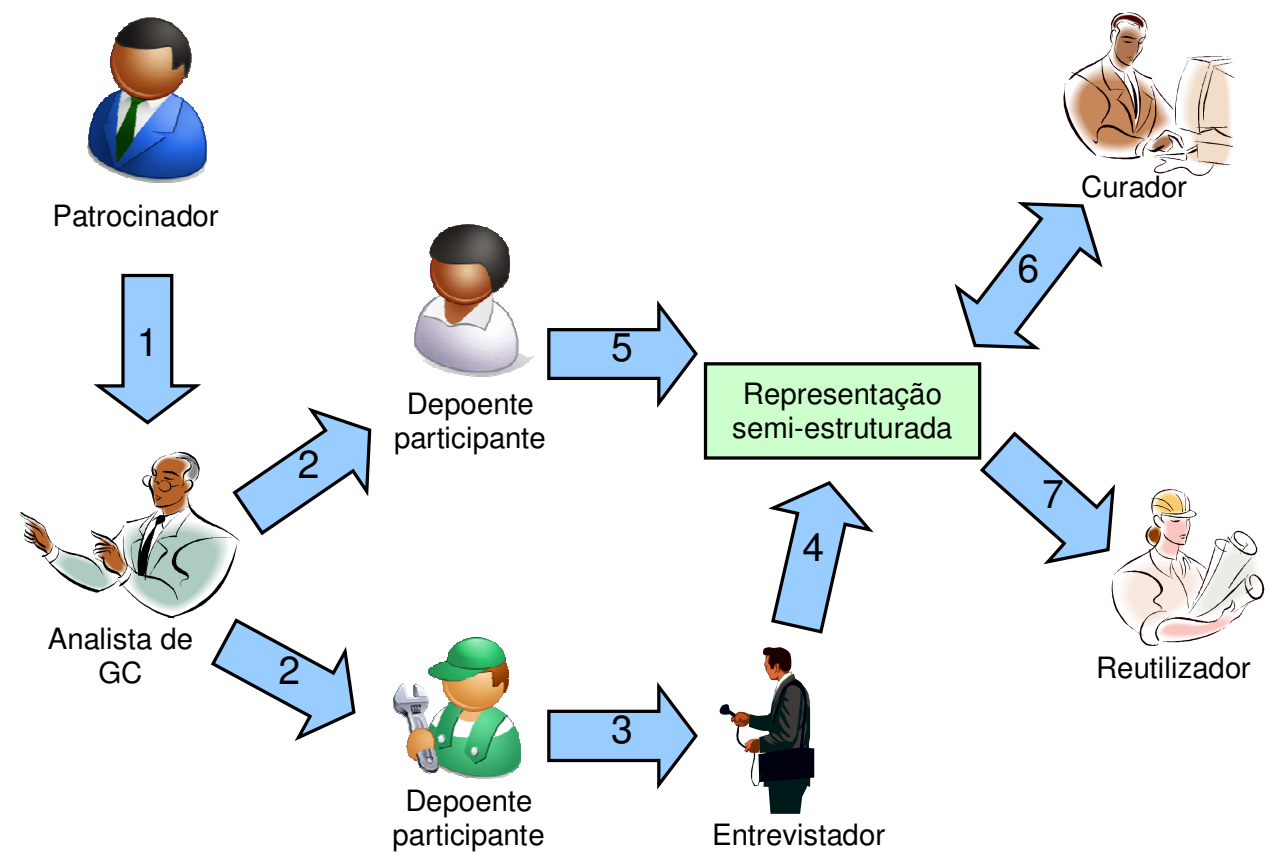

Figura 18 - Visão geral da solução proposta.

\subsection{Papéis existentes}

Assim como no modelo de group storytelling, proposto pelo StoryMapper (Vale, 2003) e Tellstory (Santoro \& Brézillon, 2005), identifica-se aqui também a necessidade de desempenhar os seguintes papéis:

a) Patrocinador - pessoa que patrocina e incentiva a iniciativa de fazer o mapeamento da história.

b) Analista de gestão do conhecimento - responsável por identificar, a partir da estratégia da empresa ou de algum problema a ser enfrentado, os conhecimentos e experiências que devem ser priorizados em processos de transferência de conhecimento.

c) Depoente participante - pessoa que participou da história que está sendo descrita. Descreve, com base em sua experiência, tanto as questões objetivas como as subjetivas. Pode descrever sua experiência por meio de entrevista ou textualmente.

d) Depoente não participante - pessoa que não participou da história que está sendo descrita. Por isso, descreve apenas questões subjetivas acerca dos acontecimentos descritos pelos participantes. 
e) Entrevistador - pessoa que entrevista um depoente participante, visando explicitar sua experiência acerca de determinada história.

f) Curador (Facilitador) - pessoa que analisará os depoimentos, visando relacioná-los, explicitamente, a outros conceitos nas ontologias existentes. Também, buscará identificar inconsistências e padrões nos depoimentos.

g) Reutilizador - pessoa que reutilizará as experiências descritas pelos depoentes. 
A tabela 11 apresenta os papéis desempenhados em relação às fases do framework de Gestão do Conhecimento.

\begin{tabular}{|c|c|c|c|c|c|c|c|c|}
\hline & \multicolumn{7}{|c|}{ Framework de GC } \\
\hline & & Identificar & Coletar & Organizar & Compartilhar & Adaptar & Usar & Criar \\
\hline \multirow{9}{*}{ 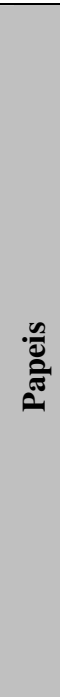 } & Patrocinador & & & & & & & \\
\hline & $\begin{array}{l}\text { Analista de } \\
\text { GC }\end{array}$ & & & & & & & \\
\hline & $\begin{array}{l}\text { Depoente } \\
\text { Participante }\end{array}$ & & & & & & & \\
\hline & Depoente & & & & & & & \\
\hline & & & & & & & & \\
\hline & Participante & & & & & & & \\
\hline & Entrevistador & & & & & & & \\
\hline & Curador & & & & & & & \\
\hline & Reutilizador & & & & & & & \\
\hline
\end{tabular}

\subsubsection{Atividades por papel}

Nesta seção, apresentam-se as atividades associadas a cada um dos papéis previamente definidos. Os casos de uso mencionados estão descritos no Apêndice II.

\subsubsection{Patrocinador}

São atividades do patrocinador:

a) incentivar os depoentes a relatarem as experiências adquiridas na execução de um projeto ou história;

b) visualizar questões obtidas a partir da história relatada (caso de uso 6 - Visualizar questões);

c) indicar possíveis reutilizadores dessa história; e

d) visualizar experiências de usos da história (caso de uso 9 Visualizar experiências de uso).

Estas atividades acontecem aqui em um nível mais estratégico. 


\subsubsection{Analista de gestão do conhecimento}

São atividades do analista de gestão do conhecimento:

a) incentivar os depoentes a relatarem as experiências adquiridas na execução de um projeto ou história;

b) visualizar questões obtidas a partir da história relatada (caso de uso 6 - Visualizar questões);

c) indicar possíveis reutilizadores dessa história;

d) construir e publicar questões a partir da análise dos depoimentos (caso de uso 5 - Publicar elemento de raciocínio);

e) visualizar experiências de usos da história (caso de uso 9 Visualizar experiências de uso); e

f) analisar os depoimentos de forma a obter lições aprendidas ou questões. (caso de uso 7 - Buscar padrões em depoimentos).

Estas atividades acontecem aqui em um nível mais tático.

\subsubsection{Depoente participante}

São atividades do depoente participante:

a) publicar fragmentos sobre a experiência da qual ele participou. Esse fragmento pode ser explicitado tanto por meio de entrevista como na publicação do fragmentos, diretamente no sistema (caso de uso 2 Visualizar significado; e caso de uso 1 - Publicar fragmento);

b) modificar erros percebidos nos fragmentos ou significados existentes (caso de uso 2 - Visualizar significado; e caso de uso 3 Modificar significado); e

c) validar fragmentos ou significados realizados por ele, após sua publicação pelo entrevistador, ou devido a possíveis modificações realizadas por outros depoentes ou pelo facilitador (caso de uso 4 Validar significado). 


\subsubsection{Depoente não participante}

São atividades do depoente não participante:

a) publicar conteúdo sobre os fragmentos ou significados existentes no ambiente (caso de uso 2 - Visualizar significado; e caso de uso 1 Publicar fragmento);

b) modificar erros percebidos nos fragmentos ou significados existentes (caso de uso 2 - Visualizar significado; e caso de uso 3 Modificar significado); e

c) validar fragmentos ou significados realizados por ele devido a possíveis modificações realizadas por outros depoentes ou pelo facilitador (caso de uso 4 - Validar significado).

\subsubsection{Entrevistador}

São atividades do entrevistador:
a) entrevistar o participante sobre a sua experiência vivida na história que está sendo mapeada; e
b) publicar fragmentos sobre a experiência do participante que ele entrevistou (caso de uso 2 - Visualizar significado; e caso de uso 1 - Publicar fragmento).

\subsubsection{Curador}

São atividades do curador:

a) estruturar os relacionamentos não evidenciados nos eventos (por exemplo, relacionamento entre locais, pessoas envolvidas, processos associados ao significado etc.) (caso de uso 2 - Visualizar significado; e caso de uso 3 - Modificar significado);

b) analisar os fragmentos ou significados de forma a obter lições aprendidas ou questões. (caso de uso 7 - Buscar padrões em depoimentos);

c) construir e publicar questões a partir da análise dos depoimentos (caso de uso 5 - Publicar elemento de raciocínio); e 
d) visualizar questões obtidas a partir da história relatada (caso de uso 6 - Visualizar questões).

Estas atividades acontecem aqui em um nível mais operacional.

\subsubsection{Reutilizador}

São atividades do reutilizador:

a) visualizar questões, significados e experiências de uso que possam ser utilizados na sua necessidade atual (caso de uso 6 - Visualizar questões; caso de uso 2 - Visualizar significado; e caso de uso 9 Visualizar experiências de uso); e

b) publicar sua experiência de utilização de determinado significado (caso de uso 8 - Publicar experiência de uso). 


\subsection{Processo de trabalho}

O processo de trabalho deve estar de acordo com o framework de GC (seção 3.1).

O framework de GC propõe um processo genérico, que deve ser adaptado conforme as peculiaridades do contexto de sua aplicação. $\mathrm{O}$ processo de trabalho aqui desenvolvido compõe-se das seguintes etapas:

- Identificação de uma experiência/história que tenha relevância dentro da estratégia da empresa (etapa identificar).

- Identificação dos participantes diretos e indiretos dessa experiência (etapa identificar).

- Coleta de conteúdo sobre a experiência vivida. Pode ser realizada diretamente na ferramenta de colaboração ou por meio de entrevistas (etapa coletar).

- Uma vez que a coleta foi realizada, ela é passada para o ambiente tecnológico (etapa coletar).

- Uma vez estando o conteúdo no ambiente tecnológico, é realizada uma revisão desse material pelos depoentes (nos casos de realização de entrevistas) (etapa coletar).

- Posteriormente, o curador analisa os depoimentos, com base na granularidade dos conteúdos que se deseja buscar. É também seu papel correlacionar as relações do texto do depoente com a ontologia utilizada (etapa organizar).

- Uma vez que todos os depoimentos estejam no ambiente, o curador busca lições aprendidas/questões dessa história (etapa organizar). Esta etapa também conta com a ajuda dos participantes da experiência.

- O conteúdo oriundo dessa experiência pode ser formatado para comunidades de prática (por exemplo, na forma de lições aprendidas) ou para ser usado em treinamentos (por exemplo, na forma de estudo de casos) - (etapa organizar e compartilhar).

- As lições aprendidas podem ser adaptadas e usadas na execução das atividades onde são aplicáveis (etapa adaptar e usar). 
- Uma vez que essa lição aprendida é usada, obtêm-se novas experiências, que podem ser relevantes para a empresa (etapa criar). Uma vez identificada a relevância desta nova experiência, inicia-se a coleta de novos depoimentos acerca dela, reiniciando assim o ciclo. A figura 19 ilustra o processo de trabalho. 


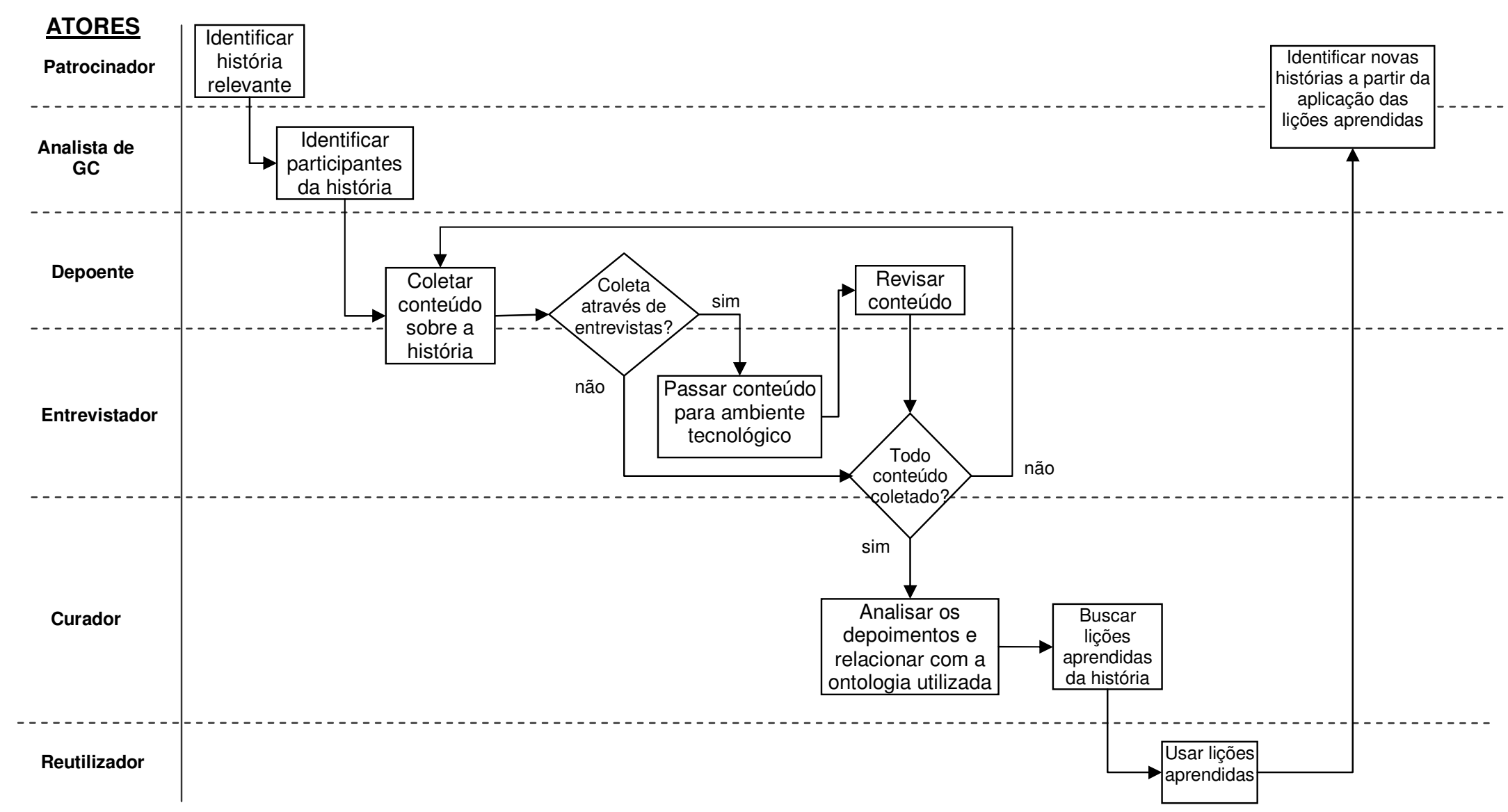

Figura 19 - Processo de trabalho proposto. 


\subsection{Ontologia proposta}

A figura 20 apresenta a ontologia proposta por este trabalho, usando uma notação gráfica no estilo UML, com o intuito de auxiliar a visualização. Algumas regras e restrições foram suprimidas por questões de legibilidade. Uma versão completa em formato Turtle pode ser vista no Apêndice IV.

Como o conhecimento trabalhado está representado na forma de depoimentos, a ontologia construída é modelada no nível da representação das falas desse grupo.

Em uma visão breve, a ontologia é composta de quatro módulos:

- Depoimento (amarela) - é o módulo principal. Nele, encontram-se os conceitos relativos aos fragmentos e significados. É neste módulo que está definida a forma de representação que se utilizou para estruturar os depoimentos que compõem a história.

- História (azul piscina) - nele, encontram-se os conceitos relativos à história.

- Kuaba (abóbora) - contém os conceitos relativos ao design rationale de um conjunto de depoimentos.

- Empresa (roxa) - nele, são representados os conceitos relativos ao ambiente empresarial.

Cada um destes módulos será explicado a seguir. 
PUC-Rio - Certificação Digital № 1012689/CA

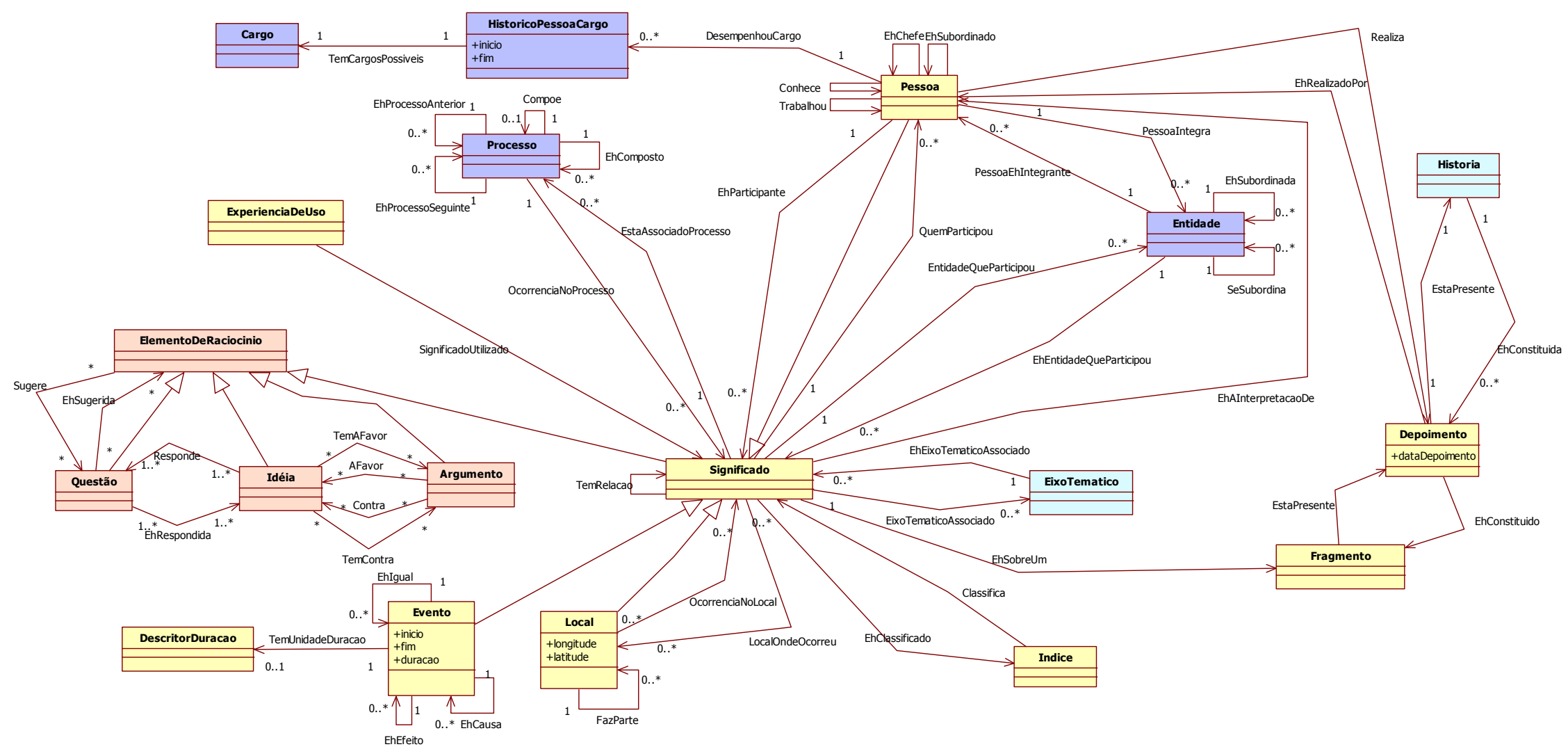

Figura 20 - Ontologia proposta. 


\subsubsection{Módulo Depoimento}

O módulo Depoimento é o central da ontologia. Muito do que foi visto no capítulo 5 influenciou a construção deste módulo. Ele é apresentado na figura 21.

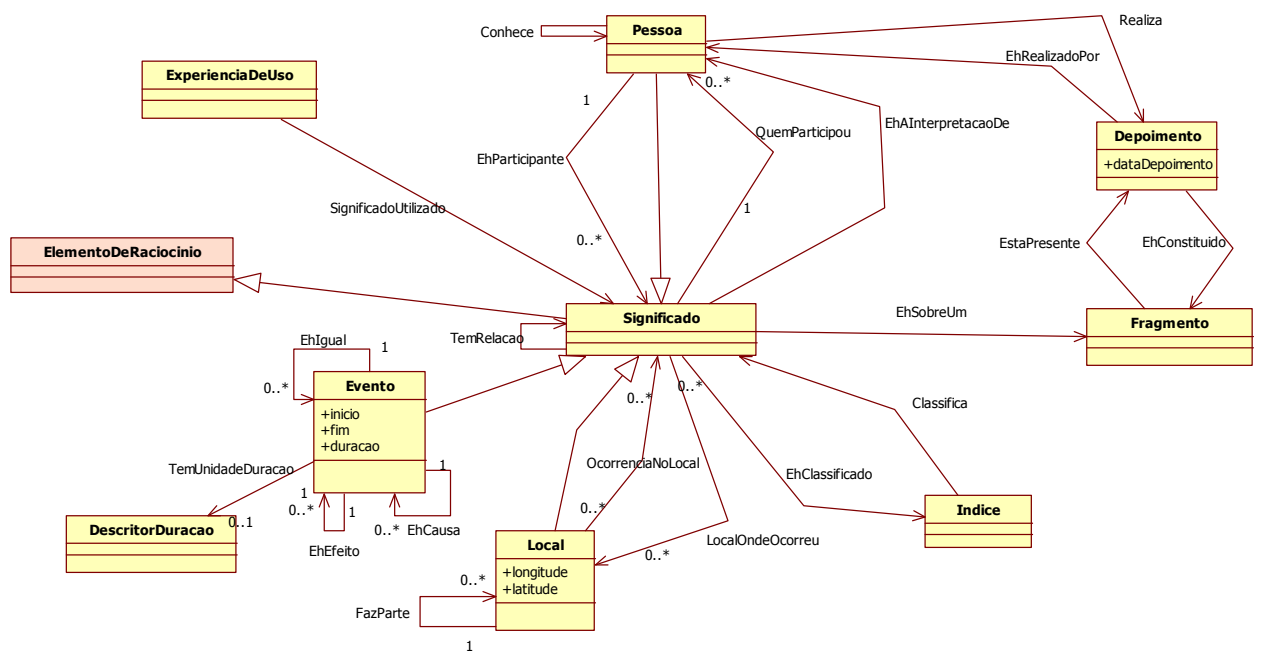

Figura 21 - Módulo Depoimento.

A principal questão de competência para esta ontologia, na perspectiva da Gestão do Conhecimento, é a possibilidade de evidenciar as diferentes interpretações de um mesmo fenômeno, visando facilitar a etapa de adaptação do conhecimento compartilhado. Dessa forma, com o uso do conceito de semiótica deve ser possível representar a interpretação de um indivíduo sobre determinada realidade. Apesar disso, alguns itens da ontologia proposta devem ter um significado comum a todos da comunidade. Por exemplo, as classes derivadas de Índice são de senso comum.

A partir da análise do conteúdo do material utilizado no trabalho piloto desta tese, do trabalho de Scherp (2009) com a ontologia Event-Model-F e de alguns conceitos de semiótica (Souza, 2005), chegou-se à conclusão que o conceito de Evento não atenderia à necessidade deste trabalho, pois era preciso modelar não apenas a visão objetiva dos eventos, mas também o significado deles para um determinado depoente.

No modelo proposto, o conceito de Fragmento é utilizado para indicar um trecho textual do Depoimento que se deseja atribuir uma interpretação. 
O conceito de Significado ${ }^{29}$ foi introduzido visando compreender como o depoente percebe/interpreta o Fragmento. Isso é importante, pois permite compreender não apenas o contexto do Fragmento em si (por meio do Local e Pessoas envolvidas), como também o contexto do depoente. Um exemplo de como um mesmo evento pode ter um significado totalmente diferente para as pessoas que o descrevem é o ato de matar uma vaca para um depoente indiano e para um brasileiro. A interpretação/significação deste mesmo ato para esses dois depoentes é totalmente diferente.

Pode-se ver na ontologia que os conceitos de Evento, Pessoa e Local herdam características do conceito Significado, pois tudo que é subjetivo deve herdar a "idéia" de significado. Os Eventos, assim como Pessoa e Local, são uma visão subjetiva da realidade, visão esta alinhada ao conceito de Evento da ontologia Event-Model-F (Scherp et al., 2009).

Sendo o Fragmento a base para a construção da história, é importante que ele seja contextualizado, de forma a permitir seu melhor entendimento. Conforme apresentado em Tellstory (Santoro \& Brézillon, 2005), tal fato permite maior entendimento do Fragmento em si, fazendo com que sua construção e recuperação sejam facilitadas. Os seguintes conceitos estão relacionados ao conceito Significado com esse objetivo:

- Local - locais que são mencionados no fragmento. Esta relação se dá por meio da propriedade LocalOndeOcorreu. Um local pode estar contido em outro (por exemplo: a cidade do Rio de Janeiro faz parte do estado do Rio de Janeiro), sendo esta a função da propriedade FazParte, que é uma relação transitiva. Todo local tem uma latitude e longitude.

- Pessoa - pessoas que participaram ou são mencionadas no fragmento. Esta relação se dá por meio da propriedade Quem

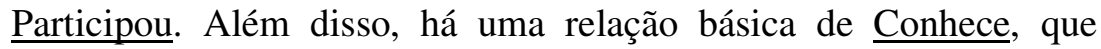
indica que uma pessoa conhece a outra, e vice-versa. Há, ainda, a relação entre as pessoas e o significado do que ela interpretou por meio da propriedade EhAInterpretacaoDe.

\footnotetext{
${ }^{29}$ É importante resalvar que, para efeitos práticos, utilizaremos o termo "Significado" com uma conotação diferente da Semiótica. O "Significado" aqui é um entendimento comum de algo no contexto de uma determinada comunidade.
} 
O conceito ExperiênciaDeUso é uma forma de medir o quanto o processo de coletar e organizar os Significados está sendo útil. Por meio da relação

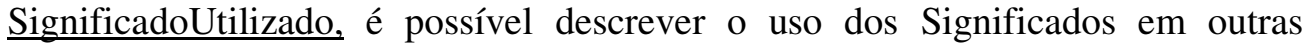
experiências de uso.

\subsubsection{Módulo História}

O conceito de história permite que se agrupem os depoimentos dispersos dentro de uma história, construindo, assim, enredos específicos. A figura 22 apresenta este módulo.
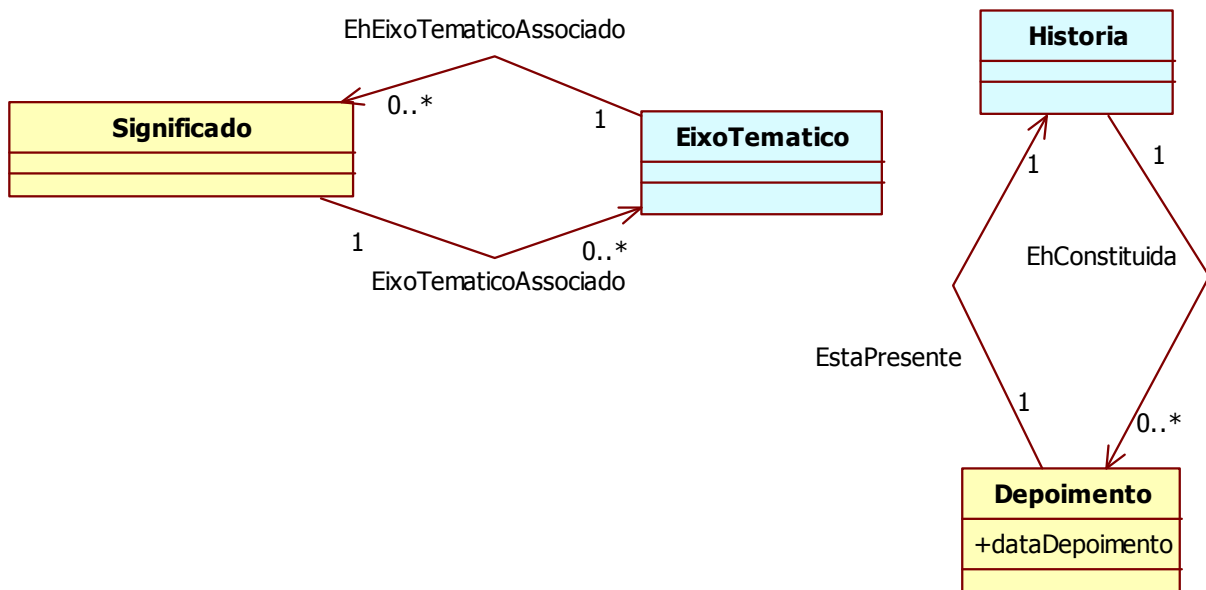

Figura 22 - Módulo História.

Além do conceito História, há também o conceito EixoTematico, que indica que tema está sendo abordado em determinado Significado.

\subsubsection{Módulo Kuaba}

Parte do modelo da ontologia Kuaba (Medeiros, 2006) foi aqui utilizada com o objetivo de construir conclusões mais elaboradas sobre os depoimentos realizados. A figura 23 apresenta este módulo. 


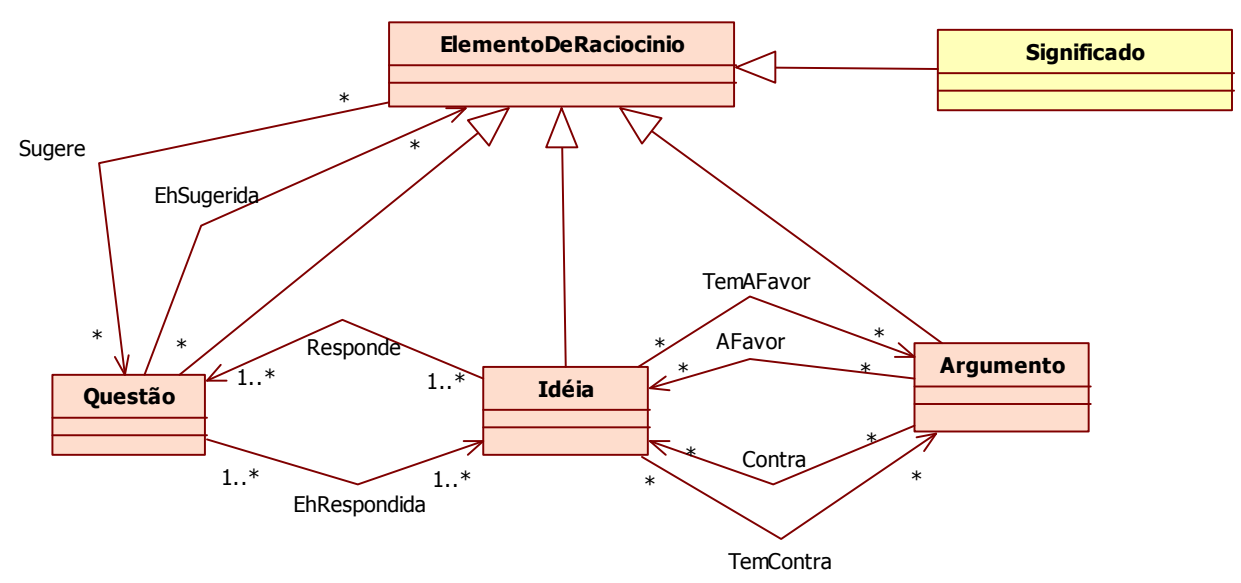

Figura 23 - Módulo Kuaba. Fonte: Medeiros (2006).

Os conceitos que compõem este módulo são:

- Questão - representa um problema que precisa ser resolvido.

- Ideia - é uma possível solução, ou parte de uma solução, para o problema apresentado no elemento questão.

- Argumento - é uma razão, contra ou a favor, da adoção de uma ideia como uma solução para a questão que está sendo tratada.

Durante o processo de criação de questões, novas questões podem ser sugeridas a partir de um elemento de raciocínio (questão, ideia ou argumento). Estas indicam que é preciso resolver outros problemas. A sugestão de novas questões é representada no modelo pelas relações: $\underline{\text { Sugere e EhSugerida (a relação }}$ inversa de $\underline{\text { Sugere })}$. Estas relações também podem ser usadas para representar a decomposição de uma questão em outras mais simples e para facilitar a exploração de ideias sobre possíveis soluções.

\subsubsection{Módulo Empresa}

Este módulo traz para a ontologia alguns conceitos relativos ao ambiente empresarial. A figura 24 apresenta este módulo. 


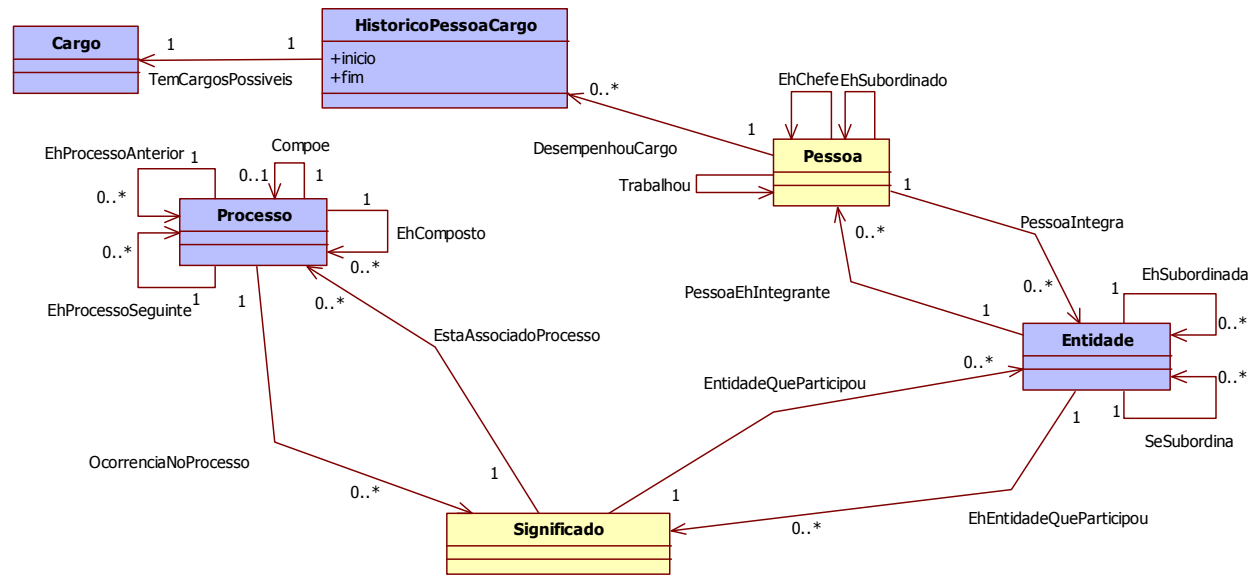

Figura 24 - Módulo empresa.

A ontologia proposta tem por objetivo facilitar a organização e a análise dos Significados de experiências em um contexto empresarial. $\mathrm{Na}$ perspectiva organizacional, torna-se importante esclarecer algumas questões:

- Como os Significados influenciam o posicionamento da empresa em relação a sua rede de interesse (clientes, fornecedores e concorrentes)? Isso é modelado pelo conceito de Entidade e pela relação EntidadeQueParticipou. São representadas também relações de subordinação entre entidades.

- Como os Significados estão relacionados com os processos da empresa? Isso é modelado pelo conceito de Processo. Neste, há relações hierárquicas entre os processos (Compoe) e relações de precedência entre os mesmos (EhProcessoAnterior e EhProcesso Seguinte).

- Como os Significados estão indicando a organização das pessoas dentro da empresa? A classe Pessoa delineia os atores da história. Não somente, mas principalmente, no contexto empresarial a compreensão da relação entre os personagens é importante para o entendimento dos eventos. Os trabalhos de Kao (2005) e Reithinger (2005) lidam com essa questão. Em Kao (2005), busca-se modelar as relações entre agentes de software. Segundo ele, há relações sociais e regras institucionais. As relações sociais são aquelas que os agentes podem estabelecer entre si, modificar ou terminar (por exemplo, 
relações de amizade). Já as regras institucionais são relações globais, de um papel específico dentro da organização (por exemplo, é proibido que uma ordem seja dada de uma pessoa de nível hierárquico menor a uma de nível maior). Dessa forma, têm-se as relações Trabalhou, EhChefe e EhSubordinado. Outra forma de trabalhar isso é por meio do histórico da pessoa (HistóricoPessoaCargo).

\subsubsection{Exemplo do uso da ontologia proposta}

Visando ilustrar o uso da ontologia proposta, a figura 25 apresenta um exemplo de material que se deseja transpor para a ontologia.

A figura 26 apresenta a transposição desse material para dentro da ontologia. Visando facilitar a leitura dessa figura, não estão representadas as relações inversas presentes na ontologia (por exemplo, OcorrenciaNoLocal, EhEixoTematicoAssociado, etc.).

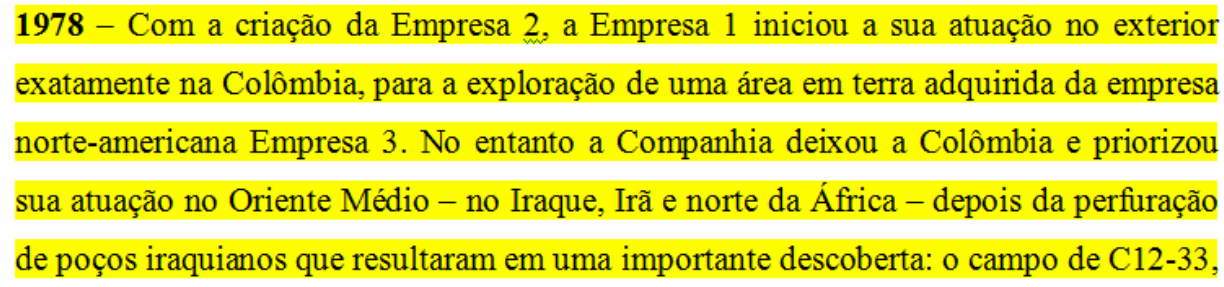

1979 - A Empresa 1, através da Empresa 2, contava com 30 expatriado e 3 colombianos no seu quadro de funcionários atuando na Colômbia.

1982 - A Empresa 2 adquiriu a participação da Empresa 4 na Associação TriCalles, no Campo C23-44, sua primeira experiência como operadora na Colômbia.

Figura 25 - Exemplo de material a ser transposto para a ontologia (material marcado). Fonte: Relatório histórico da construção da refinaria. 


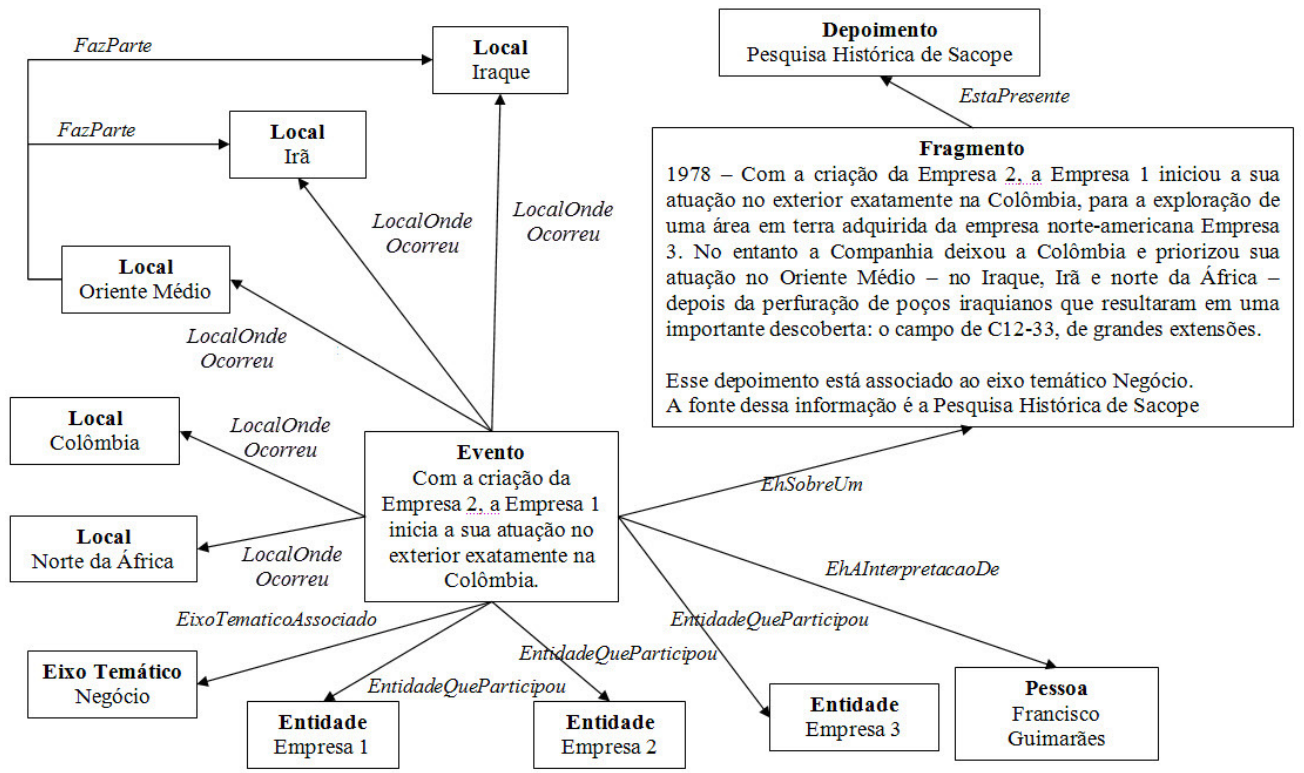

Figura 26 - Material da figura 25 representado na ontologia (não exaustivo).

$\mathrm{Na}$ seção 6.4.1 será utilizado este mesmo exemplo para ilustrar como ele seria inserido na ferramenta proposta.

\subsubsection{Observações sobre a ontologia}

Pode-se observar que na ontologia proposta todos os requisitos não funcionais apresentados na Event-Model-F (seção 5.2.7) estão sendo satisfeitos. Esses requisitos são:

a) $\mathrm{O}$ modelo suporta extensões. Têm-se os módulos centrais (Depoimento e História) e os módulos do domínio de conhecimento modelado (Kuaba e Empresa).

b) Tem precisão formal.

c) É modular, permitindo uso de módulos específicos.

d) Permite o reaproveitamento de módulos específicos.

e) Têm-se os módulos centrais (Depoimento e História) e os módulos do domínio de conhecimento. Por exemplo, é possível retirar o módulo Empresa e substituir por um módulo sobre esportes.

Observando-se também a comparação entre as ontologias da seção 5.3, a ontologia proposta está posicionada da seguinte forma:

a) Representar a participação de objetos no Significado, sejam estes vivos ou não. Existe o conceito de Pessoas, necessário para que seja possível fazer uma análise de rede social. 
b) Representar a duração temporal de um evento, porém apenas de forma absoluta. Este conceito permite a elaboração de linhas do tempo.

c) Representar a extensão espacial de um objeto, porém apenas de forma absoluta.

d) Representar apenas relacionamentos estruturais de causa e efeito entre os Eventos.

e) Propiciar suporte documental para eventos.

f) Permitir a representação da interpretação de eventos por meio do conceito de Significado. Isso permite maior compreenção, pois pode-se ver um mesmo evento sobre várias perspectivas.

g) É uma ontologia formal, facilitando, assim, o processo de análise do conteúdo (por exemplo, em um processo de análise, pode-se observar somente páginas wiki de determinados tipos).

Um ponto a favor da ontologia proposta é a sua simplicidade em relação a outras de mesmo objetivo (por exemplo, a Event-Model-F). A representação do significado feita por Event-Model-F torna-a muito complexa (seção 5.2.7). Já no caso de TellStory (seção 5.2.4) não há tão claramente a colocação do conceito de significado (que aparece por meio do conceito de Emoções) e também não há uma ontologia formal.

Visando reutilizar e permitir a integração com outras ontologias, buscou-se na literatura outras ontologias que modelassem esses conceitos apresentados. As seguintes ontologias de alto nível (upper level ontologies) foram pesquisadas: DOLCE (Masolo, 2003), UMBEL (UMBEL, 2008), GFO (Herre, 2007) e SUMO (Niles \& Pease, 2001). Apesar de todas elas terem modelos específicos para os conceitos de Pessoas, Tempo, Local e Evento, escolheu-se a UMBEL, visto que ela utiliza uma série de ontologias que estão de acordo com a necessidade desta tese (por exemplo, foaf, event, geo). A figura 27 apresenta a relação entre UMBEL e as outras ontologias.

O uso da UMBEL é interessante, pois faz uma ponte entre outras ontologias de alto nível, o que facilitaria a integração com outras bases já existentes. Não há o uso direto de UMBEL nesse trabalho, sendo apenas referenciado como uma ontologia de alto nível em que a maioria dos conceitos estão alinhados a ontologia proposta. 


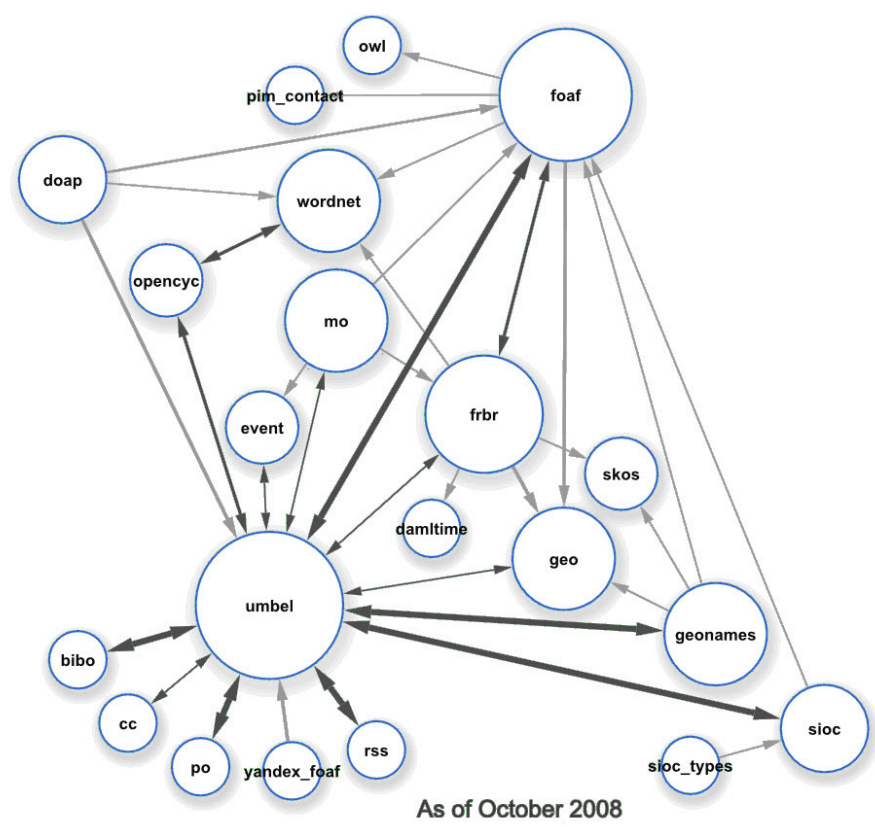

Figura 27 - Relação da UMBEL com outras ontologias. Fonte: UMBEL (2008)

$\mathrm{Na}$ seção seguinte, apresenta-se a ferramenta de wiki semântico que foi utilizada como instrumento para permitir a colaboração entre os diversos papéis. Ela foi escolhida devido a sua flexibilidade (seção 4.3) e a capacidade de lidar com a ontologia proposta.

\subsection{Wiki semântico}

O wiki semântico estende o wiki (seção 4.3) com "tecnologias semânticas", tais como RDF e OWL (seção 4.2), o que permite que os usuários façam anotações semânticas no conteúdo wiki por eles criado. A figura 28 apresenta um exemplo simples da organização de um wiki semântico. 


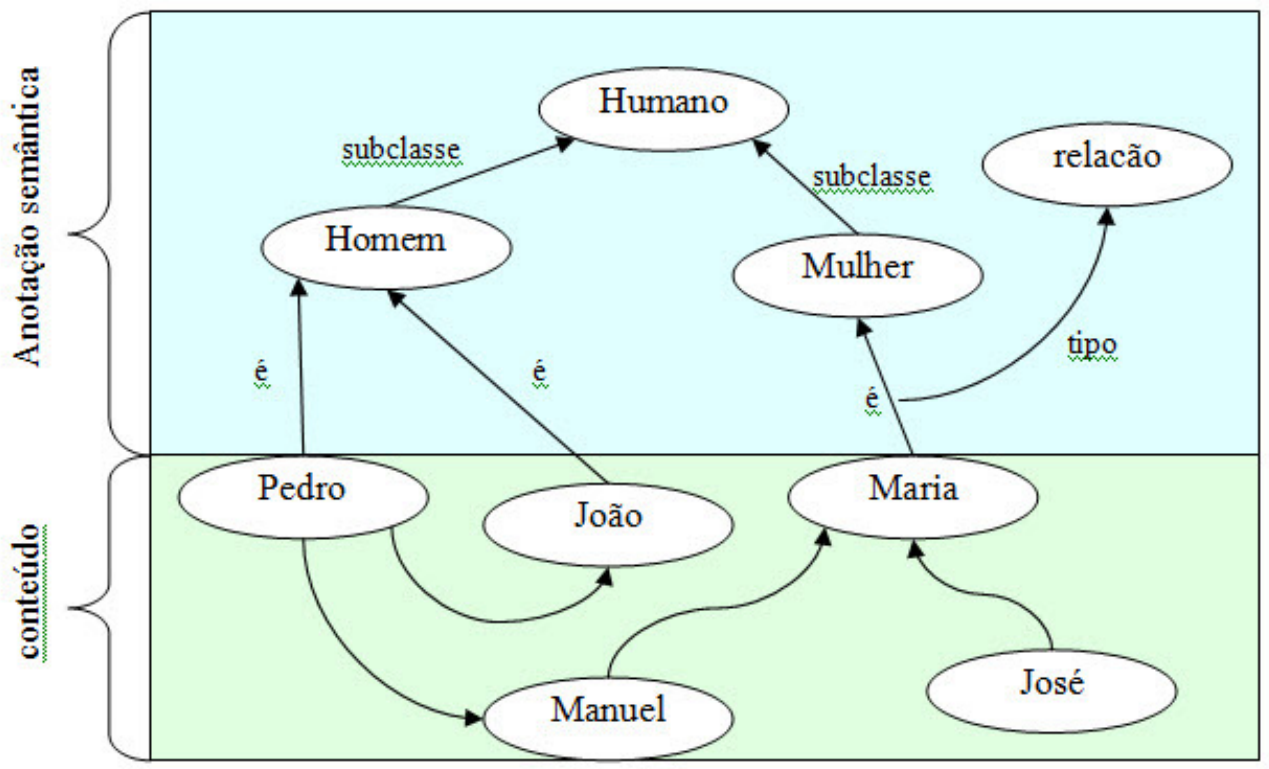

Figura 28 - O wiki semântico.

Existem vários tipos de wikis semânticos, alguns com foco maior na criação do conteúdo, e que veem a anotação semântica como um adicional; ou seja, têm baixo foco na edição da ontologia. De outro lado, outros dão mais importância à anotação semântica que ao conteúdo propriamente dito. Apesar dessas diferenças, essas ferramentas apresentam algumas características em comum (Schaffert et al., 2006):

- Permitem a criação de links tipificados, além de sua navegação.

- Sua apresentação baseia-se em contexto, modificando a forma de apresentação do conteúdo estruturado em anotações semânticas atreladas a ele.

- A navegação é semântica, em que links com semânticas equivalentes podem ser agrupados.

- Proporcionam busca semântica.

- Têm a capacidade de inferência em relação a conteúdos previamente inseridos.

Pode-se ver que o wiki semântico tem o potencial de superar as limitações apresentadas na seção 4.3, aparecendo como uma ferramenta interessante a ser utilizada para a solução proposta, pois facilitaria tanto o relato do depoente (buscando e complementado depoimentos semelhantes ao seu) quanto o trabalho do Curador (que, posteriormente, analisa esses depoimentos). 
O wiki semântico é útil em diversas fases do framework de GC. Uma vez identificada a experiência da qual se deseja extrair conhecimento, o uso do wiki semântico auxilia nas fases de coleta, organização, compartilhamento e adaptação, conforme será visto nos parágrafos seguintes.

Na fase de coleta, o uso de um wiki semântico permitiria um acesso mais homogêneo de todos os envolvidos em uma história, uma vez que seria possível relatar, mais livremente, todos os seus depoimentos. Porém, algumas questões devem ser levadas em consideração nesta etapa:

- Nem todos os envolvidos na experiência que se deseja analisar sabem usar um wiki. No caso do uso de um wiki semântico, isso pode ser um agravante. Para solucionar esta questão, têm-se o papel do Entrevistador e o do Curador, os quais têm por objetivo adaptar o texto mais livre do depoente em um texto mais aderente à ontologia utilizada. Isso compreende, desde identificar relações explícitas no texto com entidades da ontologia até acertar o nível de granularidade de um depoimento (por exemplo, um depoimento pode ter uma série de eventos).

- Muitas pessoas se sentem mais à vontade em falar do que em escrever sobre suas experiências. Uma forma de solucionar essa questão está no papel do Entrevistador, que auxilia as pessoas na externalização de seus conhecimentos.

$\mathrm{Na}$ fase de organização, o wiki semântico contribui por ter uma ontologia que permite a estruturação dos depoimentos.

$\mathrm{Na}$ fase de compartilhamento, apesar de ser possível segmentar o acesso, o conceito do wiki é que ele seja o mais acessível possível. Em algumas aplicações específicas, faz-se necessário que os indivíduos não vejam os depoimentos de outros - por exemplo, em uma investigação sobre um acidente em que se deseja apurar os culpados.

Já na fase de adaptação, devido à existência de depoimentos que proporcionam mais contexto ao conhecimento explícito que está sendo reutilizado, esse reaproveitamento é facilitado. Por exemplo, caso se tenha, além 
de um padrão ou descrição de uma lição aprendida ${ }^{30}$, acesso aos depoimentos que os originaram, pode-se compreender melhor o contexto que aquele padrão, ou aquela lição aprendida, foi elaborado. Isso permitirá um uso mais criterioso, uma vez que é possível compreender se o contexto que gerou esses documentos está aderente ao qual se está aplicando.

\subsubsection{HDEWiki}

O HDEWiki é um wiki semântico, implementado sobre a plataforma HyperDE (Nunes, 2005).

O HyperDE é a combinação de um framework MVC e um ambiente de desenvolvimento rápido, que permite a arquitetos de informação construírem, em curto espaço de tempo, um protótipo de uma aplicação modelada segundo os métodos OOHDM ${ }^{31}$ ou SHDM $^{32}$ (Nunes, 2005).

A ontologia apresentada foi implementada nessa estrutura básica de wiki semântico. A figura 29 apresenta uma tela do HDEWiki. O conteúdo da página se encontra dentro do retângulo, em evidência na figura.

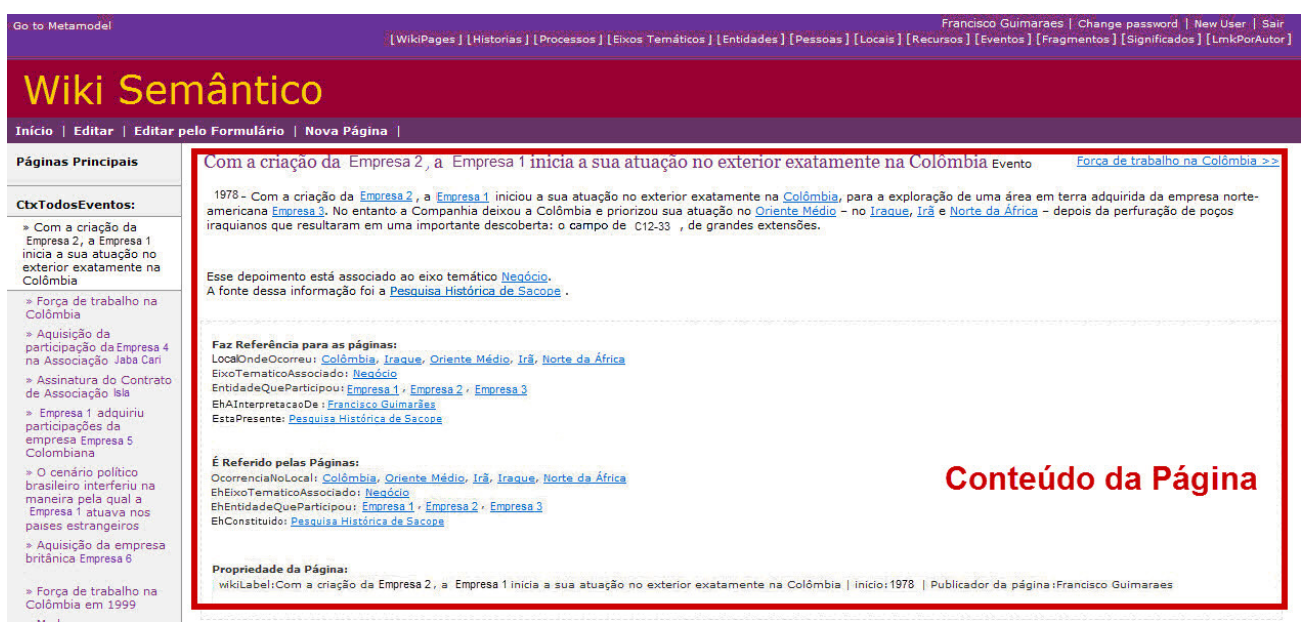

Figura 29 - Tela do wiki semântico.

A figura 30 apresenta o conteúdo da figura 25 (seção 6.3.5) inserido na ferramenta. A figura 31 apresenta a tela de edição desse conteúdo. Para uma melhor visualização, apresenta-se apenas parte do conteúdo da página.

${ }^{30}$ Perguntas que compõem a Lição Aprendida: O que era esperado acontecer? O que realmente aconteceu? Por que ocorreram as diferenças do planejado com o executado? O que podemos aprender com a Lição Aprendida? (Pereira et al., 2008)

${ }^{31}$ Object-Oriented Hypermedia Design Method (Schwabe \& Rossi, 1998)

${ }^{32}$ Semantic Hypermedia Design Method (Lima, 2003) 


\section{PUC-Rio - Certificação Digital № 1012689/CA}

1978 - Com a criação da Empresa 2, a Empresa 1 iniciou a sua atuação no exterior exatamente na Colômbią, para a exploração de uma área em terra adquirida da empresa norte-

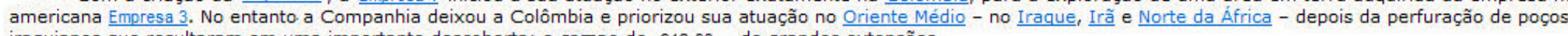
iraquianos que resultaram em uma importante descoberta: o campo de $12-33$, de grandes extensões.

Esse depoimento está associado ao eixo temático Neqócio.

A fonte dessa informação foi a Pesquisa Histórica de Sacope.

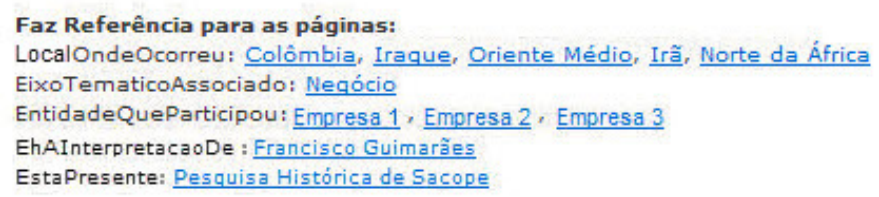

\section{É Referido pelas Páginas:}

OcorrenciaNoLocal: Colômbiä, Oriente Médio, Irã, Iraque, Norte da África EhEixoTematicoAssociado: Neqócio

EhEntidadeQueParticipou: Empresa 1, Empresa 2 , Empresa 3

\section{Links da ontologia}

1 - LocalOndeOcorreu

2 - EixoTematicoAssociado

3 - EntidadeQueParticipou

4 - EhAInterpretacaoDe

5- EstaPresente

\section{Links da ontologia}

1 - OcorrenciaNoLocal

2 - EhEixoTematicoAssociado

3 - EhEntidadeQueParticipou

4 - EhConstituido

Propriedade da Página:

vikiLabel:Com a criação da Empresa 2, a Empresa 1 inicia a sua atuação no exterior exatamente na Colômbia | inicio: 1978 | Publicador da página :Francisco Guimaraes

Figura 30 - Visualização do exemplo presente na figura 25 (conteúdo da página).

Na figura 30, pode-se perceber que, diferente de um wiki comum, o wiki semântico permite que os links e as páginas wiki sejam tipados.

Isso é importante, pois:

- possibilita a elaboração da rede social dos participantes da história a partir dos depoimentos. Por meio do uso de todas as páginas do tipo "Pessoa" e dos relacionamentos "Conhece" e "Trabalhou", é possível construir essas redes (na seção 7.2.2, isso é exemplificado); 
- além da rede social, é possível adicionar a essa rede a relação das pessoas com entidades, por meio do relacionamento "PessoaIntegra" (na seção 7.2.2, isso é exemplificado);

- facilita a análise dos conteúdos, uma vez que é mais fácil perceber o tipo do conteúdo em si (por meio do tipo da página) e também os relacionamentos entre eles (por meio do tipo nos link) (na seção 7.2.1, isso é exemplificado).

\section{Com a criação da Empresa2, a Empresa1 inicia a sua atuação no exterior exatamente na Colômbia}

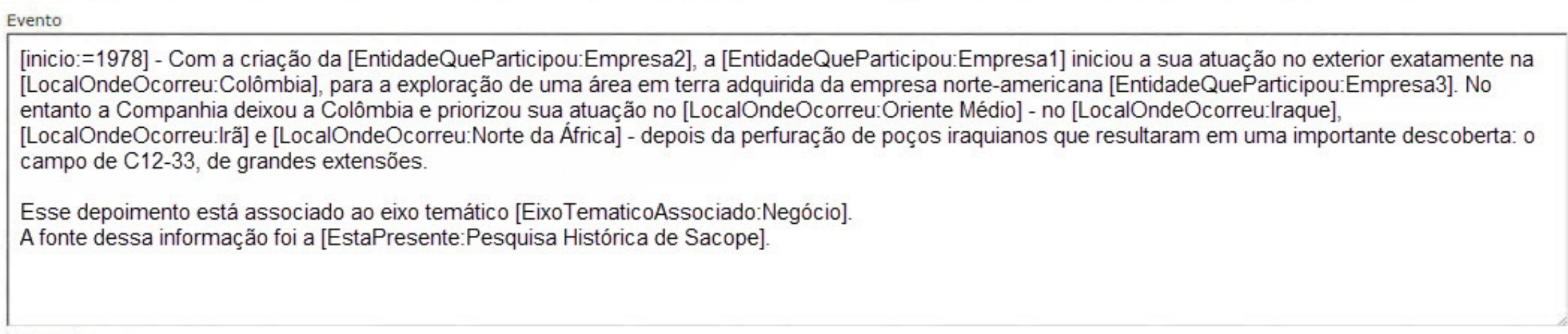

\section{Salvar Cancelar,}

\section{Links}

| EixoTematicoAssociado Negócio $[X]||$ EntidadeQueParticipou Empresa1 $[X]||$ EntidadeQueParticipou Empresa2 $[\chi]$ || EntidadeQueParticipou Empresa3 $[X]$ || LocalOndeOcorreu

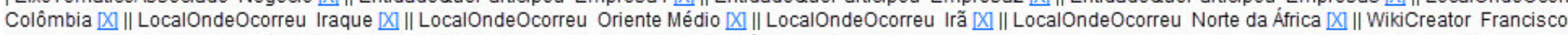
Guimaraes [Х] || WikiEditor Francisco Guimaraes [X] || EstaPresente Pesquisa Histórica de Sacope [X] |

Figura 31 - Visualização da tela de edição do exemplo presente na figura 30 (conteúdo da página). 
A figura 31 apresenta a tela de edição do wiki semântico. Diferente dos wikis comuns, é necessário tipar a página do wiki, no início da criação da página, e também tipar os links. Para tipar um link, é usado o comando "[TIPO DO LINK : LABEL DA PÁGINA A SER INFORMADA]" durante a inserção do conteúdo. O comando "[ATRIBUTO := VALOR]" atribui um valor a página tipada.

\subsection{Demais ferramentas utilizadas}

\subsubsection{Exhibit}

O uso desta API (Application Programming Interface) permite a visualização das informações presentes no wiki semântico das seguintes formas:

- Por meio da visualização multifacetada, é possível ver as informações presentes no wiki semântico filtradas por diversos atributos.

- Por meio da visualização temporal, é possível ver os eventos da história ao longo de uma linha do tempo (a figura 32 apresenta essa visão).

- Por meio da visualização espacial, é possível ver onde ocorreram os depoimentos dentro de um mapa.

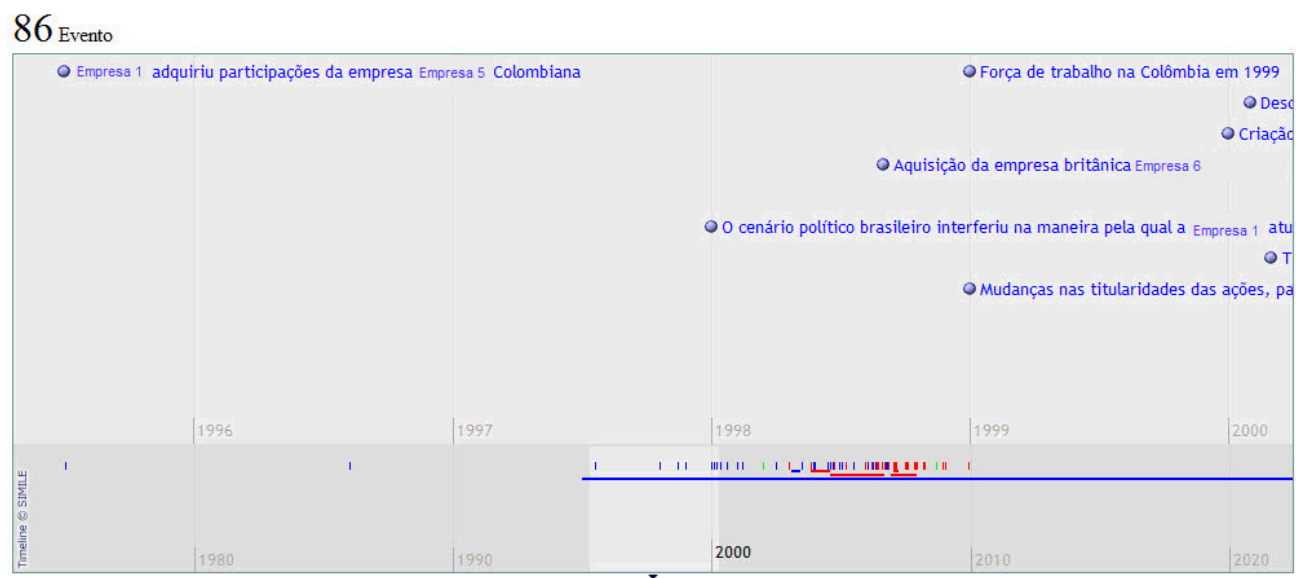

Figura 32 - Visão linha do tempo. 


\subsubsection{NetDraw}

O uso desta aplicação permite obter uma visão dos dados presentes no wiki semântico, na forma de um grafo. Podem-se filtrar os nós que devem aparecer no grafo, permitindo, assim, uma análise mais focada em determinado aspecto que se deseja analisar. A figura 33 apresenta a visão pelo grafo.

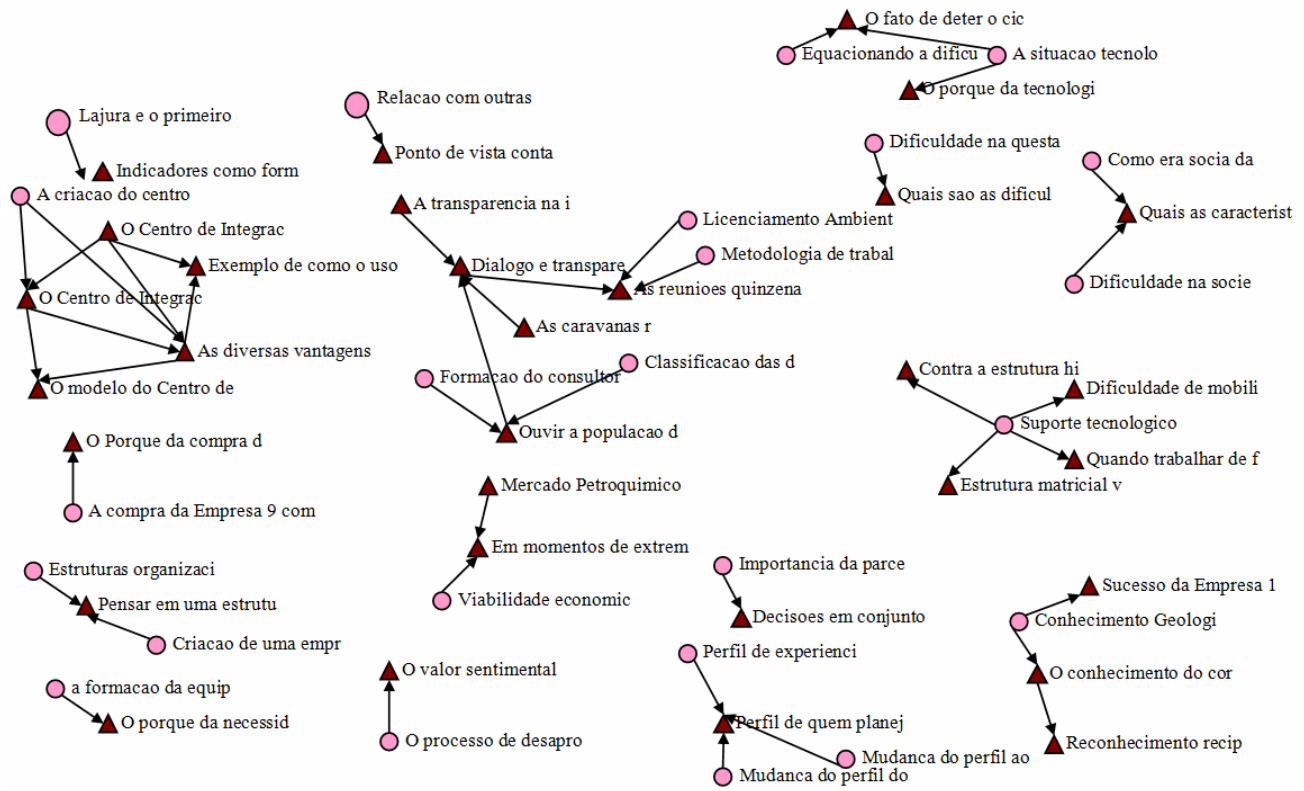

Figura 33 - Exemplo de visualização de um grafo: Eventos (vértices triangulares marrons), Significados (vértices circulares rosa), Relações TemRelação.

A tabela 12 mostra como as ferramentas mencionadas são utilizadas em que parte do framework de GC.

\begin{tabular}{|c|c|c|c|c|c|c|c|c|}
\hline & \multicolumn{7}{|c|}{ Framework de GC } \\
\hline & & Identificar & Coletar & Organizar & Compartilhar & Adaptar & Usar & Criar \\
\hline \multirow{5}{*}{ 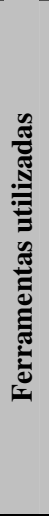 } & $\begin{array}{c}\text { Wiki } \\
\text { semântico } \\
\text { (HDEWiki) }\end{array}$ & & $X$ & $X$ & $X$ & $\mathrm{X}$ & & $\mathrm{X}$ \\
\hline & $\begin{array}{l}\text { Visualização } \\
\text { multifacetada } \\
\text { (Exhibit) }\end{array}$ & & & $\mathrm{X}$ & & & & \\
\hline & $\begin{array}{c}\text { Visualização } \\
\text { temporal } \\
\text { (Exhibit) } \\
\end{array}$ & & & $\mathrm{X}$ & & & & \\
\hline & $\begin{array}{l}\text { Visualização } \\
\text { espacial } \\
\text { (Exhibit) }\end{array}$ & & & $X$ & & & & \\
\hline & $\begin{array}{l}\text { Visualização } \\
\text { grafo } \\
\text { (NetDraw) }\end{array}$ & & & $\mathrm{X}$ & & & & \\
\hline
\end{tabular}

Tabela 12 - Ferramentas utilizadas nas fases do framework de GC. 


\section{7 Análise dos resultados}

Este capítulo apresenta uma aplicação prática (seção 7.2) da solução proposta no capítulo anterior. Na seção 7.3, analisam-se os resultados de quatro experimentos realizados visando comprovar a utilidade da representação proposta ante as questões centrais apresentadas no capítulo 1 .

Inicialmente, na seção 7.1, descreve-se a aplicação real (estado atual), que forneceu insumos para a aplicação prática da solução proposta e para os experimentos.

\subsection{Aplicação real utilizada}

A aplicação real utilizada (estado atual) nesta tese focaliza a construção de uma refinaria de petróleo, em que se busca perpetuar as experiências sobre os fatos marcantes e disseminá-los na empresa. Seu objetivo é promover a retenção e a transferência do conhecimento tácito estratégico, por meio de instrumentos vivos, para debate e reflexão sobre estes fatos marcantes em ambientes de aprendizagem $^{33}$, desenvolvendo a visão sistêmica e estimulando o pensamento inovador.

A metodologia da aplicação contempla a combinação da técnica de narrativas $^{34}$ com o método de estudos de caso $^{35}$ (Gomes, 2006), permitindo, assim, transformar conhecimentos individuais dos empregados da Companhia em conhecimento organizacional, por meio do registro em vários meios que facilitam a sua utilização em ambientes de aprendizagem e de disseminação na Companhia.

${ }^{33}$ Universidade Corporativa, Redes virtuais com foco em conhecimento, etc.

34 Diferentes do conceito de narrativas que vimos anteriormente nesse contexto, as narrativas fazem referência à ferramenta de gestão, que consiste no uso de sessões de relatos de experiências de forma fácil e coloquial, para transformar em palavras as emoções, experiências e reflexões do narrador. Objetiva a passagem de um conhecimento tácito, não registrado, entre os colaboradores de uma empresa (Korowajczuk \& Almeida, 2007).

${ }^{35}$ Estudo de caso é um método ativo de aprendizagem que permite descrever uma situação real de determinada atividade que envolve um problema, uma decisão, um desafio ou uma oportunidade a ser considerada, sendo possível observar como a teoria é praticada (Korowajczuk \& Almeida, 2007) 
É importante observar aqui que a técnica de estudo de caso utilizada é a mesma aplicada nos cursos de gestão (management) da Universidade de Harvard. A principal diferença aqui é que, ao invés de se estudar casos de fora da empresa, estudam-se casos que ocorreram dentro da empresa, o que permite não somente desenvolver conhecimentos a partir das lições aprendidas como também se discutir a cultura da empresa.

Entre os principais resultados obtidos com essa técnica são apontados (Korowajczuk \& Almeida, 2007):

- desenvolvimento de competências gerenciais e técnicas;

- desenvolvimento da visão sistêmica;

- valorização da contribuição do empregado;

- transmissão de valores da cultura;

- integração entre os indivíduos de várias áreas;

- disseminação das redes informais estabelecidas;

- construção de novas redes;

- reflexão sobre as soluções adotadas e criação de novas alternativas;

- melhoria contínua;

- construção de um ambiente propício à inovação; e

- conscientização da importância do compartilhamento de conhecimento.

Atualmente, já foram realizados dois estudos de caso seguindo esta metodologia. Um novo estudo está sendo conduzido, sendo que o conteúdo deste último será utilizado nesse trabalho.

\subsubsection{O processo de criação do estudo de caso}

O processo para a criação de um estudo de caso é apresentado na figura 34. A partir da descrição deste processo e da análise de sua aplicação nos três estudos de caso citados, pode-se dizer que ele é composto das seguintes etapas:

1 $)$ Pesquisa - é realizado o levantamento histórico, mediante a utilização de fontes documentais e orais, em que se identificam os marcos e as rupturas, os atores e os eixos temáticos sobre o evento ou projeto em questão. São realizadas algumas entrevistas de delineamento com alguns dos atores mapeados, buscando-se 
identificar outros marcos, fontes e atores que participaram da história. O documento resultante desta etapa é o Relatório Histórico, composto de uma ou mais linhas do tempo de fatos importantes (por exemplo, do contexto da história a ser estudada - Linha do tempo da petroquímica - e da história especificamente - Linha do tempo da construção de uma determinada refinaria) e o Mapeamento dos Atores.

$2^{\mathrm{a}}$ ) Delineamento - aqui se constrói a proposta de delineamento, a partir da qual se pretende identificar:

a) alinhamento à estratégia da Unidade Organizacional;

b) alinhamento às necessidades de desenvolvimento de pessoas da Unidade Organizacional;

c) identificação dos eixos temáticos; e

d) identificação dos atores.

O documento resultante desta etapa é o Relatório de Delineamento, que propõe: eixos temáticos a serem explorados pelo caso, casos específicos a serem explorados (seleção de eixo temático como único objeto de foco para estudo), os atores que estão associados a cada eixo temático, lista de atores detalhada (mapeamento dos atores), fatos destacados (linha do tempo), roteiro para entrevista de campo e a lista geral de atores por eixo temático.

$3^{\text {a) }}$ Planejamento - aqui se definem a lista de atores que serão entrevistados e o roteiro de cada entrevista. Os aspectos de logística para coleta do áudio e do vídeo destas entrevistas são definidos neste momento. Os documentos resultantes desta etapa são: Agenda de Entrevistas e Roteiro de Entrevistas. O Roteiro de Entrevistas é composto de: formulário de cadastro do depoente (para entrada de dados pessoais e profissionais), orientações (eixos temáticos e perguntas que visam explorá-los), informações (local, data, pessoas citadas, fatos citados etc.) e um campo para observações.

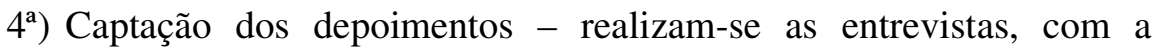
gravação das narrativas e, posteriormente, sua transcrição. Os documentos resultantes são as gravações e as transcrições das entrevistas. 


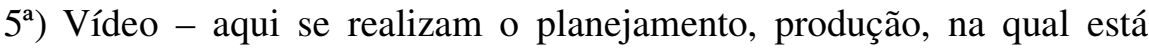
implícito o processo de revisão para a obtenção do resultado final, e a pós-produção do vídeo que ilustra o estudo de caso. O documento resultante é o vídeo, que deverá ser validado.

$6^{\text {a }) ~ T e x t o s ~-~ e s t a ~ e ́ ~ a ~ f a s e ~ d e ~ p r o d u c ̧ a ̃ o ~ d o s ~ t e x t o s ~ q u e ~ c o m p o ̃ e m ~ o ~ e s t u d o ~}$ de caso geral e os estudos de casos específicos. A fim de atingir o resultado final desejável, desenvolveu-se um processo de revisão, que ocorre em quatro etapas: revisão da equipe do projeto; do ator revisor de determinado eixo temático; do patrocinador; e de um revisor profissional (que visa organizar de forma mais didática o texto). O documento resultante é a versão final dos textos do estudo de caso que serão encaminhados para finalização, os quais serão transformados em volumes da Série Desafios. Os textos apresentam os seguintes elementos: introdução; caracterização do desafio; desenvolvimento dos eixos temáticos; identificação de desafios futuros; lições aprendidas; os grandes marcos (linha do tempo); e uma tabela de atores com nome, cargo e função no período que se desenrolou o estudo de caso.

$\left.7^{a}\right)$ Encerramento - é realizada uma oficina com o estudo de caso, que conta com a participação dos aprendizes (que discutirão sobre o texto do estudo de caso) e dos atores que participaram do estudo de caso (os quais participarão de uma dinâmica de troca de experiências com os aprendizes). O documento resultante é a formatação final dos produtos (textos e vídeos), a partir de melhorias identificadas durante a oficina. 


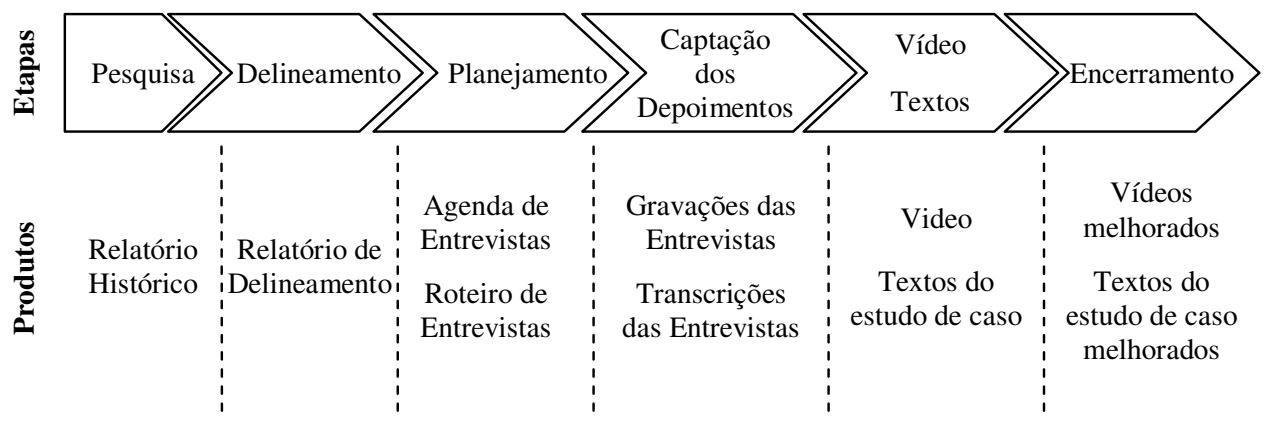

Figura 34 - O processo para criação de um estudo de caso. Fonte: Korowajczuk \& Almeida (2007)

\subsubsection{Pontos a serem melhorados no processo}

A partir da análise da aplicação deste processo nos três estudos de caso realizados, identificam-se os seguintes pontos de melhoria, que podem ser endereçados pela solução proposta no capítulo anterior:

a) Baixa capacidade do reuso das informações coletadas.

b) Impossibilidade de explorar o efeito cauda longa.

c) Há uma dificuldade de rastreabilidade dos artefatos, por exemplo: Qual é a fonte dos eventos que compõem a linha do tempo? Isso acontece por não existir um sistema que suporte a construção desses artefatos. A principal forma de consolidação é por meio de documentos Word e Excel.

d) Longo tempo de produção do conteúdo.

e) Dificuldade de conseguir uma visão global e cumulativa de todos os estudos de caso. Devido ao grande volume de informações geradas em cada estudo, torna-se difícil a utilização de estudos anteriores.

f) A visão de entidades (empresas etc.) é pouco explorada. O foco maior está nos atores e nos fatos em detrimento à percepção da dinâmica das entidades envolvidas.

g) A visão espacial dos eventos é pouco explorada. 


\subsection{Aplicação da solução}

Para a realização de um piloto da solução, utilizou-se o material proveniente do estudo de caso do planejamento da construção de uma refinaria de petróleo. Foram utilizados o Relatório Histórico e as Transcrições das Entrevistas. Utilizouse também o material proveniente de um estudo de caso sobre a instalação de uma unidade de produção de petróleo, porém em menor escala.

Do Relatório Histórico, utilizou-se a linha do tempo da construção da refinaria de petróleo, a qual continha vinte e oito itens, transpostos da ontologia proposta como Eventos. Todos estes itens possuíam pelo menos uma data de início.

O estudo de caso ficou composto de vinte entrevistas, que foram analisadas e inseridas no wiki semântico.

Durante a análise dessas entrevistas, buscou-se identificar trechos que tivessem a característica de Eventos ou Significados. Foram identificados doze novos Eventos (além dos vinte e oito do Relatório Histórico) e cento e setenta e oito Significados. A tabela 13 apresenta a distribuição de Eventos e Significados.

\begin{tabular}{|c|c|c|c|}
\hline & Quem examinou & Eventos & Significados \\
\hline Depoente 1 & Curador 1 & 0 & 6 \\
\hline Depoente 2 & Curador 1 & 0 & 9 \\
\hline Depoente 3 & Curador 1 & 0 & 21 \\
\hline Depoente 4 & Curador 1 & 2 & 6 \\
\hline Depoente 5 & Curador 1 & 0 & 12 \\
\hline Depoente 6 & Curador 1 & 4 & 0 \\
\hline Depoente 7 & Curador 2 & 2 & 6 \\
\hline Depoente 8 & Curador 1 & 2 & 6 \\
\hline Depoente 9 & Curador 1 & 0 & 1 \\
\hline Depoente 10 & Curador 1 & 0 & 13 \\
\hline Depoente 11 & Curador 1 & 0 & 5 \\
\hline Depoente 12 & Curador 2 & 0 & 8 \\
\hline Depoente 13 & Curador 1 & 0 & 14 \\
\hline Depoente 14 & Curador 1 & 1 & 7 \\
\hline Depoente 15 & Curador 1 & 0 & 29 \\
\hline Depoente 16 & Curador 1 & 1 & 16 \\
\hline Depoente 17 & Curador 2 & 0 & 9 \\
\hline Depoente 18 & Curador 3 & 0 & 4 \\
\hline Depoente 21 & Curador 3 & 0 & 6 \\
\hline \multicolumn{2}{|c|}{ Total } & 12 & 178 \\
\hline
\end{tabular}

Tabela 13 - Distribuição de Eventos e Significados do planejamento da construção de uma refinaria. 
Para o estudo de caso da instalação de uma unidade de produção de petróleo, utilizaram-se a linha do tempo proveniente do seu Relatório Histórico e uma entrevista, escolhida devido ao fato de que seu depoente tinha participado dos dois estudos de caso.

A linha do tempo da unidade de produção de petróleo ficou composta por 45 Eventos. Já a entrevista com o depoente (depoente 13 da construção da refinaria) identificou 12 Significados.

\subsubsection{Análise dos conteúdos}

Uma vez que os Eventos e os Significados estão inseridos no wiki semântico, é possível fazer uma série de análises deste material utilizando as ferramentas NetDraw e Exhibit. A figura 35 apresenta um exemplo de visualização dos Significados por meio da ferramenta NetDraw.

Durante a análise, buscou-se identificar os agrupamentos de Eventos e de Significados. A partir disso, pretendeu-se compreender o que aquele agrupamento estava descrevendo.

Um exemplo de análise obtido a partir desta visão de Eventos e de Significados é apresentado na figura 36 , em que se discute qual é a melhor estrutura de organização do trabalho para conduzir o projeto. 


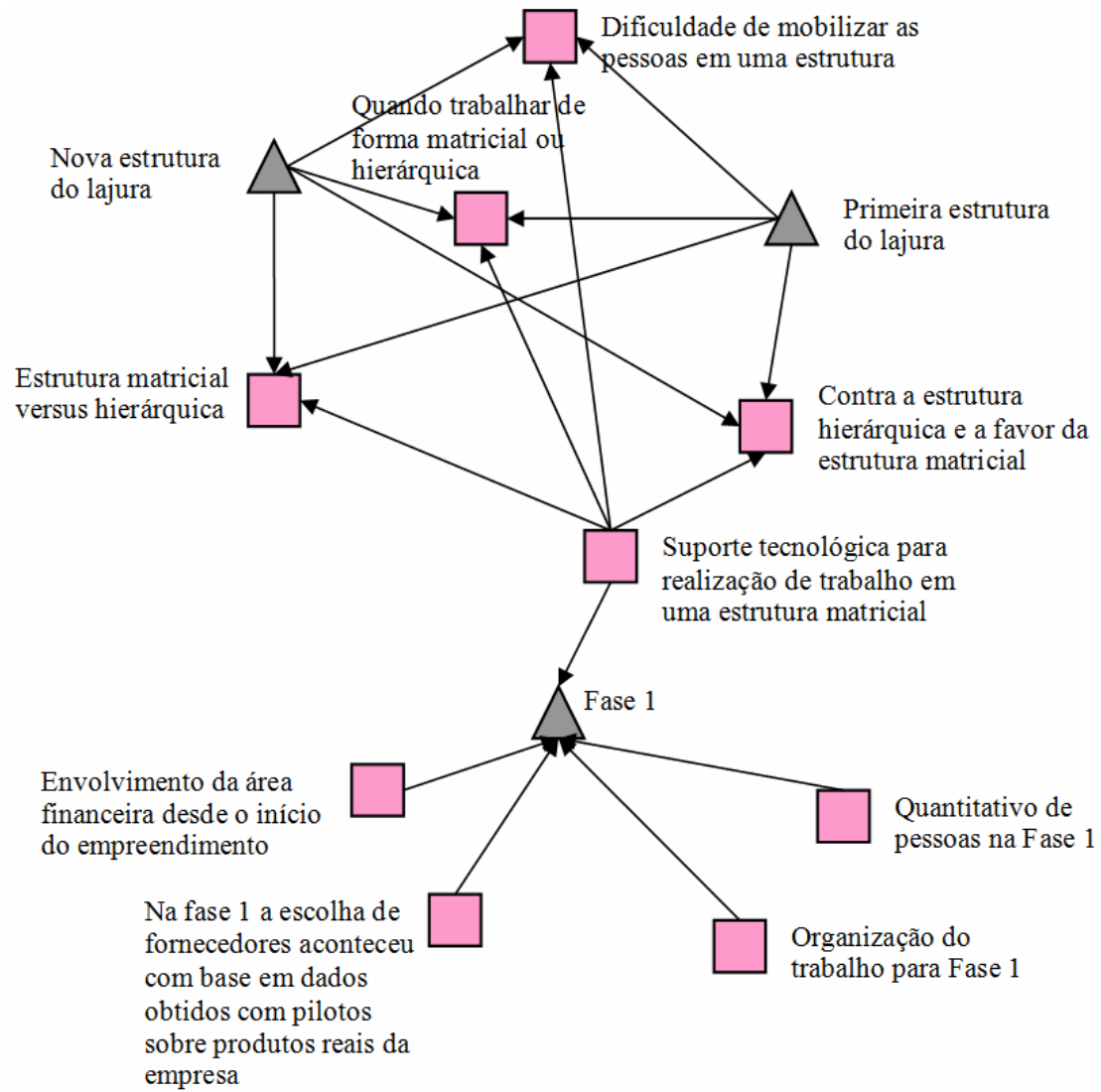

Figura 35 - Exemplo 1: Eventos (vértices triangulares cinza), Significados (vértices quadrados rosa), Relações TemRelação.

A análise desses fragmentos resulta na estrutura de discurso, utilizando o vocabulário do Kuaba, da seguinte forma:

Questão 1: "Qual é a estrutura organizacional mais adequada para projetos do tipo da construção da refinaria?"

a) Ideia 1: "A estrutura hierárquica é a mais apropriada"

i. Argumento contra 1 - (Significado) "Contra a estrutura hierárquica e a favor da estrutura matricial", afirma que a estrutura matricial é mais econômica e viável em contexto de rápida expansão da empresa.

ii. Argumento contra 2 - (Significado) "Dificuldade de mobilizar as pessoas em uma estrutura" coloca uma dificuldade muito interessante da utilização de estruturas hierárquicas: a dificuldade de conseguir a alocação de pessoas "certas" para a estrutura hierárquica idealizada. 
b) Ideia 2: "A estrutura matricial é a mais apropriada"

i. Argumento contra 1 - (Significado) "Estrutura matricial versus hierárquica", conclui que é difícil trabalhar e ter dois chefes (um funcional e outro do projeto (matricial)).

ii. Argumento contra 2 - (Significado) "Quando trabalhar de forma matricial ou hierárquica", aqui se procura certo entendimento de quando utilizar uma estrutura matricial e de quando utilizar uma estrutura hierárquica, porém, dado o contexto deste projeto, é contrário ao uso de uma estrutura matricial.

iii. Argumento a favor 1 - (Significado) "Suporte tecnológico para realização de trabalho em uma estrutura matricial" coloca a necessidade, no trabalho matricial, de se utilizar ferramentas que permitam que pessoas que se encontram geograficamente distribuídas possam se manter atualizadas sobre questões do projeto.

A figura 36 é a representação gráfica deste exemplo.

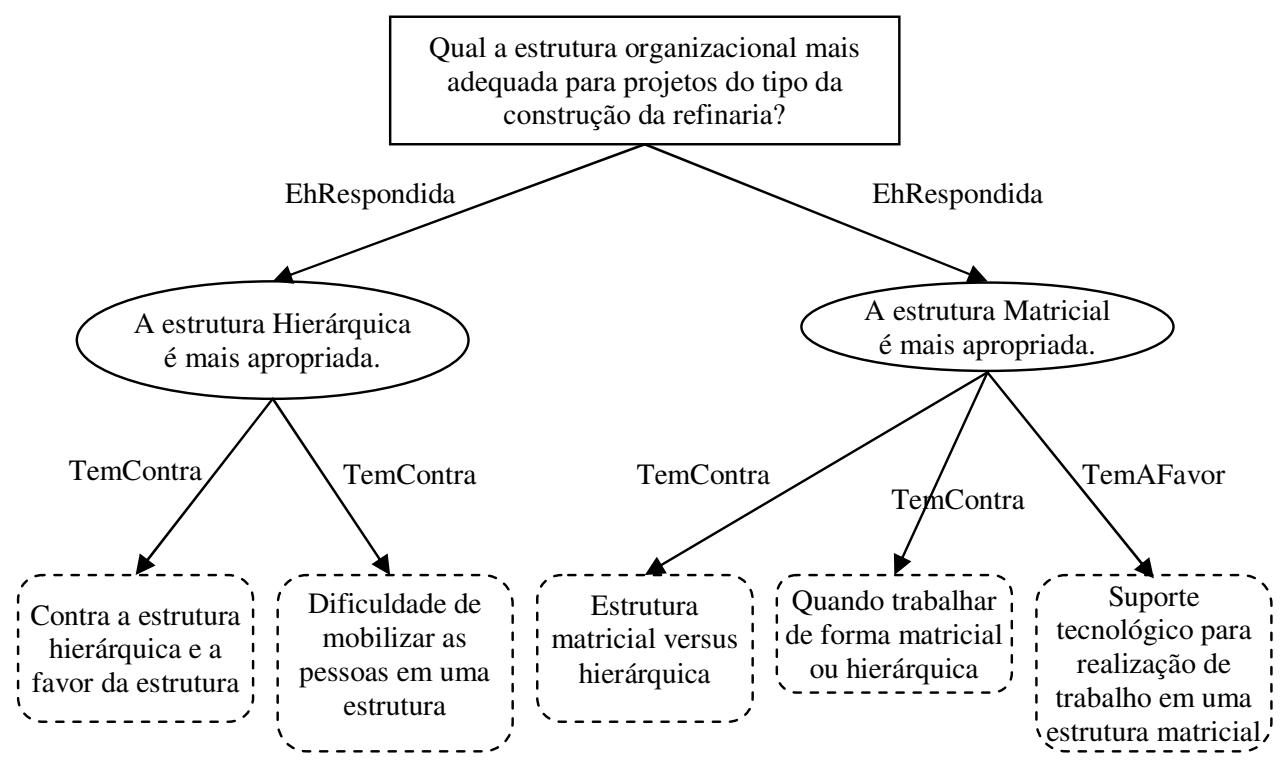

Figura 36 - Exemplo de análise (retângulo = Questão; Elipse = Idéia; retângulo tracejado = Argumento). 


\subsubsection{Análise da rede social}

Os depoentes, muitas vezes, explicitam as pessoas que conhecem ou com quem trabalharam. Dessa forma, ao se analisar o conceito Pessoa e seus

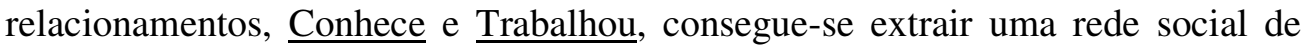
trabalho. Pode-se, dessa forma, compreender a posição de determinados atores dentro do projeto. A figura 37 apresenta a rede social de trabalho da construção da refinaria.

A compreensão da posição das pessoas na rede é importante, pois permite identificar padrões positivos ou negativos dentro de uma rede. Alguns exemplos destes padrões são (Guimarães \& Melo, 2005):

- Conectores centrais, ou hubs - são pessoas que possuem um desproporcional número de relacionamentos na rede. Isso pode ser preocupante, pois pode gerar um gargalo no fluxo de informação na rede. Por exemplo, o depoente 4 na figura 37 está desempenhando este papel.

- Interfaceadores, ou boundary spanners - são pessoas que conectam subgrupos de uma rede, fazendo o papel de interface entre esses subgrupos. Por exemplo, o depoente 14 na figura 37 está desempenhando esse papel.

- Pessoas periféricas - são aquelas que têm poucas conexões dentro da rede. Por exemplo, o depoente 2 na figura 37 está desempenhando esse papel. 


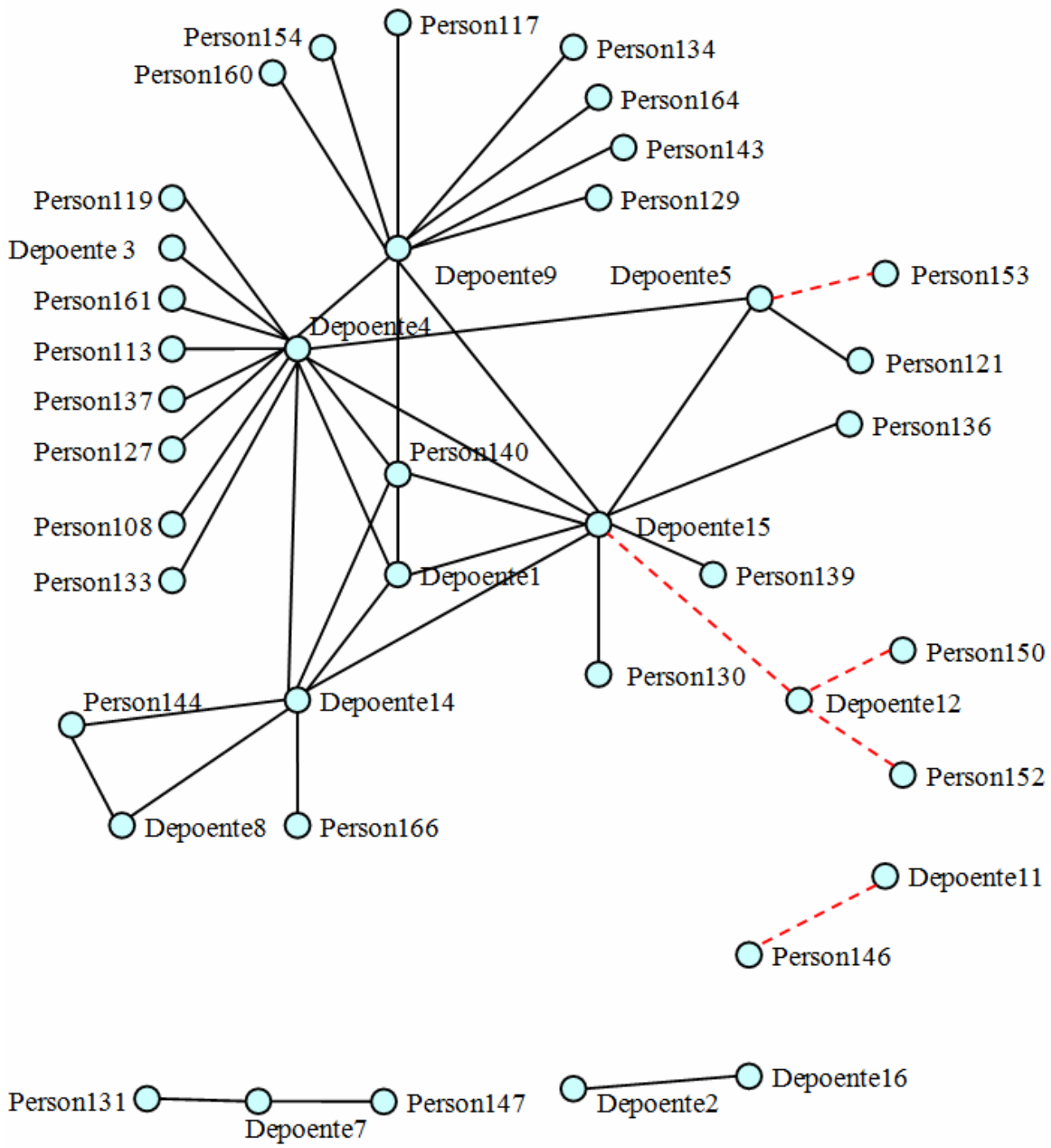

Figura 37 - Rede social de trabalho da construção da refinaria (vértices representam pessoas; arestas contínuas pretas - relacionamento de TrabalharCom; arestas vermelhas tracejadas - relacionamento de Conhecer).

Ao se adicionar à análise o conceito de Entidade e o relacionamento PessoaIntegra (que indica a que entidade a pessoa faz parte), podem-se visualizar potenciais fragilidades nesta rede.

A figura 38 apresenta a rede social de trabalho da construção da refinaria considerando as entidades envolvidas. Nesta rede, pode-se observar que os depoentes 14 e 15 integram outra entidade diferente daquela dos demais. Provavelmente, ao final deste projeto, eles poderão sair desta rede, o que, no caso do depoente 14, causaria a desconexão do depoente 8 e de Person 144 e 166. 


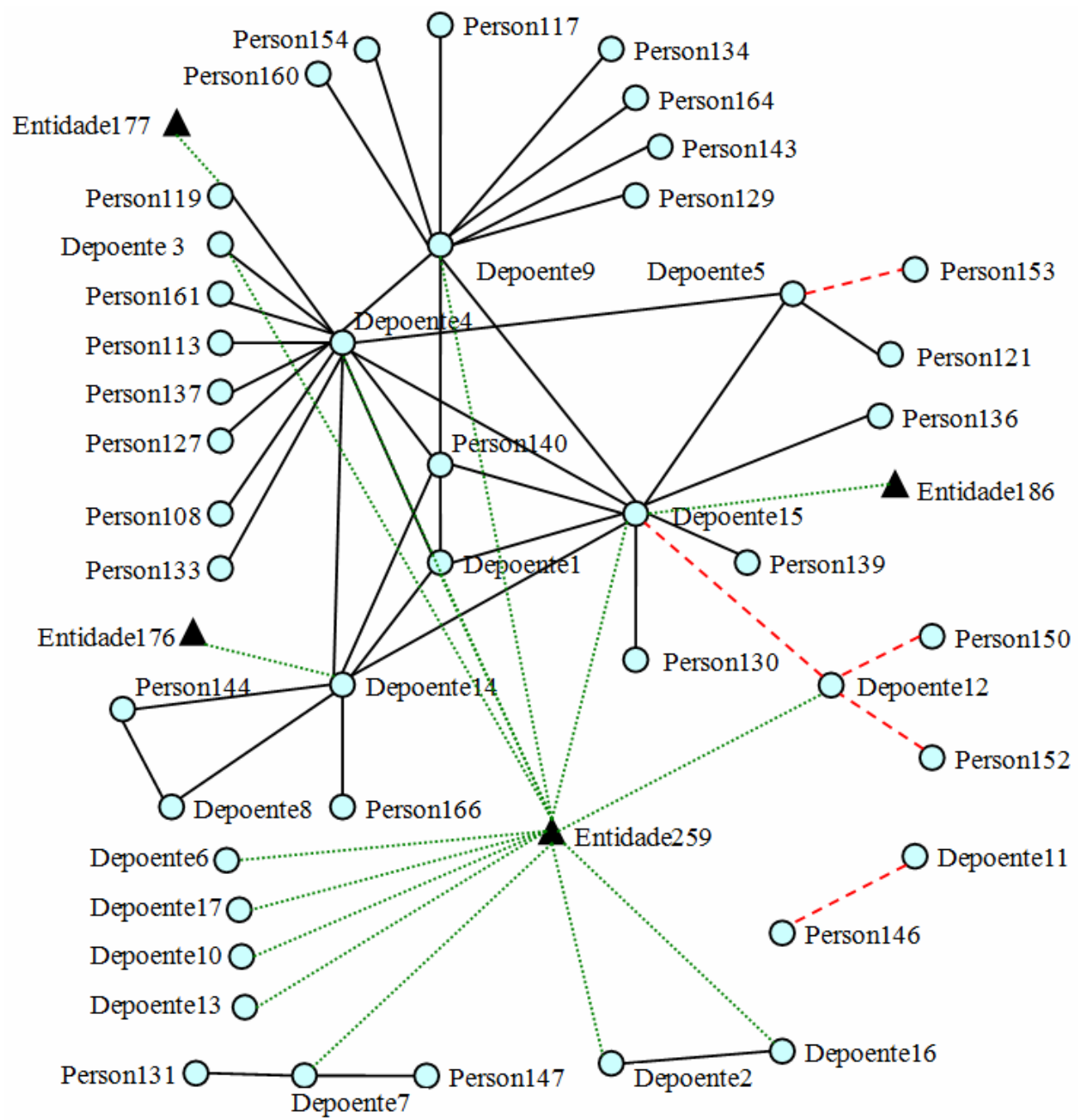

Figura 38 - Rede social de trabalho da construção da refinaria considerando as entidades envolvidas (vértices triangulares pretos representam entidades; vértices circulares azuis representam pessoas; arestas contínuas pretas - relacionamento de TrabalharCom; arestas tracejadas vermelhas - relacionamento de Conhecer; arestas pontilhadas verdes - relacionamento de Pessoalntegra determinada entidade).

\subsubsection{Resultado da entrevista com os curadores}

Visando compreender a percepção dos curadores quanto à utilização da ontologia, foi realizada uma entrevista com todos, trabalho que contou com a participação de três curadores, sendo que um deles era o autor da ontologia. Os outros dois, que foram o foco da entrevista, eram bibliotecários que tinham conhecimento básico sobre os conceitos da ontologia. O papel deles era buscar, na transcrição das entrevistas, fragmentos de depoimentos de interesse para a história 
da construção da refinaria. $\mathrm{O}$ apêndice VI apresenta as perguntas da entrevista. $\mathrm{O}$ resultado da entrevista é apresentado na tabela 14.

\begin{tabular}{|c|c|c|c|}
\hline & $\begin{array}{l}\text { 1. Você teve alguma dificuldade em } \\
\text { identificar depoimertos de interesse para a } \\
\text { históriajprojeto que está sendo descrito na } \\
\text { ertrevista? Quais foran? }\end{array}$ & $\begin{array}{l}\text { 2. Voồ vê alguma outra } \\
\text { informaçẫo de interesse que } \\
\text { está na ertrevista, porém } \\
\text { nẫo está sendo coletacta? }\end{array}$ & $\begin{array}{c}\text { 3. Quanto tem po você gastou para identificar } \\
\text { os depoimentos de interesse de uma } \\
\text { entrevista? }\end{array}$ \\
\hline Facilitador 2 & $\begin{array}{l}\text { Acho que nẫo, consegui ver os pontos } \\
\text { importantes pio projeto lajura , mas } \\
\text { tal vez tenha marcado falas demais para } \\
\text { peca por excesso e nẫo por falta. }\end{array}$ & Nẫo vejo rấo. & $\begin{array}{l}\text { Nấo é uma tarefa rápida, precisa-se andisar } \\
\text { bem o conteúdo para destaca ou nấo uma } \\
\text { fala, pensar num título, o que às vezes pode } \\
\text { ser complicado porque pode ficar muito } \\
\text { extenso e tento ser bern objetiva e ainda } \\
\text { dassificar de acordo com a dassificaçấo feita } \\
\text { pơ você, pode demorar um pouoo. }\end{array}$ \\
\hline F acilitador 3 & $\begin{array}{l}\text { A dificuldade foi no que tange à } \\
\text { informaçốes sobre os objetivos, o que seria } \\
\text { importante identificar naquele cortexto. }\end{array}$ & $\begin{array}{l}\text { Acredito que essa peroepçẫo } \\
\text { depende de uma definiçấo } \\
\text { mais dara do objetivo da } \\
\text { análise, onde poderíamos } \\
\text { aguçar o olhar sobre as } \\
\text { informaôñes. }\end{array}$ & $\begin{array}{c}\text { Gastei, em média, cerca de } 15 \mathrm{~min} \text {. por } \\
\text { entrevista. }\end{array}$ \\
\hline
\end{tabular}

Tabela 14 - Resultado das entrevistas.

Um ponto importante diz respeito ao tempo gasto na análise de cada entrevista. O curador 2, que é mais experiente que o 3 , indicou que a análise da entrevista foi um processo um pouco demorado. Outro trabalho para realização futura consiste em prever mecanismos, automáticos ou não, que auxiliem na busca e na identificação de fragmentos de interesse.

\subsection{Experimentos realizados}

A partir de um subconjunto do material utilizado no estudo de caso do planejamento da construção da refinaria (transcrições das entrevistas), foram realizados quatro experimentos, que visavam verificar se a representação proposta neste trabalho facilitava a dinâmica de reflexão coletiva. Para a realização destes experimentos, utilizou-se o material de cinco entrevistas, o que gerou um total de 54 fragmentos. No apêndice III, apresenta-se o enunciado de cada um dos experimentos.

$\mathrm{O}$ primeiro experimento (teste de associação entre significante e significado) buscou, por meio de uma pesquisa de levantamento (Creswell, 2002), identificar se era fácil a associação entre os títulos (Significado) e os textos dos Fragmentos. Para tanto, solicitou-se que um grupo de pessoas fizesse uma associação de um conjunto de dez textos de Fragmentos e seus títulos.

O segundo experimento (teste de reutilização) procurou, por meio de uma pesquisa experimental (Creswell, 2002), identificar se o conteúdo organizado seguindo a representação proposta para descrever a história/significados facilitava 
o processo de interpretação e a reutilização desse conteúdo. Para isso, foram utilizados dois grupos, em que cada qual leu o mesmo conteúdo em representações diferentes (o grupo 1 leu uma parte do texto bruto das entrevistas e o grupo 2 leu o mesmo conteúdo na representação proposta no wiki semântico). Após a leitura, compararam-se os resultados dos dois grupos, respondendo a um mesmo conjunto de perguntas sobre o conteúdo lido.

O terceiro experimento (teste de completude), por meio de uma pesquisa de levantamento, procurou identificar se havia algum outro fragmento no texto de um depoimento/entrevista considerado interessante para ser colocado como significado pelo curador. Para isso, um grupo de pessoas leu um conjunto de entrevistas e buscou identificar se havia algum fragmento que eles considerassem de interesse no contexto empresarial.

Por fim, o quarto experimento (teste da cauda longa) buscou, também por meio de uma pesquisa de levantamento, identificar se, a partir de um conjunto de fragmentos, as pessoas conseguiam inserir outros, oriundos de sua própria experiência, que permitiriam aumentar e enriquecer a história e suas conclusões. Para tanto, solicitou-se a um grupo de pessoas que lesse um conjunto de fragmentos sobre determinado eixo temático, a respeito dos quais tivessem alguma experiência de trabalho e criassem novos fragmentos associados aos lidos naquele eixo temático.

A tabela 15 apresenta o relacionamento entre os problemas associados ao problema central deste trabalho, apresentado no capítulo 1, com os experimentos que visam avaliá-los. 


\begin{tabular}{|c|c|c|c|c|}
\hline Experimentos & $\begin{array}{c}\text { teste de associação } \\
\text { entre significante e } \\
\text { significado }\end{array}$ & $\begin{array}{c}\text { teste de } \\
\text { reuso }\end{array}$ & $\begin{array}{c}\text { teste de } \\
\text { completude }\end{array}$ & $\begin{array}{c}\text { teste da } \\
\text { cauda } \\
\text { longa }\end{array}$ \\
\hline $\begin{array}{c}\text { Como melhorar a eficácia da coleta de } \\
\text { conhecimento no contexto de uma } \\
\text { comunidade a respeito de determinado } \\
\text { evento? }\end{array}$ & $\mathrm{X}$ & $\mathrm{X}$ & $\mathrm{X}$ \\
\hline $\begin{array}{c}\text { Existe uma forma que represente o } \\
\text { conhecimento que permita o seu } \\
\text { posterior reaproveitamento de uma } \\
\text { forma melhor do que a narrativa } \\
\text { puramente textual? }\end{array}$ & & & \\
\hline
\end{tabular}

Tabela 15 - Relacionamento entre os problemas associados ao problema central desse trabalho e os experimentos.

A tabela 16 apresenta o perfil do universo de pessoas que responderam aos experimentos. Substituiu-se o nome das pessoas pelo nome de animais, visando preservar a identidade dos entrevistados. Todos os respondentes tinham nível universitário concluído.

\begin{tabular}{|l|c|c|}
\hline & $\begin{array}{c}\text { Trabalha no assunto } \\
(\mathbf{0 - 1 0 )}\end{array}$ & $\begin{array}{c}\text { Tempo de empresa em anos (0 a } \\
\mathbf{2} ; \mathbf{3} \text { a 5; 6 a 10; 11 a 20; 21 a 30) }\end{array}$ \\
\hline Baleia & 2 & 0 \\
\hline Camaleão & 9 & 21 a 30 \\
\hline Camêlo & 7 & 3 a 5 \\
\hline Cavalo & 4 & 0 a 2 \\
\hline Cisnei & 6 & 6 a 10 \\
\hline Cobra & 0 & 0 \\
\hline Elefante & 10 & 3 a 5 \\
\hline Galinha & 0 & 0 \\
\hline Gato & 0 & 0 \\
\hline Girafa & 10 & 21 a 30 \\
\hline Jacaré & 7 & 0 a 2 \\
\hline Leão & 6 & 6 a 10 \\
\hline Papagaio & 7 & 3 a 5 \\
\hline Pato & 6 & 21 a 30 \\
\hline Rato & 0 & 0 \\
\hline Sapo & 9 & 21 a 30 \\
\hline Tigre & 0 & 6 a 10 \\
\hline Tubarão & 6 & 0 \\
\hline Tucano & 1 & 0 \\
\hline Vaca & 0 & \\
\hline & & 0 \\
\hline
\end{tabular}

Tabela 16 - perfil do universo de pessoas que responderam os experimentos.

Nas seções a seguir apresentam-se os resultados de cada experimento. 


\subsubsection{Resultado do teste de associação entre significante e significado}

Neste experimento, buscou-se identificar se era fácil fazer a associação entre os títulos (Significado) e os textos dos fragmentos. Para isso, solicitou-se a um grupo de vinte pessoas que fizesse um associação de um conjunto de dez textos de Fragmentos e seus títulos. A tabela 17 apresenta os resultados.

\begin{tabular}{|c|c|c|c|c|c|c|c|c|c|c|c|c|}
\hline & \multicolumn{10}{|c|}{ Questões } & \multirow[b]{2}{*}{ Erro } & \multirow[b]{2}{*}{$\begin{array}{l}\text { tempo de } \\
\text { resposta }\end{array}$} \\
\hline & 1 & 2 & 3 & 4 & 5 & 6 & 7 & 8 & 9 & 10 & & \\
\hline Gabatiro & $\mathrm{B}$ & $\mathrm{G}$ & $A$ & $F$ & $\mathrm{C}$ & $\mathrm{J}$ & $\mathrm{D}$ & $\mathrm{H}$ & $\mathrm{I}$ & $E$ & & \\
\hline Baleia & $\mathrm{B}$ & $\mathrm{G}$ & $\mathrm{A}$ & $\mathrm{F}$ & $\mathrm{C}$ & $\mathrm{J}$ & $\mathrm{D}$ & $\mathrm{H}$ & $\mathrm{I}$ & $E$ & $0,00 \%$ & 26 min. \\
\hline Camaleão & $\mathrm{B}$ & $\mathrm{G}$ & $A$ & $\mathrm{~F}$ & $\mathrm{C}$ & $\mathrm{J}$ & $\mathrm{D}$ & $\mathrm{H}$ & I & $E$ & $0,00 \%$ & $10 \mathrm{~min}$. \\
\hline Camêlo & $\underline{\mathrm{G}}$ & B & $A$ & $\mathrm{~F}$ & $\mathrm{C}$ & $\mathrm{J}$ & $\mathrm{D}$ & $\mathrm{H}$ & $\mathrm{I}$ & $E$ & $20,00 \%$ & $16 \mathrm{~min}$. \\
\hline Cavalo & $\bar{B}$ & $\bar{G}$ & $\mathrm{~A}$ & $\mathrm{~F}$ & C & $\mathrm{J}$ & $\mathrm{D}$ & $\mathrm{H}$ & $\mathrm{I}$ & $E$ & $0,00 \%$ & 23 min. \\
\hline Cisnei & $\mathrm{G}$ & $\mathrm{B}$ & $\mathrm{A}$ & $\bar{F}$ & C & $\mathrm{J}$ & $\mathrm{D}$ & $\mathrm{H}$ & $\mathrm{I}$ & $E$ & $20,00 \%$ & $12 \mathrm{~min}$. \\
\hline Cobra & $\bar{B}$ & $\overline{\mathrm{G}}$ & $\mathrm{A}$ & $\mathrm{F}$ & $\mathrm{C}$ & $\mathrm{J}$ & $\mathrm{D}$ & $\mathrm{H}$ & $\mathrm{I}$ & $\mathrm{E}$ & $0,00 \%$ & $21 \mathrm{~min}$. \\
\hline Elefante & $\mathrm{B}$ & $\mathrm{G}$ & $\mathrm{A}$ & $\mathrm{F}$ & $\mathrm{C}$ & $\mathrm{J}$ & $\mathrm{D}$ & $\mathrm{H}$ & $\mathrm{I}$ & $E$ & $0,00 \%$ & $40 \mathrm{~min}$. \\
\hline Galinha & $\mathrm{B}$ & $\mathrm{G}$ & $\mathrm{A}$ & $\underline{E}$ & $\mathrm{C}$ & $\mathrm{J}$ & $\mathrm{D}$ & $\mathrm{H}$ & $\mathrm{I}$ & $\underline{F}$ & $20,00 \%$ & $10 \mathrm{~min}$. \\
\hline Gato & $B$ & $\mathrm{G}$ & $A$ & $\mathrm{~F}$ & $\mathrm{C}$ & $\mathrm{J}$ & $\mathrm{D}$ & $\mathrm{H}$ & $\mathrm{I}$ & $E$ & $0,00 \%$ & $18 \mathrm{~min}$. \\
\hline Girafa & B & $\mathrm{G}$ & $\mathrm{A}$ & $\mathrm{F}$ & C & $\mathrm{J}$ & $\mathrm{D}$ & $\mathrm{H}$ & $\mathrm{I}$ & $E$ & $0,00 \%$ & $15 \mathrm{~min}$. \\
\hline Jacaré & B & $\mathrm{G}$ & A & $E$ & C & $\mathrm{J}$ & $\mathrm{D}$ & $\mathrm{H}$ & $\mathrm{I}$ & F & $20,00 \%$ & $11 \mathrm{~min}$. \\
\hline Leão & $B$ & $\mathrm{G}$ & $\mathrm{A}$ & $\bar{F}$ & $\mathrm{C}$ & $\mathrm{J}$ & $\mathrm{D}$ & $\mathrm{H}$ & $\mathrm{I}$ & $\bar{E}$ & $0,00 \%$ & 12 min. \\
\hline Papagaio & B & $\mathrm{G}$ & A & $F$ & C & $\mathrm{J}$ & $\mathrm{D}$ & $\mathrm{H}$ & $\mathrm{I}$ & $E$ & $0,00 \%$ & 20 min. \\
\hline Pato & $B$ & $\mathrm{G}$ & $\mathrm{A}$ & $F$ & C & $\mathrm{J}$ & $\mathrm{D}$ & $\mathrm{H}$ & $\mathrm{I}$ & $E$ & $0,00 \%$ & 19 min. \\
\hline Rato & $\underline{\mathrm{G}}$ & B & $\mathrm{A}$ & $\mathrm{F}$ & $\mathrm{C}$ & $\mathrm{J}$ & $\mathrm{D}$ & $\mathrm{H}$ & $\mathrm{I}$ & $E$ & $20,00 \%$ & $14 \mathrm{~min}$. \\
\hline Sapo & $\overline{\mathrm{G}}$ & $\underline{B}$ & $\mathrm{~A}$ & $\underline{E}$ & $\underline{F}$ & $\mathrm{~J}$ & $\mathrm{D}$ & $\mathrm{H}$ & $\mathrm{I}$ & $\underline{\underline{C}}$ & $50,00 \%$ & $10 \mathrm{~min}$. \\
\hline Tigre & $\bar{B}$ & $\bar{G}$ & $\mathrm{~A}$ & $\mathrm{~F}$ & $\bar{C}$ & $\mathrm{~J}$ & $\mathrm{D}$ & $\mathrm{H}$ & $\mathrm{I}$ & $\bar{E}$ & $0,00 \%$ & 24 min. \\
\hline Tubarão & $\mathrm{B}$ & $\mathrm{G}$ & $A$ & $\mathrm{~F}$ & $\mathrm{C}$ & $\mathrm{J}$ & $\mathrm{D}$ & $\mathrm{H}$ & I & $\mathrm{E}$ & $0,00 \%$ & $23 \mathrm{~min}$. \\
\hline Tucano & $B$ & $\mathrm{G}$ & $A$ & $\mathrm{~F}$ & $\mathrm{C}$ & $\mathrm{J}$ & $\mathrm{D}$ & $\mathrm{H}$ & $\mathrm{I}$ & $E$ & $0,00 \%$ & $30 \mathrm{~min}$. \\
\hline Vaca & B & $\mathrm{G}$ & $A$ & $\mathrm{~F}$ & C & $\mathrm{J}$ & $\mathrm{D}$ & $\mathrm{H}$ & I & $E$ & $0,00 \%$ & $25 \mathrm{~min}$. \\
\hline Erro & $20,00 \%$ & $20,00 \%$ & \begin{tabular}{|l|}
$0,00 \%$ \\
\end{tabular} & $15,00 \%$ & $5,00 \%$ & $0,00 \%$ & $0,00 \%$ & $0,00 \%$ & $0,00 \%$ & $15,00 \%$ & & \\
\hline
\end{tabular}

Tabela 17 - Resultados do teste de associação entre significante e significado. Nota: Os itens em vermelho e sublinhados são respostas erradas.

Pode-se observar que $70 \%$ das pessoas responderam conforme o gabarito, o que indica que a associação entre significante e significado é bem razoável de ser realizada. Somente $25 \%$ das pessoas trocaram apenas 1 item, trocas estas muito focadas em algumas questões (troca da resposta da questão 1 com a 2 e a questão 4 com a 10).

Outro ponto importante a observar é que quem respondeu mais rápido teve maior propensão a errar. O tempo médio de leitura de quem acertou todas as questões foi de 22 minutos, enquanto o tempo médio de leitura de quem errou ao menos uma questão foi de 12 minutos. 


\subsubsection{Resultado do teste de reutilização}

Neste experimento, tentou-se identificar se a representação proposta para descrever a história/significados facilitou o processo de interpretação e reutilização do conteúdo.

Utilizou-se um mesmo conteúdo, representado de duas formas diferentes: diálogos brutos das entrevistas e representação proposta em um wiki. Um grupo de nove pessoas leu os diálogos brutos, enquanto outro de onze leu a representação proposta. Os dois grupos deveriam marcar o tempo gasto para a leitura. É importante observar que a escolha dos participantes de cada grupo se deu de forma aleatória.

Ao fim da leitura, era solicitado que cada pessoa respondesse às seguintes questões:

Questão 1 - Quais são os assuntos em comum desses fragmentos?

Questão 2 - Quais são as linhas de pensamento sobre esses

assuntos?

Questão 3 - Há linhas de pensamentos contraditórias? Quais são?

Questão 4 - Qual foi a sua estratégia de leitura?

Questão 5 - Comentários.

$\mathrm{Na}$ leitura, cada pessoa deveria marcar o tempo gasto em cada resposta.

O conteúdo lido pelos dois grupos apresentou visões dos entrevistados sobre as seguintes questões:

- Melhor forma de construir a estrutura organizacional de uma empresa: orientação hierárquica versus orientação matricial.

- Vantagens e desvantagens do uso de pessoal com pouca experiência de trabalho (juniores) na condução de projetos complexos.

A tabela 18 apresenta a análise das respostas dos participantes sobre essas questões. 


\begin{tabular}{|c|c|c|c|c|c|c|c|c|}
\hline & \multirow[b]{2}{*}{$\begin{array}{l}\text { Representação } \\
\text { utilizada }\end{array}$} & \multicolumn{4}{|c|}{ Respostas possiveis } & \multirow[b]{2}{*}{$\begin{array}{c}\text { Tempo de } \\
\text { resposta } \\
\text { questão 1, } \\
\text { questão 2, } \\
\text { questão } 3 \\
\text { (minutos) }\end{array}$} & \multirow[b]{2}{*}{\begin{tabular}{|} 
Tempo de leitura + \\
Tempo de \\
resposta questão \\
1, questão 2, \\
questão 3 \\
(minutos)
\end{tabular}} & \multirow[b]{2}{*}{$\begin{array}{c}\text { Número } \\
\text { de } \\
\text { acertos }\end{array}$} \\
\hline & & $\begin{array}{l}\text { Identificou a } \\
\text { questão sobre } \\
\text { estrutura? }\end{array}$ & $\begin{array}{c}\text { Identificou que há } \\
\text { duas correntes sobre } \\
\text { estrutura } \\
\text { organizacional } \\
\text { (matricial X } \\
\text { hierárquica)? } \\
\end{array}$ & $\begin{array}{l}\text { Identificou a } \\
\text { questão sobre } \\
\text { experiência no } \\
\text { trabalho? }\end{array}$ & $\begin{array}{l}\text { Identificou que há duas } \\
\text { correntes sobre } \\
\text { experiência no trabalho } \\
\text { (ter só gente experiente X } \\
\text { mescla juniores e } \\
\text { experientes) }\end{array}$ & & & \\
\hline Pato & Texto bruto & Sim & Não & Sim & Não & 5 & 51 & 2 \\
\hline Rato & Texto bruto & Sim & Não & Sim & Não & 11 & 85 & 2 \\
\hline Tigre & Texto bruto & Sim & Sim & Não & Não & 10 & 77 & 2 \\
\hline Tubarão & Texto bruto & Sim & Não & Sim & Não & 10 & 55 & 2 \\
\hline Cisnei & Texto bruto & Sim & Não & Sim & Sim & 9 & 73 & 3 \\
\hline Tucano & Texto bruto & Sim & Não & Sim & Sim & 13 & 95 & 3 \\
\hline Baleia & Texto bruto & Sim & Sim & Sim & Sim & 13 & 87 & 4 \\
\hline Leão & Texto bruto & Sim & Sim & Sim & Sim & 10 & 78 & 4 \\
\hline Vaca & Texto bruto & Sim & Sim & Sim & Sim & 14 & 98 & 4 \\
\hline Gato & Wiki semântico & Sim & Sim & Não & Não & 18 & 128 & 2 \\
\hline Cavalo & Wiki semântico & Sim & Não & Sim & Sim & 5 & 22 & 3 \\
\hline Galinha & Wiki semântico & Sim & Sim & Sim & Não & 8 & 53 & 3 \\
\hline Camaleão & Wiki semântico & Sim & Sim & Sim & Sim & 25 & 42 & 4 \\
\hline Camêlo & Wiki semântico & Sim & Sim & Sim & Sim & 9 & 26 & 4 \\
\hline Cobra & Wiki semântico & Sim & Sim & Sim & Sim & 10 & 45 & 4 \\
\hline Elefante & Wiki semântico & Sim & Sim & Sim & Sim & 18 & 37 & 4 \\
\hline Girafa & Wiki semântico & Sim & Sim & Sim & Sim & 17 & 32 & 4 \\
\hline Jacaré & Wiki semântico & Sim & Sim & Sim & Sim & 7 & 21 & 4 \\
\hline Sapo & Wiki semântico & Sim & Sim & Sim & Sim & 5 & 35 & 4 \\
\hline Papagaio & Wiki semântico & Sim & Sim & Sim & Sim & 10 & 18 & 4 \\
\hline
\end{tabular}

Tabela 18 - Resultados do teste de reuso.

Pode-se observar que, conforme o esperado, as pessoas que utilizaram a representação proposta obtiveram um resultado um pouco melhor em um tempo de leitura muito menor. A média de acertos de quem utilizou os diálogos brutos foi de 2,9 questões para um tempo médio de leitura de 78 minutos. Já a média de acertos de quem utilizou a representação proposta em um wiki foi de 3,6 questões para um tempo médio de leitura de 42 minutos.

Do grupo que leu a representação proposta em um wiki, apenas Gato, Cavalo e Galinha tiveram desempenho ruim. Isso se deveu ao fato que, conforme a tabela do perfil do universo de pessoas que responderam aos experimentos (tabela 16), Gato, Cavalo e Galinha apresentavam pouco conhecimento sobre o assunto presente no conteúdo. Isso é um indício de que a representação proposta facilita, somente, uma comunidade de pessoas que lidam com o conteúdo discutido, que, no caso deste trabalho, é o assunto "Gestão".

\subsubsection{Resultado do teste de completude}

Aqui, procurou-se identificar se existia fragmento no texto de um depoimento/entrevista que fosse interessante, o qual pudesse ser colocado como significado pelo curador. Para realizar isso, um grupo leu uma de duas transcrições de entrevistas que faziam parte do conjunto daquelas utilizadas no estudo de caso da construção da refinaria. No texto destas entrevistas, estavam explicitados os fragmentos de texto considerados pelo curador durante a passagem da entrevista bruta para a representação proposta. 
Durante a leitura, pediu-se para que cada pessoa identificasse se havia algum fragmento que eles identificavam como de interesse no contexto empresarial.

A tabela 19 apresenta os resultados desse experimento, sendo que:

- FI é o número de fragmentos identificados, inicialmente, pelo curador na leitura da transcrição.

- NF é o número total de fragmentos identificados pelos leitores. Entre eles, estão fragmentos originais e reinterpretações de outros fragmentos. O número na tabela é o valor agregado de todos os leitores para cada coluna.

- FO corresponde ao número de fragmentos originais identificados pelos leitores. Estes são os fragmentos realmente novos, não achados pelos curadores (FI). O número na tabela é o valor agregado de todos os leitores para cada coluna.

- FSC é o número de fragmentos não originais identificados pelos leitores, em que não houve correlação com fragmentos já existentes. O ideal é que esse número seja o menor possível, uma vez que ele representa a inserção de conteúdo já existente. O número na tabela é o valor agregado de todos os leitores para cada coluna.

\begin{tabular}{|c|c|c|}
\hline & $\begin{array}{c}\text { Entrevista de } \\
\text { Depoente 17 } \\
\text { (7 leitores) }\end{array}$ & $\begin{array}{c}\text { Entrevista de } \\
\text { Depoente 15 } \\
\text { (7 leitores) }\end{array}$ \\
\hline $\begin{array}{c}\text { FI - número de fragmentos identificados } \\
\text { inicialmente pelo curador }\end{array}$ & 9 & 12 \\
\hline $\begin{array}{c}\text { NF - número total de framentos } \\
\text { identificados pelos leitores. }\end{array}$ & 20 & 3 \\
\hline $\begin{array}{c}\text { FO - número de fragmentos originais } \\
\text { identificados pelos leitores }\end{array}$ & 3 & 3 \\
\hline $\begin{array}{c}\text { FSC - número de fragmentos não } \\
\text { originais identificado pelos leitores, onde } \\
\text { não houve correlação com fragmentos já } \\
\text { existentes. }\end{array}$ & 2 & \\
\hline \begin{tabular}{l} 
haves. \\
\hline
\end{tabular}
\end{tabular}

Tabela 19 - Resultados do teste de completude.

Pode-se observar que o número de fragmentos originais identificados pelos leitores (FO) é baixo ( 3 de 9 na entrevista com Depoente 17 e 3 de 12 na entrevista com Depoente 15). Isso indica que, a partir de certo ponto, esgota-se a capacidade de identificação de novos conteúdos úteis numa entrevista. 
Outro ponto positivo foi que houve baixo número de fragmentos não originais em que não houve correlação (FSC) (2 de 9 na entrevista com Depoente 17 e 3 de 12 na entrevista com Depoente 15). Isso indica que poucos são os casos em que as pessoas não conseguem detectar que estão colocando conteúdo já existente.

\subsubsection{Resultado do teste da cauda longa}

Neste experimento, buscou-se identificar se, a partir de um conjunto de fragmentos, as pessoas conseguiam inserir outros oriundos de sua própria experiência que permitissem aumentar e enriquecer a história e suas conclusões.

Para a realização deste experimento, solicitou-se a um grupo de pessoas que lesse um conjunto de fragmentos sobre determinado eixo temático sobre o qual elas tivessem alguma experiência de trabalho e, assim, criasse fragmentos associados aos lidos neste eixo temático.

Das 15 pessoas para as quais foi solicitado que respondessem este teste, apenas 7 inseriram fragmentos oriundos de suas experiências. A tabela 20 apresenta os resultados.

\begin{tabular}{|c|c|c|}
\hline Respondete & $\begin{array}{c}\text { Número de fragmentos } \\
\text { inseridos }\end{array}$ & $\begin{array}{c}\text { Tempo de empresa em anos (0 a } \\
\text { 2; 3 a 5; 6 a 10; 11 a 20; 21 a 30) }\end{array}$ \\
\hline Gato & 0 & 0 \\
\hline Cobra & 0 & 0 \\
\hline Rato & 1 & 0 \\
\hline Vaca & 0 & 0 \\
\hline Tigre & 0 & 0 \\
\hline Baleia & 0 & 0 \\
\hline Cavalo & 0 & 0 a 2 \\
\hline Jacaré & 0 & 0 a 2 \\
\hline Camêlo & 0 & 3 a 5 \\
\hline Papagaio & 1 & 3 a 5 \\
\hline Leão & 1 & 6 a 10 \\
\hline Cisnei & 1 & 6 a 10 \\
\hline Camaleão & 2 & 21 a 30 \\
\hline Girafa & 4 & 21 a 30 30 \\
\hline Sapo & 6 & 21 a 30 \\
\hline
\end{tabular}

Tabela 20 - Resultados do teste da cauda longa.

Com base nos resultados deste experimento, pode-se observar que o número de fragmentos próprios dos indivíduos está diretamente relacionado ao seu tempo de experiência na empresa e ao fato de se trabalhar no assunto. 
Observa-se nesse experimento que obteve-se 16 novos significados. Esse valor corresponde a $30 \%$ dos 54 significados obtidos por meio de entrevistas. Dessa forma, vê-se que conseguiu-se aproveitar as experiências de outras pessoas a um custo de obtenção dessa informação muito baixo em relação a realização de entrevistas. A figura 39 ilustra esse conceito.

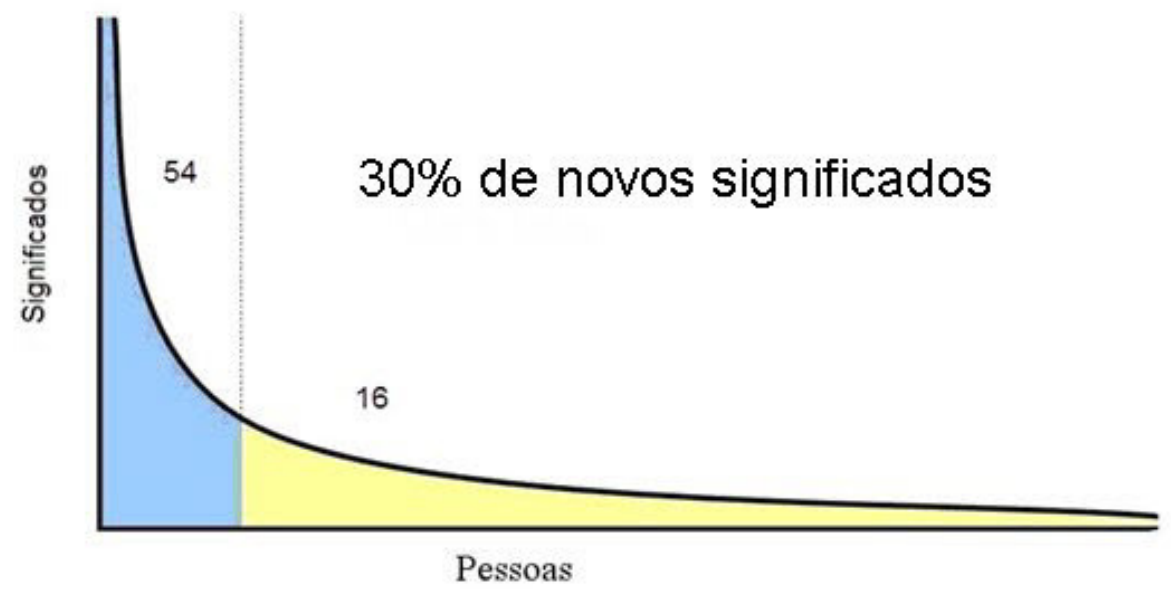

Figura 39 - A exemplificação do conceito de cauda longa do experimento.

\subsubsection{Comentários sobre os experimentos}

Ao final dos experimentos, alguns participantes fizeram, espontaneamente, comentários sobre o conteúdo e a representação proposta. Como para a maioria dos participantes o conteúdo apresentado faz parte dos assuntos tratados por eles em seu dia a dia, este experimento teve também um caráter utilitário. Em alguns de seus comentários, há a indicação de potenciais reaproveitamentos reais desse conteúdo.

Camêlo indicou que, a partir do fragmento "Como foram as indicações das pessoas para trabalharem no projeto ${ }^{" 36}$, ele vislumbrava uma solução prática para um problema que estava enfrentando na condução de alguns Grupos de Trabalho na empresa.

\footnotetext{
36 "Ata de reunião ela tinha todos os participantes, né, os oficiais, os que vinham substituindo. Então se um vinha substituindo algum outro que não podia vir, a gente colocava presente por substituto. Ele estava substituto lá em baixo. E os outros levavam ausente. É simples. Ausente quer dizer: ele concordou com aquilo que foi dito. Porque comentar ata de reunião da qual você não participou a gente não deixava não. Entendeu? Você comenta ata da qual, da reunião da qual você participou. Se foi resolvido alguma coisa na reunião da qual você não participou, você não pode comentar. Então aí as pessoas acabam indo."
} 
A partir da leitura do material como um todo, Girafa indicou dois possíveis projetos a serem trabalhados:

$1^{\circ}$ ) "Ensinar as pessoas e gerentes da empresa a trabalhar matricialmente. Isto é superimportante e não faz parte de nossa cultura. Não é fácil, e seria superlegal haver uma palestra ou curso chamado Trabalhando em Matriz".

$2^{\circ}$ ) "A Companhia deveria ter mecanismos para orientar pessoas certas para as áreas em que serão mais necessárias. Um dos mecanismos para isto é a própria estrutura organizacional: você aumenta a densidade de funções gerenciais nas áreas críticas, porque isto irá atrair os talentos que as levarão ao sucesso. Infelizmente, a companhia não utiliza este mecanismo de forma consistente e aparentemente não percebe a importância do assunto."

Apesar de o comentário de Girafa não indicar a reutilização direta de um fragmento, diferente da forma que Camelo fez, ela indica uma percepção mais clara de uma característica cultural da empresa. 


\section{8 Conclusão}

Neste trabalho, propôs-se a utilização de estruturas mais flexíveis de explicitação do discurso (depoimentos) como forma de facilitar o processo de externalização do conhecimento de um indivíduo e a etapa de adaptação e reutilização desses conhecimentos externalizados. Com base nos resultados apresentados na seção 7.3, comprovou-se que, de fato, o processo de coleta e reutilização de conhecimentos é facilitado por meio dessa representação.

Observando as questões extraídas do problema central (Como gerir o conhecimento produzido coletivamente), podesse observar que:

a) O teste de completude (seção 7.3.3) e o teste da cauda longa (seção 7.3.4) confirmam a melhora da eficácia da coleta de conhecimento no contexto de uma comunidade a respeito de determinado evento.

b) $\mathrm{O}$ teste de associação entre significante e significado (seção 7.3.1) e o teste de reuso (seção 7.3.2) confirmam que existe uma forma de representação do conhecimento que permite o seu posterior reaproveitamento de uma forma melhor do que a narrativa puramente textual.

$\mathrm{Na}$ abordagem proposta, além dos depoimentos, que, posteriormente, foram analisados em busca de lições aprendidas/questões (seção 7.2.1), obtiveram-se outros insumos de interesse da Gestão do Conhecimento, tal como a rede social da história (seção 7.2.2).

É importante evidenciar aqui que este trabalho é um complemento do trabalho realizado pelo programa Desafios (seção 7.1), o qual buscou trabalhar os aspectos emocional e narrativo do estudo de caso por meio de vídeos e da construção de textos dos estudos de caso. Já o trabalho aqui proposto busca identificar padrões de depoimentos, com o objetivo de transformá-los em lições aprendidas/questões (seção 7.2), focalizando, assim, mais o aspecto da fábula e da história.

Este trabalho pôde complementar o programa Desafios da seguinte forma: 
a) Fornece a rastreabilidade entre os fragmentos dos depoimentos, o que torna mais fácil entender e reutilizar estudos de casos anteriores.

b) Diminui o tempo de produção do conteúdo, uma vez que as pessoas poderiam colocar, diretamente, seus depoimentos no wiki.

c) Facilita a obtenção de uma visão global dos vários estudos de casos já realizados. Por exemplo, na figura 40 podem-se visualizar as diversas linhas do tempo de vários estudos de caso. Isso facilita a identificação de possíveis relacionamentos entre esses estudos de caso.

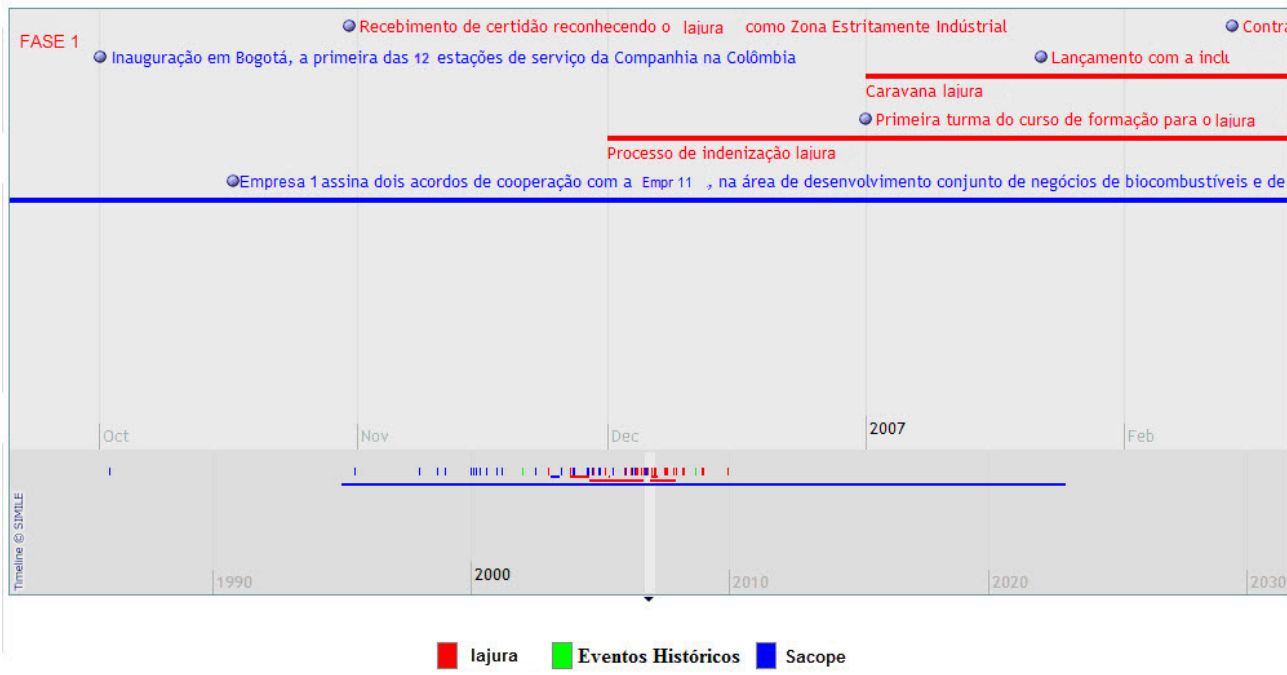

Figura 40 - Visão temporal das linhas do tempo da construção da refinaria, da unidade de produção de petróleo e dos Eventos Históricos.

\subsection{Contribuições deste estudo}

A principal contribuição deste estudo prende-se à definição de uma representação de história por meio de uma semântica formal, que permita que sejam realizadas inferências sobre ela. Essa representação da história é possível de ser reutilizada em vários contextos e, também, é de fácil compreensão e utilização pelas pessoas que lidam com ela (são necessários poucos conceitos para iniciar sua utilização, comparativamente com outras ontologias de mesmo fim). Isso é evidenciado nas seções 5.3 e 6.3.6.

Comparativamente com outras abordagens de representação de histórias, esta propicia melhor compreensão do contexto, uma vez que se consegue ver a 
relação entre pessoas e entidades envolvidas nele. Outro ponto a favor da ontologia proposta é a sua simplicidade (menor número de conceitos) em relação à ontologia de mesmo objetivo (Event-Model-F).

Mais detalhadamente, as principais contribuições deste trabalho são:

- Definição de uma ontologia modular para a representação de histórias e depoimentos em uma linguagem de especificação formal. Isso pode ser observado na seção 6.3.

- O número de conceitos existentes na representação utilizada para descrever a história é pequeno e de fácil entendimento. Isso pode ser constatado nas seções 5.3 e 6.3.6.

- Definição de um processo de trabalho, com atividades e papéis, para a coleta e reutilização dessas histórias. Isso foi o assunto das seções 6.1 e 6.2 .

- A utilização de uma ontologia formal permitiu a geração de outras formas de visualização dos depoimentos, facilitando o processo de análise.

- Definição de uma ontologia específica para o domínio empresarial, com o objetivo de representar entidades, processos e pessoas (chefes, subordinados, trabalhadores).

- A utilização de um wiki semântico, possibilitando a descentralização da coleta de depoimento.

- Proposição de um conjunto de experimentos que permite avaliar o quão determinada solução é eficaz na coleta e reutilização de conteúdo, questão essa central para a Gestão do Conhecimento. Isso pode ser visto na seção 7.3.

- A integração de várias abordagens: storytelling, análise de redes sociais, comunidades e wiki semântico.

\subsection{Limitações do estudo}

Apesar de todo o esforço realizado, este estudo possui algumas limitações, como:

- Os experimentos realizados concentraram-se principalmente na validação da representação proposta. Pouco se falou sobre o 
processo proposto e não houve uma validação efetiva da ferramenta de wiki semântica proposta.

- As limitações da metodologia adotada dizem respeito à amostra de conveniência. Ainda assim, os resultados oferecem bons indícios de que a solução proposta se aplica, ao menos, a algumas classes de problemas. Resumidamente, a metodologia adotada permite obter indícios bem fundamentados sobre a viabilidade da solução proposta. São necessários, no entanto, estudos mais aprofundados para confirmá-los e para comprovar a real eficácia dessa solução.

- Não foi avaliado de forma sistemática o poder expressivo, cobertura e questões de competência da ontologia.

\subsection{Trabalhos futuros}

Ainda existem algumas áreas que podem ser exploradas, sendo assim considerados trabalhos futuros relativos a esta tese:

- Realizar uma análise da usabilidade da ferramenta de wiki semântico, visando propor melhorias em sua interação com o usuário.

- Elaborar um mecanismo semiautomático que facilite o processo de análise das entrevistas pelo Curador. A utilização de tag clouds e de ferramentas de processamento de linguagem natural pode ser útil ao Curador.

- Elaborar uma integração mais ampla entre as ferramentas de análise (Exhibit e NetDraw) e o wiki semântico (HDEWiki), tornando mais fluida a passagem do usuário de uma ferramenta para outra. Atualmente, são necessárias algumas exportações e adaptações para integração do wiki semântico com as ferramentas de análise.

- Estender a solução proposta para trabalhar com outros tipos de conteúdo, tais como áudio e vídeo.

- Identificar melhorias na solução proposta, a partir da utilização desta em um volume maior de histórias, observando as interfaces entre essas histórias. 
- Identificar outras melhorias na solução proposta, a partir da utilização desta em histórias de cunho mais técnico ou operacional. A utilização da ontologia em histórias mais operacionais deve demandar a agregação de novos conceitos na ontologia, tal como o conceito de recurso.

- Integrar outras práticas de GC a esse trabalho. Uma prática que pode se aproveitar deste trabalho é a extração de informações dos depoimentos para enriquecer as páginas pessoais (páginas amarelas) dos envolvidos nas histórias.

Outras propostas identificadas ao longo deste trabalho incluem:

- Aprofundar os mecanismos de validação de práticas de Gestão do Conhecimento presentes na seção 7.3. Não se identificou na literatura nenhum mecanismo que verifique se uma nova prática proposta realmente facilita a dinâmica de troca de conhecimentos.

- Explorar a aplicação desta solução em outros contextos, tais como: levantamento de requisitos de software (Hoffmann \& Herrmann, 2011), mapeamento de processos de negócio (Santoro et al., 2008; Santoro et al., 2010) e avaliação de risco a partir do histórico de registros operacionais em linguagem natural (Vivacqua \& Borges, 2011). 
9

\section{Referências bibliográficas}

ACOSTA, C. E. et al. StoryMapper: a multimedia tool to externalize knowledge. In: INTERNATIONAL CONFERENCE OF THE CHILEAN COMPUTER SCIENCE SOCIETY, 14. 2004, Arica, Chile. p. 133-140. Disponível em: $<$ http://ieeexplore.ieee.org/stamp/stamp.jsp?tp=\&isnumber=\&arnumber=1372113 >. Acesso em: 19 Ago. 2007.

AHMED, D. M. et al. Knowledge-based scenario management - process and support. Journal Decision Support System, v. 49, n. 4, p. 507-520, Nov. 2010.

ALLEN, J. F.; FERGUSON, G. Actions and events in interval temporal logic. Journal of Logic and Computation, v. 4, n. 5, p. 531-579, Oct. 1994.

ANDERSON, C. A cauda longa - Do mercado de massa para o mercado de nicho. 2 ed. Rio de Janeiro: Elsevier, 2006. 240 p.

AMERICAN PRODUCTIVITY \& QUALITY CENTER. Knowledge management: lessons from the leading edge. In: KNOWLEDGE MANAGEMENT SYMPOSIUM, 3. 1998. Proceedings from APQC's Third Knowledge Management Symposium. 1998. 139 p.

BAL, M. Narratology: introduction to the theory of narrative. 2 ed. Toronto, Canadá: University of Toronto, 1997. 256 p.

BARBOSA C. M. A. et al. Using the underlying discourse unveiling method to understand organizations of social volunteers. In: IHC2002 - WORKSHOP DE FATORES HUMANOS EM SISTEMA COMPUTACIONAIS, 5. 2002, Fortaleza. Proceedings of IHC2002 - V Symposium on Human Factors in Computer Systems. Fortaleza: BNB, 2002. p. 15-26.

BÄRENFÄNGER, M. et al. - Using OWL ontologies in discourse parsing. Disponível em: <http://ikw.uni-osnabrueck.de/ ott06/ott06-abstracts/ baerenfaenger_etal_abstract.pdf>. Acesso em: 02 Jul. 2010.

BATRES, R. et al. An upper ontology based on ISO 15926. Computers and Chemical Engineering, v. 31, n. 5-6, p. 519-534, May 2007.

BECKETT, D. RDF/XML syntax specification. W3C Recommendation, 10 feb. 2004. Relatório Técnico. Disponível em: <http://www.w3.org/TR/rdf-syntaxgrammar/>. Acesso em: 13 Abr. 2009.

BERNERS-LEE, T.; HENDLER, J.; LASSILA, O. The semantic web. Scientific American, v. 5, n. 284, p. 34-43, May 2001.

BITTNER, T.; DONNELLY, M.; SMITH, B. Endurants and perdurants in directly depicting ontologies. AI Communications - Spatial and Temporal Reasoning, v. 17, n. 4, p. 247-258, Dec. 2004.

BLECIC, I.; CECCHINI, A.; TRUNFIO, G. A. Towards a cooperative visual authoring environment for storytelling. In: INTERNATIONAL CONFERENCE 
COOPERATIVE DESIGN, VISUALIZATION, AND ENGINEERING, 5. 2008, Calvià, Mallorca, Spain. CDVE Proceedings 2008. Berlin: Springer, 2008. p. 299-306.

BREITMAN, K. et al. Supporting scenario evolution. Requirements Engineering, v. 10, n. 2, p. 112-131, May 2005.

BRICKLEY, D.; GUHA, R. V. RDF vocabulary description language 1.0: RDF schema. W3C Recommendation, 10 Feb. 2004. Relatório Técnico. Disponível em: <http://www.w3.org/TR/rdf-schema/>. Acesso em: 13 Abr. 2009.

BRIGHAM, E. F.; EHRHARDT, M. C. Financial management - theory and practice. Toronto: South-western, 2002. $1051 \mathrm{p}$.

CARTELLI, A. Communities of learners in paleography and ICT. ENCYCLOPEDIA OF COMMUNITIES OF PRACTICE IN INFORMATION AND KNOWLEDGE MANAGEMENT. Hershey: Idea Group Reference, 2006. 642 p. Bibliografia: p. 43 - 48.

CARMINATTI, N. A. Recuperação coletiva do conhecimento aplicada a situações de emergência. Rio de Janeiro, 2006, 120 f. Dissertação (Mestrado) Departamento de Ciência da Computação, UFRJ.

CARVAlHO, A. C. P. L. F. et al. Grandes desafios da pesquisa em computação no Brasil - 2006 a 2016; relatório sobre o seminário. Sociedade Brasileira de Computação, 2006. Disponível em: <http://www.sbc.org.br/index. php?option=com_jdownloads\&Itemid=195\&task=finish\&cid=11\&catid=50>.

Acesso em: 05 Jan. 2009.

CONKLIN, J. Dialogue mapping: building shared understanding of wicked problems. New York: John Wiley, 2005. 266 p.

CRESWELL, J. W. Research design: qualitative, quantitative and mixed method approach. 2 ed., Thousand Oaks, CA: Sage, 2002. 246 p.

CROSS, R.; PARKER, A. The hidden power of social networks understanding how work really gets done in organizations. Boston, Massachusetts: Harvard Business School, 2004. 304 p.

DENNING, S. O poder das narrativas nas organizações. Rio de Janeiro: Elsevier, 2006. 360 p.

FENSEL, D. Ontologies: silver bullet for knowledge management and electronic commerce. Berlin: Springer, 2001. 147 p.

GOMES, J. S. O método de estudo de caso aplicado à gestão de negócios. São Paulo: Atlas, 2006. 104 p.

GUARINO, N.; WELTY, C., An overview of OntoClean, In: STAAB, S.; STUDER, R. (eds.), Handbook on Ontologies. 2 ed. Berlin: Springer, 2009. 830 p. Bibliografia: p. 151-159.

GUIMARÃES, F. J. Z. Utilização de ontologias no domínio B2C. Rio de Janeiro, 2002, 195 f. Dissertação (Mestrado) - Departamento de Informática, PUC-RIO.

GUIMARÃES, F. J. Z.; MELO, E. S. Diagnóstico utilizando análise de redes sociais. 2005. 51p. COPPE/UFRJ (Especialização) - Engenharia de Produção, Rio de Janeiro, 2005. 
GUIMARÃES, F. J. Z.; SOUZA, C. S. Análise de um ambiente de apoio a comunidades de prática utilizando o método de inspeção semiótica. Rio de Janeiro, 2008, 22 f. Monografias em ciência da computação - Departamento de Informática - PUC-RIO. Disponível em: <http://www.dbd.puc-rio.br/depto informatica/08 06 guimaraes.pdf >. Acesso em: 05 Jan. 2009.

GUIZZARDI, G. Ontological foundations for structural conceptual models. CTIT PhD Thesis Series. Netherlands, 2005

GUIZZARDI, G.; WAGNER, G. Some applications of a unified foundational ontology in business modeling. Hershey: Idea Group, 2005. 379 p. Bibliografia: p. $345-368$.

GUIZZARDI, G.; FALBO R.; GUIZZARDI, R. S. S. Grounding software domain ontologies in the unified foundational ontology (UFO): the case of the ODE software process ontology. In: CONFERENCIA IBEROAMERICANA DE SOFTWARE ENGINEERING, 9. 2008, Pernambuco, Brasil. Proceedings of CIbSE 2008. Pernambuco: 2008, p. 127-140.

HERRE, H. et al. General formal ontology (GFO): a foundational ontology integrating objects and processes. OntoMed, 2007. Disponível em: $<$ http://www.onto-med.de/Archiv/ontomed2002/en/theories/gfo/part1-drafts/gfopart1-v1-0-1.pdf>. Acesso em: 05 Jan. 2009.

HOFFMANN, A.; HERRMANN, A. Using storytelling to record requirements: elements for an effectice requirements elicitation approach. In: MULTIMEDIA AND ENJOYABLE REQUIREMENTS ENGINEERING - BEYOND MERE DESCRIPTIONS AND WITH MORE FUN AND GAMES (MERE), 4. p. 916. Aug. 2011.

IBM. IBM watson: ushering in a new era of computing. Disponível em: <http://www-03.ibm.com/innovation/us/watson>. Acesso em: 05 Ago. 2012.

JARKE, M. et al. Scenario management: an interdisciplinary approach. Requirements Engineering, v. 3, n. 3-4, p. 155-173, 1998.

JARKE, M. Experience-based knowledge management: a cooperative information systems perspective. Journal Control Engineering Practice, v. 10, n. 5, p. 561569, May 2002.

$\mathrm{KAO}$, E. C.; et al. Using ontology to establish social context and support social reasoning. In: INTERNATIONAL WORKING CONFERENCE INTELLIGENT VIRTUAL AGENTS, 5. 2005, Kos, Greece. IVA Proceedings 2005. Berlin: Springer, 2005. p. $344-357$.

KLEIN, M. Achieving collective intelligence via large-scale on-line argumentation. In: INTERNATIONAL CONFERENCE ON INTERNET AND WEB APPLICATIONS AND SERVICES, 2., 2007, Cambridge, MA. ICIW Proceedings 2007. Los Alamitos: IEEE, 2007. 58 p.

KOROWAJCZUK, A.; ALMEIDA, A. C. F. Desafios Petrobras- histórias para preservar competências estratégicas. In: CONGRESSO IBEROAMERICANO DE CALIDAD EN LA INDUSTRIA DEL PETROLEO Y DEL GAS, 1. 2007, Mendoza, Argentina. Anais do 1 Congresso IberoAmericano de Calidad en la Industria del Petroleo y del Gas. Mendoza, Instituto Argentino del Petróleo y del gas, 2007. 
LAPORTI, V. A. et al. Collaborative approach to requirements elicitation. In: INTERNATIONAL CONFERENCE ON COMPUTER SUPPORTED COOPERATIVE WORK IN DESIGN, 11. 2007, Melbourne, Australia. Proceedings of CSCWD 2007. Los Alamitos: IEEE, 2007. p. 734-739.

LAWRENCE, K. F.; SCHRAEFEL, M. OntoMedia - creating an ontology for marking up the contents of fiction and other media. In: AKT DOCTORAL SYMPOSIUM, 1. 2005. Milton Keynes. Proceedings AKT Doctoral Symposium 2005. The Open Univeristy, p. 122-129. Disponível em: $<$ http://www.aktors.org/akt/events/docsympjune2005/proceedings/proceedingsfull.pdf>. Acesso em: 07 Mar. 2009.

LÉVY, P. From social computing to reflexive collective intelligence: the IEML research program. Information Sciences, v. 180, n. 1, p.71-94, Jan. 2010.

LÉVY, P. A Cidade como Rede e a Sustentabilidade das Cidades. In: CONFERÊNCIA INTERNACIONAL DE CIDADES INOVADORA, 2010. Disponível em: <http://www.cici2010.org.br/>. Acesso em: 10 Jan. 2011.

LINDE, C. Narrative and social tacit knowledge. Journal of Knowledge Management, v. 5, n. 2, p. 160 - 171, 2001.

LIMA, F. Modelagem semântica de aplicações na WWW. Rio de Janeiro, 2003. 128 f. Tese (Doutorado) - Departamento de Informática, PUC-RIO.

MAEDCHE, A. Ontology learning for the semantic web. Norwell, Massachusetts: Kluwer Academic, 2002. 272 p.

MASOLO, C. et al. The WonderWeb library of foundational ontologies preliminary report. ISTC-CNR - 2003. Technical Report. Disponível em: <http://www.loa-cnr.it/Papers/DOLCE2.1-FOL.pdf>. Acesso em: 09 Mai. 2008.

MASCARDI, Y.; CORDİ, V.; ROSSO P. A comparison of upper ontologies. In: AI*IA/TABOO JOINT WORKSHOP "FROM OBJECTS TO AGENTS": AGENTS AND INDUSTRY: TECHNOLOGICAL APPLICATIONS OF SOFTWARE AGENTS, 8. 2007, Genova, Italy. Proceedings of WOA 2007, Italy: Seneca, 2007. p. 55-64.

McGUINNESS, D. L.; HARMELEN, F. V. OWL web ontology language overview. W3C Recommendation, 10 feb. 2004. Relatório Técnico. Disponível em: <http://www.w3.org/TR/owl-features/>. Acesso em: 13 Abr. 2008.

MEDEIROS, A. P. Kuaba: uma abordagem para representação de design rationale para o reuso de designs baseados em modelo. Rio de Janeiro, 2006, 149 f. Tese (Doutorado) - Departamento de Informática, PUC-RIO.

NAKASONE, A. Arturo Nakasome's information research and technology ISRST project. Disponível em: <http://www.ninfort.com/isrst/isrst.html>. Acesso em: 25 Fev. 2009.

NAKASONE, A.; ISHIZUKA, M. Storytelling ontology model using RST. In: INTERNATIONAL CONFERENCE ON INTELLIGENT AGENT TECHNOLOGY. 2006, Hong Kong, China. Proceeding of the IEEE/WIC/ACM International Conference on Intelligent Agent Technology. Los Alamitos: IEEE, 2006. p. 163-169.

NAKASONE, A.; ISHIZUKA, M. ISRST: an interest based storytelling model using rhetorical relations. In: INTERNATIONAL CONFERENCE 
EDUTAInMENT, 2. 2007, Hong Kong, China. Edutainment Proceedings 2007. Berlin: Springer, 2007. p. 324-335.

NEVES, J. L. Pesquisa qualitativa - características, usos e possibilidades. Caderno de Pesquisas em Administração, v. 1, n. 3, 2º sem. 1996.

NILES, I.; PEASE, A. Towards a standard upper ontology. In: INTERNATIONAL CONFERENCE ON FORMAL ONTOLOGY IN INFORMATION SYSTEMS, 2. 2001, Ogunquit, Maine, USA. FOIS Proceedings 2001. New York: ACM, 2001. p. 2-9.

NONAKA, I.; TAKEUCHI, H. Criação de conhecimento na empresa - como as empresas japonesas geram a dinâmica da inovação. Rio de Janeiro: Elsevier, 1997. 364 p.

NOVAK, J. D.; CAÑAS, A. J. The theory underlying concept maps and how to construct and use them. Pensacola: Florida Institute for Human and Machine Cognition, 2008. Relatório Técnico. Disponível em: $<$ http://cmap.ihmc.us/Publications/ResearchPapers/TheoryCmaps/TheoryUnderlyi ngConceptMaps.htm>. Acesso em: 15 Abr. 2009.

NWANA, H. S. Software agents: an overview. The Knowledge Engineering Review, v. 11, n. 3, p. 205-244, Sep. 1996.

NUNES, D. A. HyperDE : um framework e ambiente de desenvolvimento dirigido por ontologias para aplicações hipermídia. Rio de Janeiro, 2005, 199 f. Dissertação (Mestrado) - Departamento de Informática, PUC-RIO.

ODEN, P.; O'DELL, C.; WIIG, K. Knowledge management. Houston: APQC International Bechmarking Clearinghouse, 1995.

OINONEN, K.; et al. Designing a story database for use in automatic story generation. In: INTERNATIONAL CONFERENCE ON ENTERTAINMENT COMPUTING, 5. 2006, Cambridge, UK. ICEC Proceedings 2006. Berlin: Springer, 2006. p. 298-301.

OREN, E. SemperWiki: a semantic personal wiki. In: SEMANTIC DESKTOP WORKSHOP (ISWC), 2005. Aachen, CEUR-WS, 2005. Disponível em: $<$ http://www.eyaloren.org/pubs/semdesk2005.pdf $>$. Acesso em: 15 Jan. 2009.

PEIRCE, C. S. Semiótica - Estudos. São Paulo: Perspectiva, 2005.

PEREIRA, H. J. et al. Gestão do conhecimento e prevenção a acidentes ambientais: estudo sobre as práticas de aprendizagem organizacional em empresa do setor de petróleo. Produto \& Produção, v. 9, n. 1, p. 14-40, Fev. 2008.

PRATES, E. Semiótica: uma suave introdução. TEIA - Revista da Associação Brasiliense de Comunicação \& Semiótica, 1999. Disponível em: <http://www.absbsemiotica.cjb.net/teia.htm>. Acesso em: 15 Dez. 2006.

PROBST, G.; RAUB, S.; ROMHARDT, K. Gestão do conhecimento - os elementos construtivos do sucesso. São Paulo: Bookman, 2002. 286 p.

RAIMOND, Y.; ABDALLAH, S. The ontology event. 25 Oct. 2007. Disponível em: <http://motools.sourceforge.net/event/event.html>. Acesso em: 30 Jul. 2009.

REED, C.; WELLS, S. Dialog argument as an interface to complex debates. IEEE Intelligent Systems, v. 22, n. 6, p. 60-65, Nov./Dec. 2007. 
REITHINGER, N.; PECOURT, E.; NIKOLOVA. M. Metadata for interactive storytelling. In: INTERNATIONAL CONFERENCE ON VIRTUAL STORYTELLING, 5. 2005, Strasbourg, France. ICVS Proceedings 2005. Berlin: Springer, 2005. p. 172-175.

SAMPAIO, J. C. et al. A scenario construction process. Requirements Engineering, v. 5, n.1, p. 38-61, Jul. 2000.

SANFILIPPO, A. et al. Building a human information discourse interface to uncover scenario content. In: INTERNATIONAL CONFERENCE ON INTELLIGENCE ANALYSIS. 2005, McLean, VA, USA. ICIA Proceedings 2005. Disponível em: <https://www.purdue.edu/discoverypark/vaccine/assets /pdfs/publications/pdf/Building a Human.pdf>. Acesso em: 20 Abr. 2008.

SANTORO, F. M.; BORGES, M. R. S.; PINO, J. A. Tell us your process: a group storytelling approach to cooperative process modeling. In: INTERNATIONAL CONFERENCE ON COMPUTER SUPPORTED COOPERATIVE WORK IN DESIGN, 12. 2008, Xi'na, China. CSCWD Proceedings 2008. Los Alamitos: IEEE, 2008. p. 29-34.

SANTORO, F. M.; BORGES, M. R. S.; PINO, J. A. Acquiring knowledge on business processes from stakeholders' stories. Advanced Engineering Informatics, v. 24, n. 2, p. 138-148, Apr. 2010.

SANTORO, F. M.; BRÉZILLON, P. Developing shared context within group stories. In: INTERNATIONAL WORKSHOP ON GROUPWARE: DESIGN, IMPLEMENTATION, AND USE, 11. 2005, Porto de Galinhas, Brazil. CRIWG Proceedings 2005. Berlin: Springer, 2005. p. 232-247.

SANTORO, F. M.; BRÉZILLON, P. Group storytelling approach to collect contextualized shared knowledge. In: INTERNATIONAL WORKSHOP ON DATABASE AND EXPERT SYSTEMS APPLICATIONS, 16. 2005, Copenhagen, Denmark. DEXA Proceedings 2005. Los Alamitos: IEEE, 2005. p. $388-392$.

SCHAFFERT, S. IkeWiki: A semantic wiki for collaborative knowledge management. In: INTERNATIONAL WORKSHOPS ON ENABLING TECHNOLOGIES: INFRASTRUCTURE FOR COLLABORATIVE ENTERPRISES, 15. 2006, Manchester. WETICE Proceedings 2006. Los Alamitos: IEEE, 2006. p. 388-396.

SCHAFFERT, S. et al. Learning with semantic wikis. In: WORKSHOP "SemWiki2006 - FROM WIKI TO SEMANTICS" co-located with ANNUAL EUROPEAN SEMANTIC WEB CONFERENCE, 3. 2006, Budva, Montenegro. Proceedings. Aachen, CEUR-WS, 2006.

SCHANK, R. C. Tell me a story: narrative and intelligence. Northwestern University, 2000. $253 \mathrm{p}$.

SCHERP, A. et al. F - A model of events bases on the foundational ontology Dolce+Dns Ultralite. In: INTERNATIONAL CONFERENCE ON KNOWLEDGE CAPTURE, 5. 2009, Redondo Beach, California, USA. Proceedings of International Conference on Knowledge capture. New York: ACM, 2009. p. 137-144. 
SCHWABE, D.; ROSSI, G. An object-oriented approach to web-based application design. Theory and Practice of Object Systems, v. 4, n. 4, p. 207225, Oct. 1998.

SHAW, R. LODE: an ontology for linking open descriptions of events. 2009. Disponível em: <http://linkedevents.org/ontology/>. Acesso em: 10 Abr. 2009.

SHAW, R. et al. LODE: linking open descriptions of events. Berkeley, UC Berkeley, School of Information, 2009. Report. Aug. Disponível em: $<$ http://repositories.cdlib.org/cgi/viewcontent.cgi?article=1035\&context=ischool $>$ . Acesso em: 25 Aug. 2009.

SILVA, N.; HENDERSON, P. Narrative support for technical documents: formalising rhetorical structure theory. In: INTERNATIONAL CONFERENCE ON ENTERPRISE INFORMATION SYSTEMS. 2005, Miami, FL, USA. Disponível em: <http://eprints.ecs.soton.ac.uk/10642/1/Camera-ready_paper_527 .pdf>

SINGH, P.; BARRY, B.; LIU, H. Teaching machines about everyday life. BT Technology Journal, v. 22, n. 4, p. 227-240, Oct. 2004.

SOUZA, C. S. et al. Compulsory institutionalization: investigating the paradox of computer-supported informal social processes. Interacting with Computers, v. 16, n. 4, p. 635-656, Aug. 2004.

SOUZA, C. S. The semiotic engineering of humam-computer interaction. Cambridge, Massachusetts: MIT, 2005. 283 p.

SOUZA-SILVA, J. C. Aprendizagem organizacional: condições e desafios para o desenvolvimento de comunidades de prática em organizações de ensino superior. Salvador, 2005, 281 f. Tese (Doutorado) - Faculdade de Educação, UFBA.

SOWA, J. F. Guided tour of ontology. Disponível em: <http://www.jfsowa.com/ontology/guided.htm>. Acesso em: 18 Aug. 2008.

STYHRE, A. Knowledge management beyond codification: knowing as practice/concept. Journal of Knowledge Management, v. 7, n. 5, p. 32-40, 2003.

SUTCLIFFE, A. Scenario-based requirements engineering. In: INTERNATIONAL CONFERENCE ON REQUIREMENTS ENGINEERING, 11. 2003, Monterey Bay, CA, USA. IEEE Computer Society Proceedings. Los Alamitos: IEEE Computer Society, 2003. p. 320-329.

SUN, B. et al. Scenario-based knowledge representation in case-based reasoning systems. Journal of Expert Systems, v. 20, n. 2, p. 92-99, May 2003.

SWARTJES, I.; THEUNE, M. A fabula model for emergent narrative. In: INTERNATIONAL CONFERENCE OF TECHNOLOGIES FOR INTERACTIVE DIGITAL STORYTELLING AND ENTERTAINMENT, 3. 2006, Darmstadt, Germany. TIDSE Proceedings 2006. Berlin: Springer, 2006. p. 49-60.

SWARTJES, I.M.T.; THEUNE, M. The virtual storyteller: story generation by simulation. In: BELGIAN-NETHERLANDS CONFERENCE ON ARTIFICIAL INTELLIGENCE, 20. 2008. Enschede, University of Twente, Netherland. BNAIC Proceedings 2008. p. 257-264. Disponível em: 
$<$ http://eprints.eemcs.utwente.nl/13835/01/BNAIC08_swartjes.pdf $>$. Acesso em: 20 Aug. 2010.

TAZZOLI, R. et al. Toward a semantic wiki wiki web. In: INTERNATIONAL SEMANTIC WEB CONFERENCE, 3. 2004, Hiroshima, Japan. ISWC Proceedings 2004. Berlin: Springer, 2004. Disponível em: $<$ http://iswc2004.semanticweb.org/posters/PID-LPSVVIIZ-1090243438.pdf>

Acesso em: 25 Jan. 2009.

TEMPICH, C. et al. Argumentation-based ontology engineering. IEEE Intelligent Systems, v. 22, n. 6, p. 52-59, Nov./Dec. 2007.

TUFFIELD, M. M.; MILLARD, D. E.; SHADBOLT, N. R. Ontological approaches to modelling narrative. In: SYMPOSIUM AKT DTA, 2. 2006, AKT, Aberdeen University. Disponível em <http://eprints.soton.ac.uk/261962/1/ tuffieldetal.pdf>. Acesso em: 25 Jan. 2009.

UMBEL ontology documentation. Technical documentation for UMBEL Ontology version 0.71, released 3 Sep. 2008. Disponível em: <http://www.umbel .org/doc/UMBELOntology vA1.pdf>. Acesso em: 20 Out. 2008.

VALLE C., RAYBOURN E., PRINZ W., BORGES, M. Group storytelling to support tacit knowledge externalization. In: INTERNATIONAL CONFERENCE ON HUMAN-COMPUTER INTERACTION, 10. 2003, Mahwah, NJ, USA. Proceedings of HCI International 2003. p. 1218-1222.

VIVACQUA, A. S.; BORGES, M. R. S. Using group storytelling to recall information in emergency response. In: International Conference on Collaborative Computing: Networking, Applications and Worksharing, 7. 2011, Orlando, Florida, USA. Proceedings of CollaborateCom. Los Alamitos: IEEE, 2011. p. 512-515.

WAGNER, E. J. et al. Rich interfaces for reading news on the web In: INTERNATIONAL CONFERENCE ON INTELLIGENT USER INTERFACES ARCHIVE, 13. 2009, Sanibel Island, Florida, USA. Proceedings of the 13th international conference on Intelligent user interfaces. New York: ACM, 2009. p. 27-36.

WASKO, M. M.; TEIDLAND, R. Distinguishing work groups, virtual teams, and electronic networrks of practice. In: ENCYCLOPEDIA OF COMMUNITIES OF PRACTICE IN INFORMATION AND KNOWLEDGE MANAGEMENT. Hershey: Idea Group Reference, 2006. 642 p. Bibliografia: p. $138-140$.

WENGER, E.; McDERMONTT, R.; SNYDER, W. M. Cultivating communities of practice. Boston, Massachusetts: Harvard Business School, 2002. 352 p.

WHYTE G., CLASSEN S. Using storytelling to elicit tacit knowledge from SMEs. Journal of Knowledge Management, v. 16, n.6, p.950-962, 2012.

WILLIAMS, R. Narratives of knowledge and intelligence... beyond the tacit and explicit. Journal of Knowledge Management, v. 10, n. 4, p. 81-99, 2006. 


\section{Apêndice I - Diagrama de Casos de Uso}

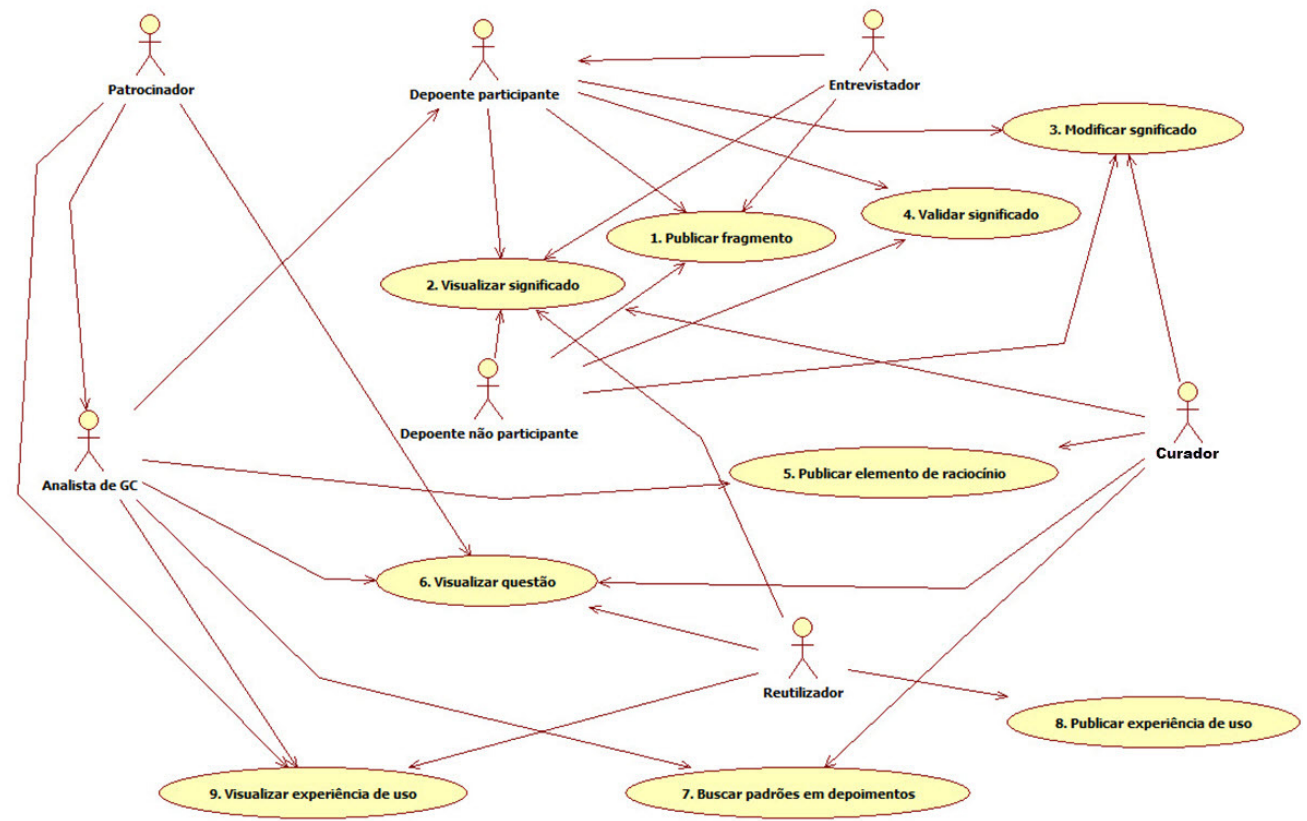

Figura 41 - Diagrama de Casos de Uso. 


\section{Apêndice II - Casos de Uso}

\begin{tabular}{|c|c|}
\hline Caso de uso & Caso 1. Publicar fragmento \\
\hline Papeis & Depoente participante, Depoente não participante, Entrevistador. \\
\hline Descrição & $\begin{array}{l}\text { 1 O usuário escolhe a opção "Novo fragmento". } \\
2 \text { O sistema retorna uma caixa de texto para a descrição do título do } \\
\text { fragmento, e também a lista de tipos de fragmentos disponíveis. } \\
3 \text { O usuário entra com o título do fragmento que deseja publicar. } \\
4 \text { O usuário escolhe o tipo de fragmento que você deseja publicar } \\
\text { (evento ou significado). } \\
5 \text { O sistema retorna uma caixa de texto para descrição do fragmento. } \\
6 \text { O usuário redige o texto que descreve o fragmento. } \\
\text { 6.1 O usuário insere o texto que descreve o fragmento com as } \\
\text { marcações semânticas possíveis: } \\
\text { 6.1.1Depoimento que esse fragmento está associado. } \\
\text { 6.1.2Processo na qual o fragmento se relaciona. } \\
\text { 6.1.3Pessoas que participaram no fragmento descrito. } \\
\text { 6.1.4Entidades que participaram no fragmento } \\
\text { descrito. } \\
\text { 6.1.5Eixo temático associado ao fragmento descrito. } \\
\text { 6.1.6Local aonde ocorreu o fragmento descrito. } \\
\text { 6.1.7Conforme o tipo de fragmento insere outras } \\
\text { marcações semânticas para relacionamento entre } \\
\text { fragmentos. } \\
\text { O usuário seleciona a opcão "Publicar". }\end{array}$ \\
\hline
\end{tabular}




\begin{tabular}{|c|c|}
\hline Caso de uso & Caso 2. Visualizar significado \\
\hline Papeis & $\begin{array}{l}\text { Depoente participante, Depoente não participante, Entrevistador, } \\
\text { Curador, Reutilizador. }\end{array}$ \\
\hline Descrição & 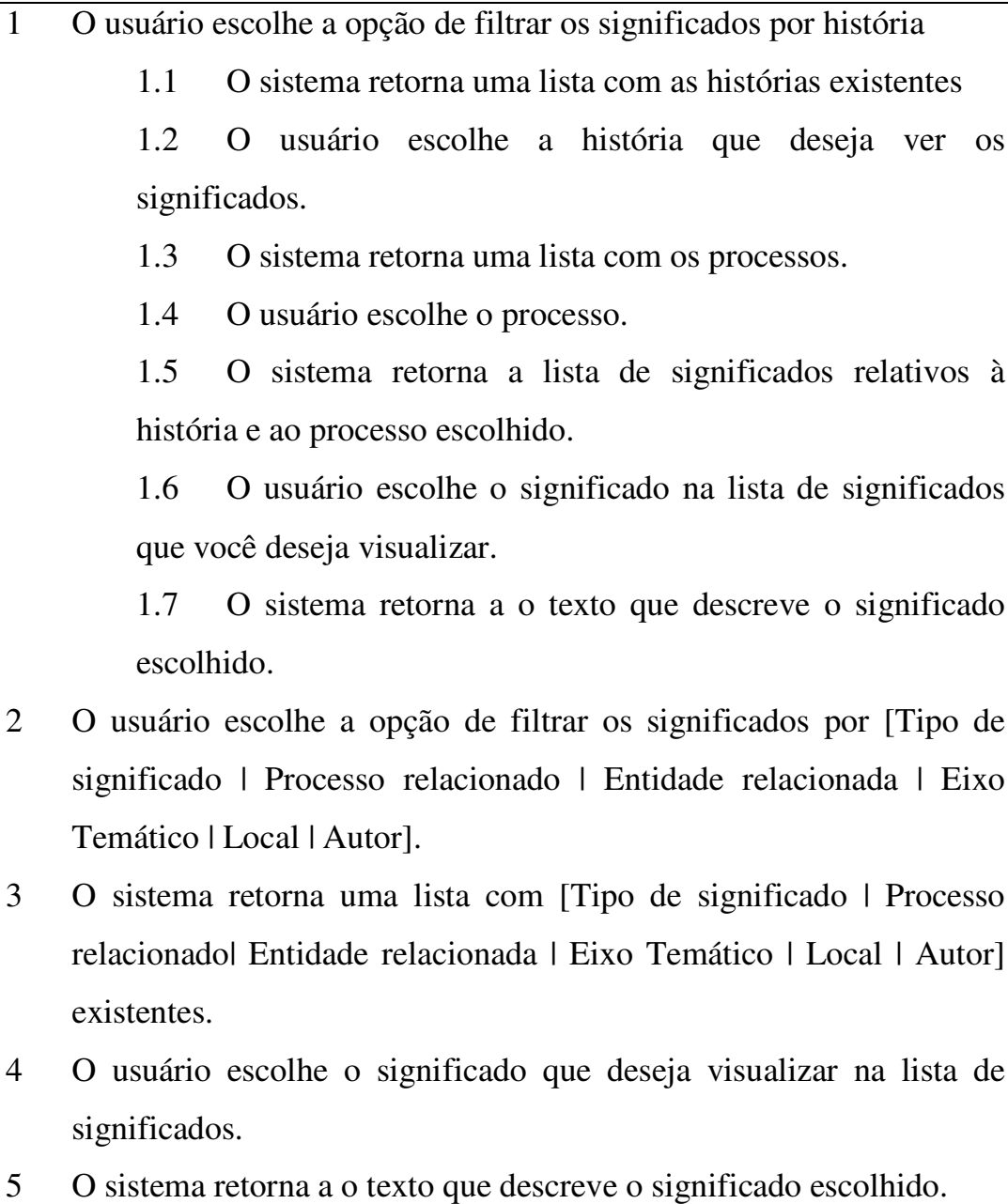 \\
\hline
\end{tabular}

\begin{tabular}{|l|ll|}
\hline Caso de uso & Caso 3. Modificar significado \\
\hline Papeis & Depoente participante, Depoente não participante, Curador. \\
\hline Descrição & $\begin{array}{l}\text { Uma vez posicionado no significado que ele deseja modificar o } \\
\end{array}$ & $\begin{array}{l}\text { usuário escolhe a opção de "Editar". } \\
\end{array}$ \\
& $\begin{array}{l}\text { O sistema retorna uma caixa de texto com a descrição do significado } \\
\text { escolhido. }\end{array}$ \\
& 3 Segue o Caso $1-6.1$ \\
\hline
\end{tabular}




\begin{tabular}{|c|c|}
\hline Caso de uso & Caso 4. Validar significado \\
\hline Papeis & Depoente participante, Depoente não participante. \\
\hline Descrição & $\begin{array}{l}\text { 1 O usuário escolhe a opção de filtrar os significados por Autor. Nesse } \\
\text { caso, o autor é ele mesmo. } \\
2 \text { O sistema retorna uma lista com significados existentes. } \\
3 \text { O usuário escolhe o significado que deseja visualizar na lista de } \\
\text { significados. } \\
4 \text { O sistema retorna a o texto que descreve o significado escolhido. } \\
5 \text { Caso seja necessário o usuário inicia o caso } 3 \text {. (Modificar } \\
\text { significado). }\end{array}$ \\
\hline
\end{tabular}

\begin{tabular}{|c|c|}
\hline Caso de uso & Caso 5. Publicar elemento de raciocínio \\
\hline Papeis & Curador, Analista de GC \\
\hline Descrição & $\begin{array}{l}\text { 1 O usuário escolhe a opção "Novo elemento de raciocínio". } \\
2 \text { O sistema retorna uma caixa de texto para a descrição do título do } \\
\text { elemento de raciocínio, e também a lista de tipos disponíveis } \\
\text { (questão, idéia ou argumento). } \\
3 \text { O usuário entra com o título do elemento de raciocínio que deseja } \\
\text { publicar. } \\
4 \text { O usuário escolhe o tipo elemento de raciocínio. } \\
5 \text { O sistema retorna uma caixa de texto para descrição do elemento de } \\
\text { raciocínio. } \\
6 \text { O usuário redige o texto que descreve o elemento de raciocínio. } \\
6.1 \quad \text { O usuário insere o texto que descreve a elemento de } \\
\text { raciocínio com as marcações semânticas possíveis: } \\
\text { 6.1.1 Por exemplo, idéias que respondem a questão. } \\
\text { O usuário seleciona a opção "Publicar". }\end{array}$ \\
\hline
\end{tabular}

\begin{tabular}{|c|c|}
\hline Caso de uso & Caso 6. Visualizar questão \\
\hline Papeis & Patrocinador, Analista de GC, Curador, Reutilizador. \\
\hline Descrição & $\begin{array}{ll}1 & \text { O usuário selecione a opção para ver a "lista de questões". } \\
2 & \text { O sistema retorna uma lista de questões. } \\
3 & \text { O usuário escolhe a questão que deseja visualizar na lista de } \\
\text { questões. } \\
4 \text { O sistema retorna o texto que descreve a questão escolhida. }\end{array}$ \\
\hline
\end{tabular}




\begin{tabular}{|l|l|}
\hline Caso de uso & Caso 7. Buscar padrões em depoimentos \\
\hline Papeis & Curador, Analista de GC. \\
\hline Descrição & $\begin{array}{ll}\text { O usuário seleciona a visualização multifacetada, temporal, espacial } \\
\text { ou grafo. }\end{array}$ \\
\hline
\end{tabular}

\begin{tabular}{|c|c|}
\hline Caso de uso & Caso 8. Publicar experiência de uso \\
\hline Papeis & Reutilizador. \\
\hline Descrição & $\begin{array}{l}\text { 1 O usuário escolhe a opção "Nova experiência de uso". } \\
2 \text { O sistema retorna uma caixa de texto para a descrição do título da } \\
\text { experiência de uso. } \\
3 \text { O usuário entra com o titulo da experiência de uso que deseja } \\
\text { publicar. } \\
4 \text { O sistema retorna uma caixa de texto para descrição da experiência } \\
\text { de uso. } \\
5 \text { O usuário redige o texto que descreve a experiência de uso. } \\
5.1 \text { O usuário insere o texto que descreve a sua experiência de } \\
\text { uso com as marcações semânticas possíveis: } \\
\text { 5.1.1 Significados que foram utilizadas. } \\
6 \text { O usuário seleciona a opção "Publicar". }\end{array}$ \\
\hline
\end{tabular}

\begin{tabular}{|c|c|}
\hline Caso de uso & Caso 9. Visualizar experiências de uso \\
\hline Papeis & Patrocinador, Analista de GC, Reutilizador. \\
\hline Descrição & $\begin{array}{l}1 \text { O usuário seleciona a opção para ver a "lista de experiências de } \\
\text { uso". } \\
2 \text { O sistema retorna uma lista de experiências de uso. } \\
3 \text { O usuário escolhe a experiências de uso que deseja visualizar na } \\
\text { lista de experiências de uso. } \\
4 \text { O sistema retorna a o texto que descreve a experiência de uso } \\
\text { escolhida. }\end{array}$ \\
\hline
\end{tabular}




\section{Apêndice III - Enunciado dos experimentos realizados}

Enunciado teste de associação entre significante e significado

$\underline{\text { Instruções }}$

1 - Marque a hora que você inicia e a hora que você termina a execução dessa atividade.

Hora de inicio da atividade $\_$:__
Hora de termino da atividade $\_-$

2 - Leia o arquivo <entrevista - associacao entre significante e

significado.doc > e faça a relação entre a Lista de títulos de fragmento em relação à Lista de fragmentos. Salve esse arquivo com suas respostas e coloque seu nome como parte do nome do arquivo (por exemplo: Francisco entrevista associacao entre significante e significado.doc).

3 - Retorne o arquivo com as respostas. 


\section{Enunciado teste de reuso}

$\underline{\text { Instruções }}$

1 - Leia o material presente em <02_teste de reuso/2011-07-05a_exp

2/Inicio.html > registrando a hora que você inicia a leitura e a hora que você terminou a leitura do texto.

\section{Hora de início da leitura ___ ___ \\ Hora de termino da leitura :}

2 - Responda as seguintes perguntas: (Marque a hora que você começou e terminou de responder cada pergunta desse questionário)

1 - Quais os assunto em comum desses fragmentos?

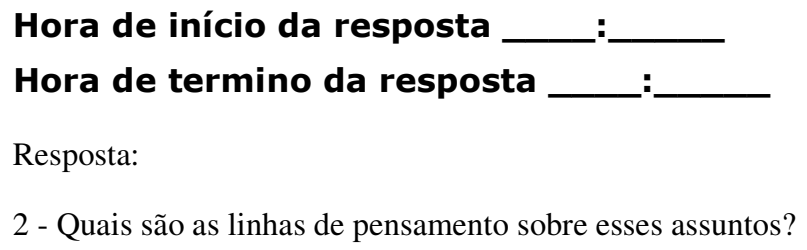

Resposta:

4 - Qual foi a sua estratégia de leitura?

\section{Hora de início da resposta \\ Hora de termino da resposta :}

Resposta:

5 - Comentários?

3 - Salve esse arquivo com suas respostas e coloque seu nome como parte do nome do arquivo (por exemplo: Francisco enunciado - reuso.doc).

4 - Retorne o arquivo com as respostas 


\section{Enunciado teste de completude}

Instruções

1 - Leia a entrevista de <Depoente 15.doc ou Depoente 17.doc> e busque identificar novos fragmentos além dos que já foram identificados no material presente em <03_teste de completude/2011-07-19a_exp3/Inicio.html>.

2 - Caso seja identificado um novo fragmento, verifique se o assunto desse novo fragmento já existe no material presente em <03_teste de completude/201107-19a_exp3/Inicio.html> publicado por outra pessoa.

3 - Preencha a tabela abaixo com o novo fragmento identificado.

\begin{tabular}{|c|c|c|c|}
\hline $\begin{array}{c}\text { Entrevista Depoente } \\
\text { 15 ou Depoente 17 }\end{array}$ & $\begin{array}{c}\text { Título do novo } \\
\text { fragmento }\end{array}$ & $\begin{array}{c}\text { Texto do novo } \\
\text { fragmento }\end{array}$ & $\begin{array}{c}\text { Título do fragmento } \\
\text { relacionado }\end{array}$ \\
\hline & & & \\
\hline & & & \\
\hline & & & \\
\hline
\end{tabular}




\section{Enunciado teste de cauda longa}

\section{$\underline{\text { Instruções }}$}

1 - Leia os fragmentos referentes aos 5 depoimentos já existentes no material presente em <04_teste da cauda longa/2011-0719a_exp4/Inicio.html> e coloque outros fragmentos relacionados aos fragmentos já existentes. Esse fragmento devem estar associados a outra história, porém deve tratar de assunto relacionado.

2 - Você pode focar na geração de novos fragmentos segundo um eixo temático de seu maior interesse.

\begin{tabular}{|l|r|r|r|}
\hline $\begin{array}{r}\text { Título do } \\
\text { novo fragmento }\end{array}$ & $\begin{array}{r}\text { Texto do } \\
\text { novo fragmento }\end{array}$ & $\begin{array}{r}\text { História } \\
\text { onde esse novo } \\
\text { fragmento } \\
\text { ocorreu? }\end{array}$ & $\begin{array}{c}\text { Título do } \\
\text { fragmento } \\
\text { relacionado }\end{array}$ \\
\hline & & & \\
\hline & & & \\
\hline & & & \\
\hline
\end{tabular}




\section{Apêndice IV - Ontologia Proposta}

Seguem abaixo as ontologias propostas neste trabalho. Elas foram implementadas na ferramenta Protégé ${ }^{37}$.

\section{wiki.owl}

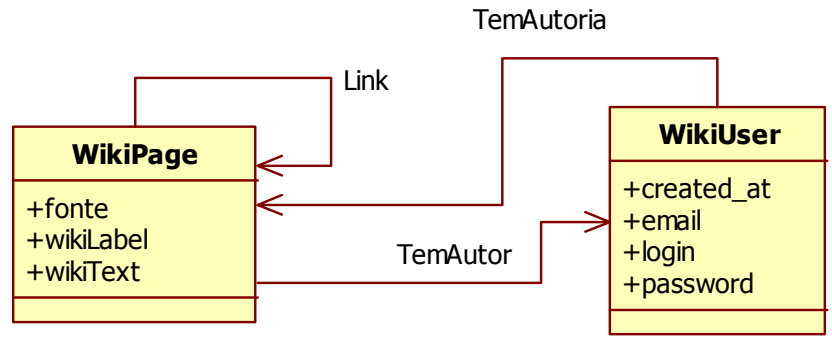

Figura 42 - Módulo Wiki.

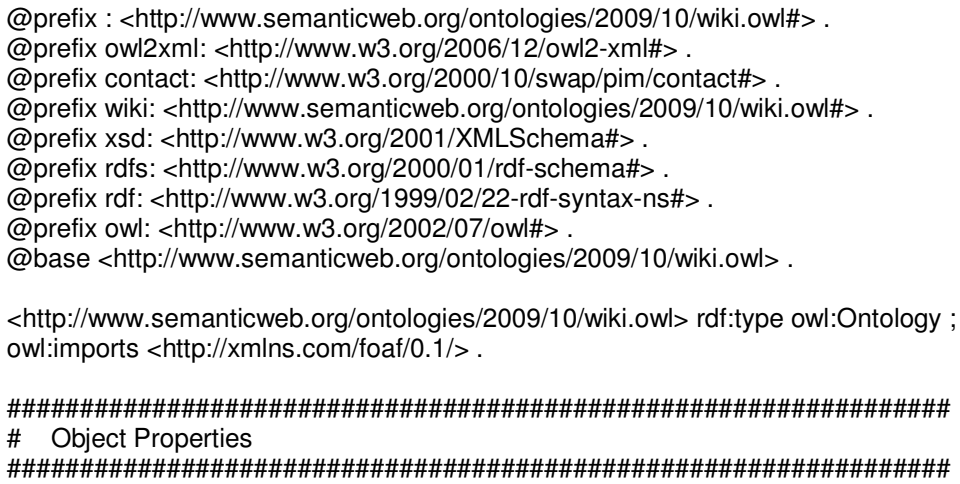

\#\#\# http://www.semanticweb.org/ontologies/2009/10/wiki.owl\#TemAutor :TemAutor rdf:type owl:ObjectProperty ;

rdfs:comment "São os autores de uma página Wiki."

owl:inverseOf :TemAutoria ;

rdfs:domain :WikiPage ;

rdfs:range contact:Person .

\#\#\# http://www.semanticweb.org/ontologies/2009/10/wiki.owl\#Link

:Link rdf:type owl:ObjectProperty ;

rdfs:comment "Ligação entre WikiPages." ;

rdfs:domain :WikiPage ;

rdfs:range :WikiPage .

\#\#\# http://www.semanticweb.org/ontologies/2009/10/wiki.owl\#TemAutoria

${ }^{37}$ http://protege.stanford.edu/ 
:TemAutoria rdf:type owl:ObjectProperty ; rdfs:comment "São as página Wiki de um autor." ; rdfs:range :WikiPage ;

rdfs:domain contact:Person .

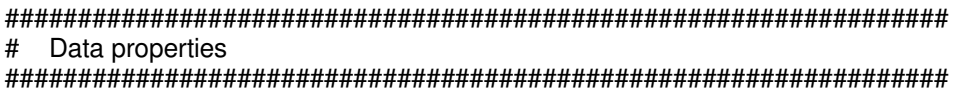

\#\#\# http://www.semanticweb.org/ontologies/2009/10/wiki.owl\#created_at :created_at rdf:type owl:DatatypeProperty ;

rdfs:comment "É a data de criação do usuário do Wiki no sistema." ; rdfs:domain :WikiUser ; rdfs:range xsd:dateTime .

\#\#\# http://www.semanticweb.org/ontologies/2009/10/wiki.owl\#email :email rdf:type owl:DatatypeProperty ;

rdfs:comment "É o email do usuário do Wiki." ;

rdfs:domain :WikiUser ;

rdfs:range xsd:string

\#\#\# http://www.semanticweb.org/ontologies/2009/10/wiki.owl\#fonte

:fonte rdf:type owl:DatatypeProperty ;

rdfs:comment "É a fonte da informação que está descrita na página Wiki." ; rdfs:domain :WikiPage ; rdfs:range xsd:string

\#\#\# http://www.semanticweb.org/ontologies/2009/10/wiki.owl\#login :login rdf:type owl:DatatypeProperty : rdfs:comment "É o login do usuário do Wiki." ; rdfs:domain :WikiUser ; rdfs:range xsd:string

\#\#\# http://www.semanticweb.org/ontologies/2009/10/wiki.owl\#password :password rdf:type owl:DatatypeProperty ;

rdfs:comment "E a password do usuário do Wiki." rdfs:domain :WikiUser ; rdfs:range xsd:string

\#\#\# http://www.semanticweb.org/ontologies/2009/10/wiki.owl\#wikiLabel :wikiLabel rdf:type owl:DatatypeProperty;

rdfs:comment "E o título da página wiki." . rdfs:domain :WikiPage ; rdfs:range xsd:string

\#\#\# http://www.semanticweb.org/ontologies/2009/10/wiki.owl\#wikiText :wikiText rdf:type owl:DatatypeProperty ;

rdfs:comment "E o texto da página Wiki." ; rdfs:domain :WikiPage ; rdfs:range xsd:string

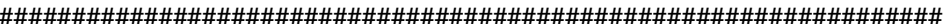

\# Classes

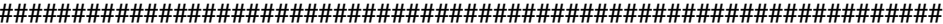

\#\#\# http://www.semanticweb.org/ontologies/2009/10/wiki.owl\#WikiPage

:WikiPage rdf:type owl:Class ; rdfs:comment "É uma página Wiki."

\#\#\# http://www.semanticweb.org/ontologies/2009/10/wiki.owl\#WikiUser

:WikiUser rdf:type owl:Class ;

rdfs:subClassOf contact:Person

wiki." .

rdfs:comment "É um usuário da ferramenta wiki. Ele pode criar e modficar uma página

\#\#\# http://www.w3.org/2000/10/swap/pim/contact\#Person contact:Person rdf:type owl:Class .

\#\#\# Generated by the OWL API (version 2.2.1.1138) http://owlapi.sourceforge.net 


\section{Depoimento.owl}

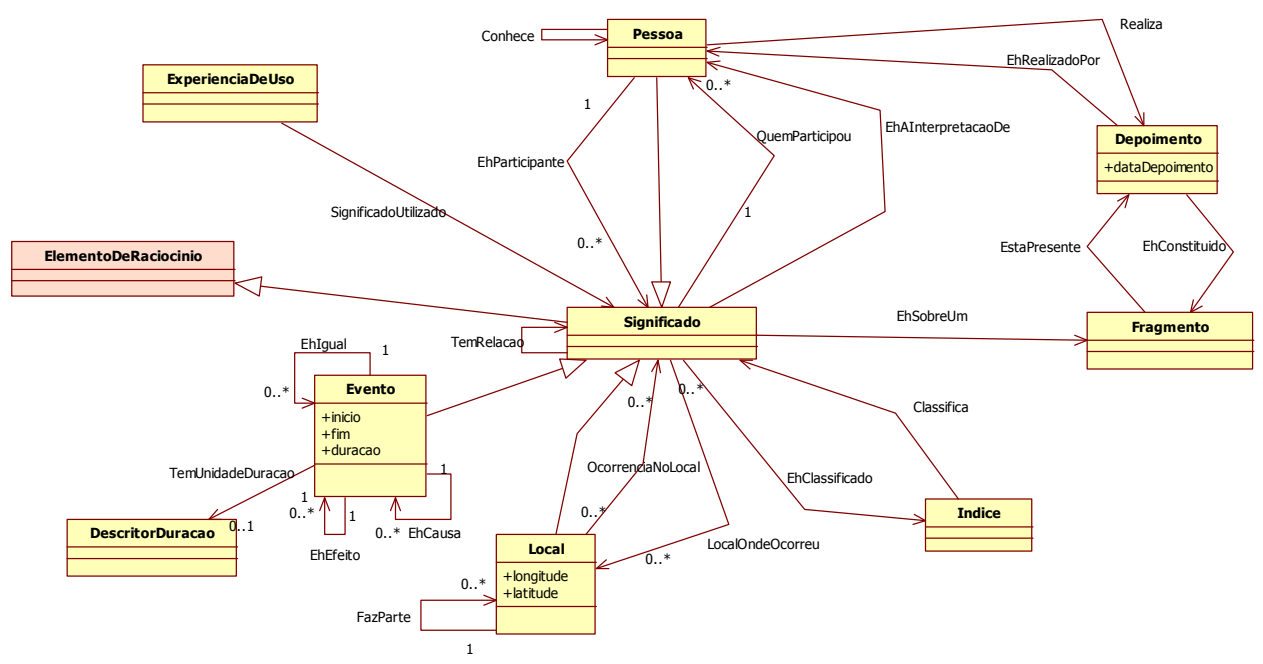

Figura 43 - Módulo Depoimento.

@prefix : <http://www.semanticweb.org/ontologies/2009/10/depoimento.owl\#> . @prefix owl2xml: <http://www.w3.org/2006/12/owl2-xml\#> .

@prefix time: <http://www.w3.org/2006/time\#> .

@prefix xsd: <http://www.w3.org/2001/XMLSchema\#> .

@prefix wiki: <http://www.semanticweb.org/ontologies/2009/10/wiki.owl\#>

@prefix rdfs: <http://www.w3.org/2000/01/rdf-schema\#> .

@prefix foaf: <http://xmlns.com/foaf/0.1/>.

@prefix owl: <http://www.w3.org/2002/07/owl\#> .

@prefix depoimento: <http://www.semanticweb.org/ontologies/2009/10/depoimento.owl\#> .

@prefix contact: <http://www.w3.org/2000/10/swap/pim/contact\#> .

@prefix kuaba: <http://www.semanticweb.org/ontologies/2009/10/kuaba.owl\#> .

@prefix wgs84_pos: <http://www.w3.org/2003/01/geo/wgs84_pos\#>

@prefix event: $<$ http://purl.org/NET/c4dm/event.owl\#> .

@prefix rdf: <http://www.w3.org/1999/02/22-rdf-syntax-ns\#> .

@base <http://www.semanticweb.org/ontologies/2009/10/depoimento.owl>

<http://www.semanticweb.org/ontologies/2009/10/depoimento.owl> rdf:type owl:Ontology ; owl:imports

<file:/C:/00_pendrive\%20doutorado/02_Tese/05_Modelo\%200wl/ontologia/wgs84_pos\%20funcionando.owl> , $<$ http://purl.org/NET/c4dm/event.owl>

<http://www.semanticweb.org/ontologies/2009/10/kuaba.owl> , $<$ http://www.semanticweb.org/ontologies/2009/10/wiki.owl> , $<$ http://www.w3.org/2006/time>

$<$ http://xmlns.com/foaf/0.1/>

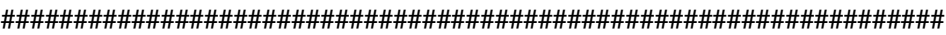

\# Object Properties

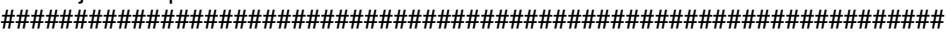

\#\#\# http://purl.org/NET/c4dm/event.owl\#agent

event:agent rdf:type owl:ObjectProperty ;

rdfs:range :Pessoa ;

owl:equivalentProperty :QuemParticipou ;

rdfs:domain :Significado

\#\#\# http://purl.org/NET/c4dm/event.owl\#place

event:place rdf:type owl:ObjectProperty ;

rdfs:range :Local

owl:equivalentProperty :LocalOndeOcorreu ;

rdfs:domain :Significado

\#\#\# http://www.semanticweb.org/ontologies/2009/10/depoimento.owl\#EhCausa

:EhCausa rdf:type owl:ObjectProperty ; rdfs:comment "'"'Indica que um Evento é a causa de outro Evento."'"' ; 
rdfs:domain :Evento ;

rdfs:range :Evento .

\#\#\# http://www.semanticweb.org/ontologies/2009/10/depoimento.owl\#Classifica

:Classifica rdf:type owl:ObjectProperty ;

owl:inverseOf :EhClassificador :

rdfs:range :Indice ;

rdfs:domain :Significado

\#\#\# http://www.semanticweb.org/ontologies/2009/10/depoimento.owl\#Conhece

:Conhece rdf:type owl:ObjectProperty

owl:SymmetricProperty ;

rdfs:comment "Indica que uma Pessoa conhece outra Pessoa e vice-versa." ;

rdfs:range :Pessoa ;

rdfs:domain :Pessoa ;

owl:equivalentProperty foaf:knows .

\#\#\# http://www.semanticweb.org/ontologies/2009/10/depoimento.owl\#EhEfeito

:EhEfeito rdf:type owl:ObjectProperty ;

rdfs:comment "Indica que um Evento é o efeito de outro Evento." ; owl:inverseOf :EhCausa ;

rdfs:range :Evento

rdfs:domain :Evento

\#\#\# http://www.semanticweb.org/ontologies/2009/10/depoimento.owl\#EhAInterpretacaDe

:EhAlnterpretacaDe rdf:type owl:ObjectProperty ;

rdfs:range :Pessoa ;

rdfs:domain :Significado .

\#\#\# http://www.semanticweb.org/ontologies/2009/10/depoimento.owl\#EhClassificador

:EhClassificador rdf:type owl:ObjectProperty ;

rdfs:domain :Indice ;

rdfs:range :Significado

\#\#\# http://www.semanticweb.org/ontologies/2009/10/depoimento.owl\#EhConstituido

:EhConstituido rdf:type owl:ObjectProperty ;

rdfs:comment "Indica os fragmentos que compõem o depoimento." ;

rdfs:domain :Depoimento :

rdfs:range :Fragmento

\#\#\# http://www.semanticweb.org/ontologies/2009/10/depoimento.owl\#EhParticipante

:EhParticipante rdf:type owl:ObjectProperty ;

rdfs:domain :Pessoa ;

rdfs:range :Significado

\#\#\# http://www.semanticweb.org/ontologies/2009/10/depoimento.owl\#EhRealizadoPor

:EhRealizadoPor rdf:type owl:ObjectProperty ;

rdfs:domain :Depoimento

rdfs:range :Pessoa .

\#\#\# http://www.semanticweb.org/ontologies/2009/10/depoimento.owl\#EhSobreUm

:EhSobreUm rdf:type owl:ObjectProperty ;

rdfs:range :Fragmento ;

rdfs:domain :Significado

\#\#\# http://www.semanticweb.org/ontologies/2009/10/depoimento.owl\#EstaPresente

:EstaPresente rdf:type owl:ObjectProperty ;

rdfs:range :Depoimento

owl:inverseOf :EhConstituido :

rdfs:domain :Fragmento

\#\#\# http://www.semanticweb.org/ontologies/2009/10/depoimento.owl\#FazParte

:FazParte rdf:type owl:ObjectProperty ;

owl:TransitiveProperty:

rdfs:comment "Indica que um Local está dentro de outro Local." ;

rdfs:domain :Local ;

rdfs:range :Local

\#\#\# http://www.semanticweb.org/ontologies/2009/10/depoimento.owl\#Ehlgual

:Ehlgual rdf:type owl:ObjectProperty ,

owl:SymmetricProperty ;

rdfs:comment "Indica que um Evento é igual a outro." ;

rdfs:range :Evento ;

rdfs:domain :Evento

\#\#\# http://www.semanticweb.org/ontologies/2009/10/depoimento.owl\#OcorrenciaNoLocal 


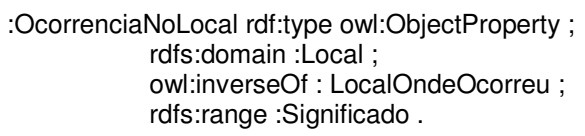

\#\#\# http://www.semanticweb.org/ontologies/2009/10/depoimento.owl\#LocalOndeOcorreu

:LocalOndeOcorreu rdf:type owl:ObjectProperty ; rdfs:isDefinedBy "Indica o Local descrito no significado." ; rdfs:range :Local ; rdfs:domain :Significado .

\#\#\# http://www.semanticweb.org/ontologies/2009/10/depoimento.owl\#QuemParticipou :QuemParticipou rdf:type owl:ObjectProperty ; rdfs:comment "Indica a pessoa que participou (fez parte) do significado." ; owl:inverseOf :EhParticipante ; rdfs:range :Pessoa ; rdfs:domain :Significado .

\#\#\# http://www.semanticweb.org/ontologies/2009/10/depoimento.owl\#Realiza

:Realiza rdf:type owl:ObjectProperty ;

rdfs:range :Depoimento

owl:inverseOf :EhRealizadoPor : rdfs:domain contact:Person .

\#\#\# http://www.semanticweb.org/ontologies/2009/10/depoimento.owl\#SignificadoUtilizado

:SignificadoUtilizado rdf:type owl:ObjectProperty ;

rdfs:domain :EsperienciaDeUso ;

rdfs:range :Significado .

\#\#\# http://www.semanticweb.org/ontologies/2009/10/depoimento.owl\#TemUnidadeDuracao

:TemUnidadeDuracao rdf:type owl:ObjectProperty ;

rdfs:comment "E a unidade da duração de um Evento. Pode ser: Anos, Meses, Semanas, widgets/wiki/Timeline_EventSources." ; rdfs:range :DescritorDuracao ; rdfs:domain :Evento .

\#\#\# http://xmlns.com/foaf/0.1/knows

foaf:knows rdf:type owl:ObjectProperty ; rdfs:domain contact:Person rdfs:range contact:Person .

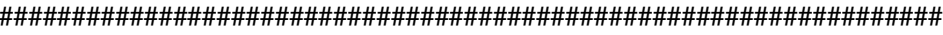 \\ \# Data properties}

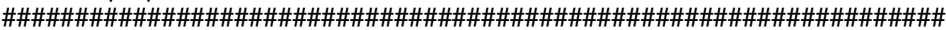

\#\#\# http://www.semanticweb.org/ontologies/2009/10/depoimento.owl\#dataDepoimento :dataDepoimento rdf:type owl:DatatypeProperty ; rdfs:domain :Depoimento rdfs:range xsd:date .

\#\#\# http://www.semanticweb.org/ontologies/2009/10/depoimento.owl\#duracao :duracao rdf:type owl:DatatypeProperty ; rdfs:comment "É a duração do Evento. Aderente a: http://code.google.com/p/simile-

widgets/wiki/Timeline EventSources" ; rdfs:domain :Evento rdfs:range xsd:decimal .

\#\#\# http://www.semanticweb.org/ontologies/2009/10/depoimento.owl\#fim :fim rdf:type owl:DatatypeProperty rdfs:comment "Indica http://code.google.com/p/simile-widgets/wiki/Timeline_EventSources." ; rdfs:domain :Evento rdfs:range xsd:date.

\#\#\# http://www.semanticweb.org/ontologies/2009/10/depoimento.owl\#inicio :inicio rdf:type owl:DatatypeProperty ;

rdfs:comment "Indica quando iniciou o Evento. Aderente a: http://code.google.com/p/similewidgets/wiki/Timeline_EventSources." ; rdfs:domain :Evento rdfs:range xsd:date.

\#\#\# http://www.semanticweb.org/ontologies/2009/10/depoimento.owl\#latitude :latitude rdf:type owl:DatatypeProperty ; rdfs:comment "É a latitude de um Local." , 
rdfs:domain :Local ; rdfs:range xsd:string .

\#\#\# http://www.semanticweb.org/ontologies/2009/10/depoimento.owl\#longitude :longitude rdf:type owl:DatatypeProperty;

rdfs:comment "E a longitude de um Local."

rdfs:domain :Local

rdfs:range xsd:string

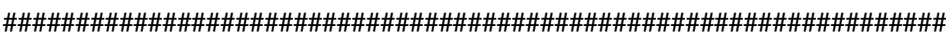 \# Classes}

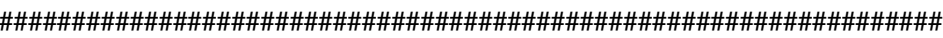

\#\#\# http://purl.org/NET/c4dm/event.owl\#Event

event:Event rdf:type owl:Class;

owl:equivalentClass :Evento .

\#\#\# http://www.semanticweb.org/ontologies/2009/10/depoimento.owl\#Depoimento

:Depoimento rdf:type owl:Class ; rdfs:subClassOf wiki:WikiPage ;

pessoa." rdfs:comment "Compõe o conjunto de fragmentos de um depoimento de uma determinada

\#\#\# http://www.semanticweb.org/ontologies/2009/10/depoimento.owl\#DescritorDuracao

:DescritorDuracao rdf:type owl:Class ; owl:equivalentClass time:DurationDescription ; rdfs:subClassOf wiki:WikiPage .

\#\#\# http://www.semanticweb.org/ontologies/2009/10/depoimento.owl\#EsperienciaDeUso :EsperienciaDeUso rdf:type owl:Class ; rdfs:subClassOf wiki:WikiPage .

\#\#\# http://www.semanticweb.org/ontologies/2009/10/depoimento.owl\#Evento

:Evento rdf:type owl:Class : rdfs:subClassOf :Significado ;

rdfs:comment "Descrição textual sobre determinado evento que ocorreu ao longo da história/projeto. Deve fazer menção a uma determinada data, que pode ser a data de início ou a data de início e fim do evento." .

\#\#\# http://www.semanticweb.org/ontologies/2009/10/depoimento.owl\#Fragmento

:Fragmento rdf:type owl:Class ;

rdfs:subClassOf wiki:WikiPage

rdfs:comment "Trecho textual do depoimento que se deseja atribuir uma interpretação." .

\#\#\# http://www.semanticweb.org/ontologies/2009/10/depoimento.owl\#Indice

:Indice rdf:type owl:Class ;

rdfs:subClassOf wiki:WikiPage ;

rdfs:comment "É um indice genérico para organização dos depoimentos." .

\#\#\# http://www.semanticweb.org/ontologies/2009/10/depoimento.owl\#Local

:Local rdf:type owl:Class ;

owl:equivalentClass wgs84 pos:SpatialThing ;

rdfs:subClassOf :Significado ;

rdfs:comment "É um local geográfico."

\#\#\# http://www.semanticweb.org/ontologies/2009/10/depoimento.owl\#Pessoa

:Pessoa rdf:type owl:Class ;

owl:equivalentClass contact:Person ;

rdfs:subClassOf :Significado ;

rdfs:comment "E uma pessoa."

\#\#\# http://www.semanticweb.org/ontologies/2009/10/depoimento.owl\#Significado

:Significado rdf:type owl:Class ;

rdfs:subClassOf kuaba:Argumento ,

wiki:WikiPage

rdfs:comment "Descrição textual da interpretação de determinado fragmento." .

\#\#\# http://www.semanticweb.org/ontologies/2009/10/kuaba.owl\#Argumento kuaba:Argumento rdf:type owl:Class .

\#\#\# http://www.semanticweb.org/ontologies/2009/10/wiki.owl\#WikiPage

wiki:WikiPage rdf:type owl:Class

\#\#\# http://www.w3.org/2000/10/swap/pim/contact\#Person

contact:Person rdf:type owl:Class . 
\#\#\# http://www.w3.org/2003/01/geo/wgs84_pos\#SpatialThing

wgs84_pos:SpatialThing rdf:type owl:Class .

\#\#\# http://www.w3.org/2006/time\#DurationDescription

time:DurationDescription rdf:type owl:Class .

\#\#\# Generated by the OWL API (version 2.2.1.1138) http://owlapi.sourceforge.net

\section{Historia.owl}

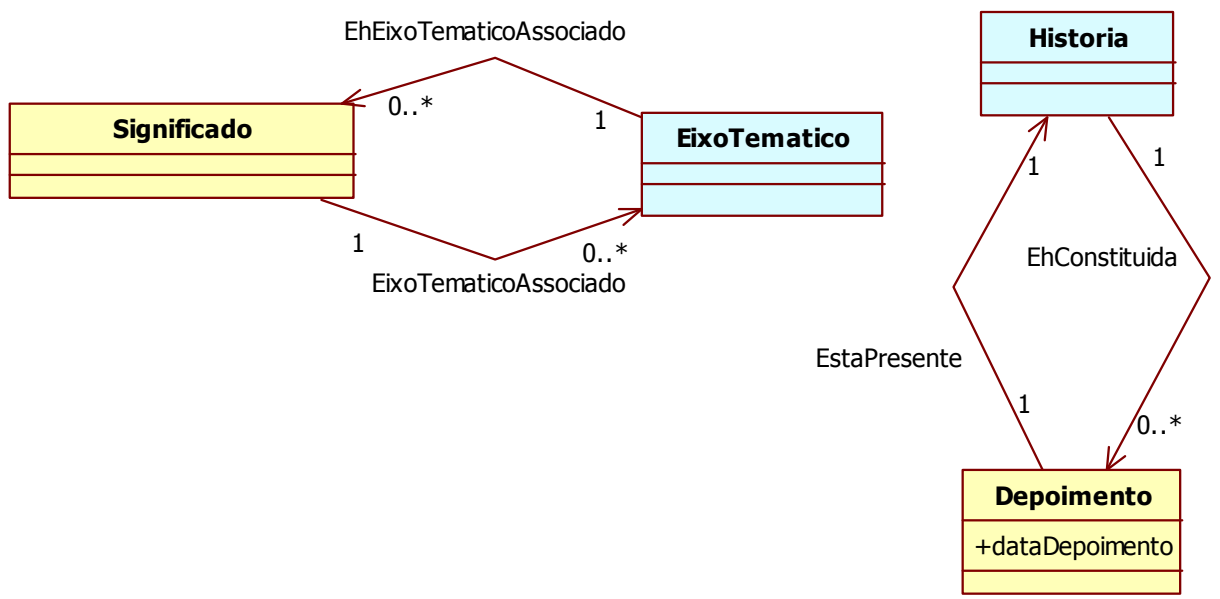

Figura 44 - Módulo Historia.

@prefix : <http://www.semanticweb.org/ontologies/2009/10/historia.owl\#> .

@prefix owl2xml: <http://www.w3.org/2006/12/owl2-xml\#> .

@prefix wiki: <http://www.semanticweb.org/ontologies/2009/10/wiki.owl\#> .

@prefix historia: <http://www.semanticweb.org/ontologies/2009/10/historia.owl\#> .

@prefix xsd: <http://www.w3.org/2001/XMLSchema\#> .

@prefix rdfs: <http://www.w3.org/2000/01/rdf-schema\#> .

@prefix rdf: <http://www.w3.org/1999/02/22-rdf-syntax-ns\#> .

@prefix depoimento: <http://www.semanticweb.org/ontologies/2009/10/depoimento.owl\#> .

@prefix owl: <http://www.w3.org/2002/07/owl\#> .

@base <http://www.semanticweb.org/ontologies/2009/10/historia.owl> .

<http://www.semanticweb.org/ontologies/2009/10/historia.owl> rdf:type owl:Ontology ;

owl:imports <http://www.semanticweb.org/ontologies/2009/10/depoimento.owl> ,

<http://www.semanticweb.org/ontologies/2009/10/wiki.owl>

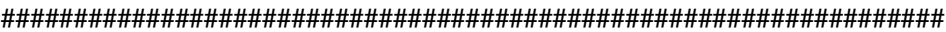

\# Object Properties

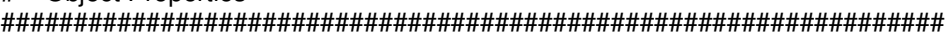

\#\#\# http://www.semanticweb.org/ontologies/2009/10/depoimento.owl\#Classifica depoimento:Classifica rdf:type owl:ObjectProperty .

\#\#\# http://www.semanticweb.org/ontologies/2009/10/depoimento.owl\#EhClassificador depoimento:EhClassificador rdf:type owl:ObjectProperty .

\#\#\# http://www.semanticweb.org/ontologies/2009/10/historia.owl\#EhConstituida

:EhConstituida rdf:type owl:ObjectProperty ;

rdfs:range depoimento:Depoimento ;

owl:inverseOf :EstaPresente ;

rdfs:domain :Historia .

\#\#\# http://www.semanticweb.org/ontologies/2009/10/historia.owl\#EhEixoTematicoAssociado

:EhEixoTematicoAssociado rdf:type owl:ObjectProperty ;

rdfs:subPropertyOf depoimento:EhClassificador ;

rdfs:range depoimento:Significado ; 
rdfs:domain :EixoTematico ;

owl:inverseOf :EixoTematicoAssociado .

\#\#\# http://www.semanticweb.org/ontologies/2009/10/historia.owl\#EixoTematicoAssociado :EixoTematicoAssociado rdf:type owl:ObjectProperty ;

rdfs:comment "É o Eixo Temático associado ao significado." ;

rdfs:subPropertyOf depoimento:Classifica;

rdfs:domain depoimento:Significado ;

rdfs:range :EixoTematico

\#\#\# http://www.semanticweb.org/ontologies/2009/10/historia.owl\#EstaPresente :EstaPresente rdf:type owl:ObjectProperty ;

rdfs:comment "Indica a que historia o depoimento está associado." rdfs:domain depoimento:Depoimento ; rdfs:range :Historia .

\#\#\#\#\#\#\#\#\#\#\#\#\#\#\#\#\#\#\#\#\#\#\#\#\#\#\#\#\#\#\#\#\#\#\#\#\#\#\#\#\#\#\#\#\#\#\#\#\#\#\#\#\#\#\#\#

\# Classes

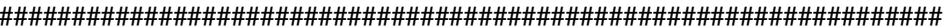

\#\#\# http://www.semanticweb.org/ontologies/2009/10/depoimento.owl\#Depoimento depoimento:Depoimento rdf:type owl:Class .

\#\#\# http://www.semanticweb.org/ontologies/2009/10/depoimento.owl\#Indice depoimento:Indice rdf:type owl:Class

\#\#\# http://www.semanticweb.org/ontologies/2009/10/depoimento.owl\#Significado depoimento:Significado rdf:type owl:Class .

\#\#\# http://www.semanticweb.org/ontologies/2009/10/historia.owl\#EixoTematico :EixoTematico rdf:type owl:Class

rdfs:subClassOf depoimento:Indice

rdfs:comment "É um indice que organiza os significados por Eixo Temático."

\#\#\# http://www.semanticweb.org/ontologies/2009/10/historia.owl\#Historia

:Historia rdf:type owl:Class

rdfs:subClassOf wiki:WikiPage :

rdfs:comment "É uma História."

\#\#\# http://www.semanticweb.org/ontologies/2009/10/wiki.owl\#WikiPage wiki:WikiPage rdf:type owl:Class .

\#\#\# Generated by the OWL API (version 2.2.1.1138) http://owlapi.sourceforge.ne

\section{Kuaba.owl}

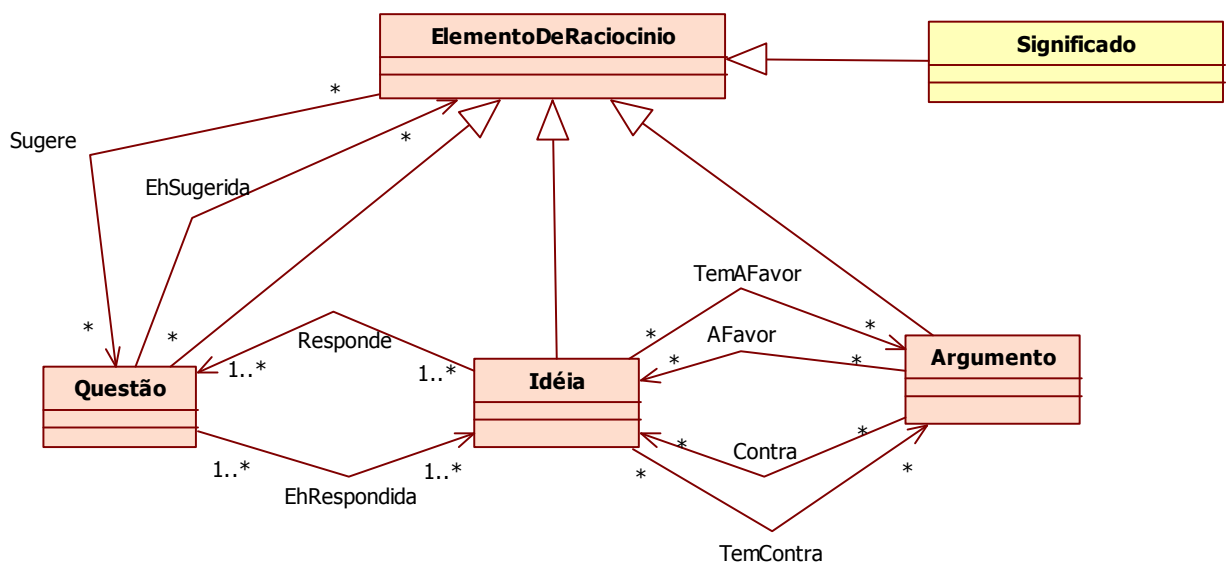

Figura 45 - Módulo Kuaba. Fonte: Medeiros (2006). 
@prefix : <http://www.semanticweb.org/ontologies/2009/10/kuaba.owl\#> . @prefix owl2xml: <http://www.w3.org/2006/12/owl2-xml\#> .

@prefix kuaba: <http://www.semanticweb.org/ontologies/2009/10/kuaba.owl\#> . @prefix wiki: <http://www.semanticweb.org/ontologies/2009/10/wiki.owl\#> @prefix xsd: <http://www.w3.org/2001/XMLSchema\#> . @prefix rdfs: <http://www.w3.org/2000/01/rdf-schema\#> .

@prefix rdf: <http://www.w3.org/1999/02/22-rdf-syntax-ns\#> . @prefix owl: <http://www.w3.org/2002/07/owl\#>.

@base <http://www.semanticweb.org/ontologies/2009/10/kuaba.owl> .

<http://www.semanticweb.org/ontologies/2009/10/kuaba.owl> rdf:type owl:Ontology ; owl:imports <http://www.semanticweb.org/ontologies/2009/10/wiki.owl> .

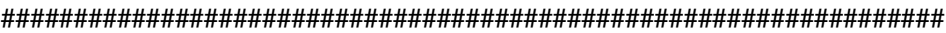 \\ \# Object Properties \\ \#\#\#\#\#\#\#\#\#\#\#\#\#\#\#\#\#\#\#\#\#\#\#\#\#\#\#\#\#\#\#\#\#\#\#\#\#\#\#\#\#\#\#\#\#\#\#\#\#\#\#\#}

\#\#\# http://www.semanticweb.org/ontologies/2009/10/kuaba.owl\#AFavor

:AFavor rdf:type owl:ObjectProperty ;

rdfs:comment "Indica um Argumento a favor da Idéia." ;

rdfs:domain :Argumento ;

rdfs:range :Ideia

owl:inverseOf :TemAFavor .

\#\#\# http://www.semanticweb.org/ontologies/2009/10/kuaba.owl\#Contra

:Contra rdf:type owl:ObjectProperty ;

rdfs:comment "Indica um Argumento contra a Idéia."

rdfs:domain :Argumento

rdfs:range :Ideia .

\#\#\# http://www.semanticweb.org/ontologies/2009/10/kuaba.owl\#EhRespondida

:EhRespondida rdf:type owl:ObjectProperty ;

rdfs:range :Ideia :

rdfs:domain :Questão ;

owl:inverseOf :Responde

\#\#\# http://www.semanticweb.org/ontologies/2009/10/kuaba.owl\#EhSugerida

:EhSugerida rdf:type owl:ObjectProperty ;

rdfs:range :ElementoDeRaciocinio ;

rdfs:domain :Questão :

owl:inverseOf :Sugere .

\#\#\# http://www.semanticweb.org/ontologies/2009/10/kuaba.owl\#Responde

:Responde rdf:type owl:ObjectProperty ;

rdfs:comment "Indica uma Idéia que responde a Questão." ;

rdfs:domain :Ideia :

rdfs:range :Questão

\#\#\# http://www.semanticweb.org/ontologies/2009/10/kuaba.owl\#Sugere

:Sugere rdf:type owl:ObjectProperty ;

rdfs:comment "Indica novas Questões a partir de um Elemento de Raciocinio." ; rdfs:domain :ElementoDeRaciocinio ;

rdfs:range :Questão.

\#\#\# http://www.semanticweb.org/ontologies/2009/10/kuaba.owl\#TemAFavor

:TemAFavor rdf:type owl:ObjectProperty ;

rdfs:range :Argumento ;

rdfs:domain :Ideia

\#\#\# http://www.semanticweb.org/ontologies/2009/10/kuaba.owl\#TemContra

:TemContra rdf:type owl:ObjectProperty ;

rdfs:range :Argumento ;

owl:inverseOf :Contra ;

rdfs:domain :Ideia

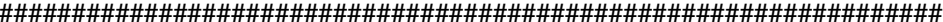 \\ \# Classes

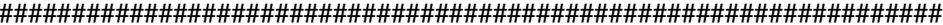

\#\#\# http://www.semanticweb.org/ontologies/2009/10/kuaba.owl\#Argumento

:Argumento rdf:type owl:Class ;

rdfs:subClassOf :ElementoDeRaciocinio ;

rdfs:comment "Argumento representa uma razão contra ou a favor da adoção de uma idéia

como uma solução para a questão que está sendo tratada." . 
\#\#\# http://www.semanticweb.org/ontologies/2009/10/kuaba.owl\#ElementoDeRaciocinio

:ElementoDeRaciocinio rdf:type owl:Class ;

rdfs:subClassOf wiki:WikiPage .

\#\#\# http://www.semanticweb.org/ontologies/2009/10/kuaba.owl\#ldeia

:Ideia rdf:type owl:Class ;

rdfs:subClassOf :ElementoDeRaciocinio :

rdfs:comment "Idéia representa uma possível solução, ou parte de uma solução de design,

para o problema apresentado no elemento Questão." .

\#\#\# http://www.semanticweb.org/ontologies/2009/10/kuaba.owl\#Questão

:Questão rdf:type owl:Class ;

rdfs:subClassOf :ElementoDeRaciocinio ;

rdfs:comment "Questão representa um problema de design que precisa ser resolvido." .

\#\#\# http://www.semanticweb.org/ontologies/2009/10/wiki.owl\#WikiPage wiki:WikiPage rdf:type owl:Class.

\#\#\# Generated by the OWL API (version 2.2.1.1138) http://owlapi.sourceforge.net

\section{Empresa.owl}

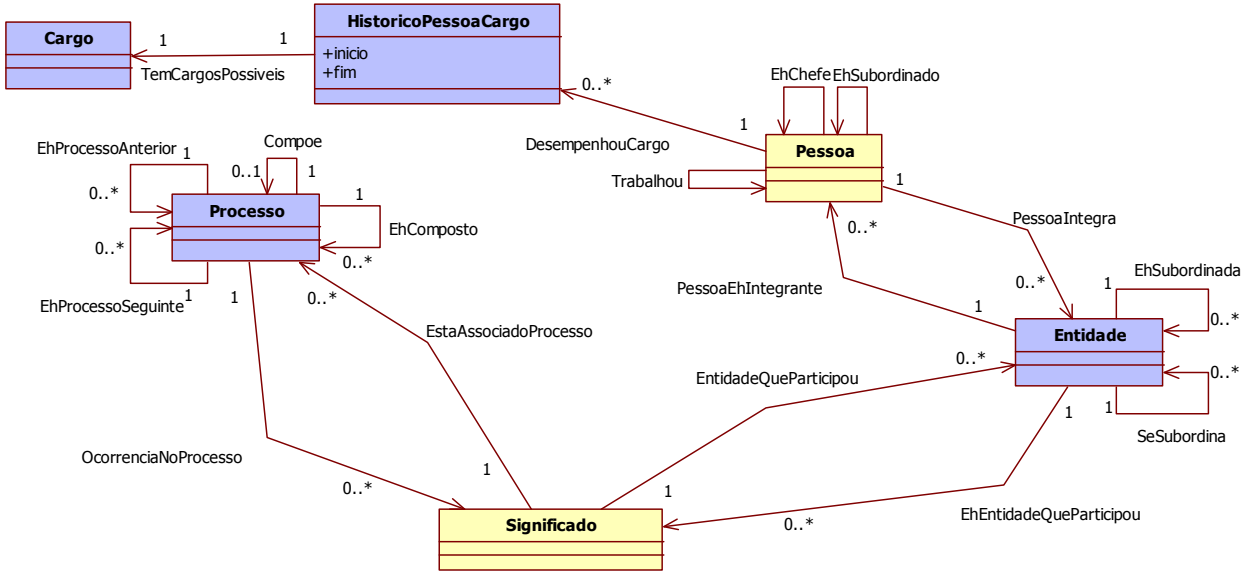

Figura 46 - Módulo Empresa.

@prefix : <http://www.semanticweb.org/ontologies/2009/10/empresa.owl\#> . @prefix owl2xml: <http://www.w3.org/2006/12/owl2-xml\#> .

@prefix wiki: <http://www.semanticweb.org/ontologies/2009/10/wiki.owl\#>

@prefix xsd: <http://www.w3.org/2001/XMLSchema\#> .

@prefix empresa: <http://www.semanticweb.org/ontologies/2009/10/empresa.owl\#> .

@prefix rdfs: <http://www.w3.org/2000/01/rdf-schema\#> .

@prefix foaf: <http://xmlns.com/foaf/0.1/>

@prefix rdf: <http://www.w3.org/1999/02/22-rdf-syntax-ns\#> .

@prefix depoimento: <http://www.semanticweb.org/ontologies/2009/10/depoimento.owl\#> .

@prefix owl: <http://www.w3.org/2002/07/owl\#> .

@base <http://www.semanticweb.org/ontologies/2009/10/empresa.owl>

$<$ http://www.semanticweb.org/ontologies/2009/10/empresa.owl> rdf:type owl:Ontology ;

owl:imports <http://www.semanticweb.org/ontologies/2009/10/depoimento.owl>, <http://www.semanticweb.org/ontologies/2009/10/wiki.owl> .

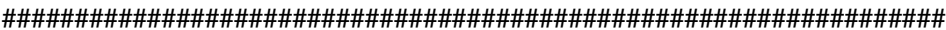
\# Object Properties

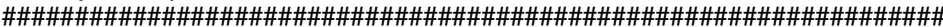

\#\#\# http://www.semanticweb.org/ontologies/2009/10/depoimento.owl\#Classifica depoimento:Classifica rdf:type owl:ObjectProperty .

\#\#\# http://www.semanticweb.org/ontologies/2009/10/depoimento.owl\#Conhece 
depoimento:Conhece rdf:type owl:ObjectProperty .

\#\#\# http://www.semanticweb.org/ontologies/2009/10/depoimento.owl\#EhClassificador depoimento:EhClassificador rdf:type owl:ObjectProperty .

\#\#\# http://www.semanticweb.org/ontologies/2009/10/empresa.owl\#EhChefe

:EhChefe rdf:type owl:ObjectProperty ;

rdfs:comment "Indica o chefe da Pessoa." ;

rdfs:range depoimento:Pessoa;

rdfs:domain depoimento:Pessoa ;

owl:inverseOf :EhSubordinado .

\#\#\# http://www.semanticweb.org/ontologies/2009/10/empresa.owl\#Compoe

:Compoe rdf:type owl:ObjectProperty ;

rdfs:range :Processo ;

rdfs:domain :Processo .

\#\#\# http://www.semanticweb.org/ontologies/2009/10/empresa.owl\#DesempenhouCargo

:DesempenhouCargo rdf:type owl:ObjectProperty ;

rdfs:comment "Historico de Cargo de uma Pessoa." ;

rdfs:domain depoimento:Pessoa;

rdfs:range :HistoriaPessoaCargo .

\#\#\# http://www.semanticweb.org/ontologies/2009/10/empresa.owl\#EhComposto

:EhComposto rdf:type owl:ObjectProperty :

rdfs:comment "Conjunto de sub-processos que compoem um Processo." ; owl:inverseOf :Compoe;

rdfs:domain :Processo ;

rdfs:range :Processo .

\#\#\# http://www.semanticweb.org/ontologies/2009/10/empresa.owl\#EhEntidadeQueParticipou :EhEntidadeQueParticipou rdf:type owl:ObjectProperty ;

rdfs:subPropertyOf depoimento:EhClassificador ;

rdfs:range depoimento:Significado ;

rdfs:domain :Entidade

\#\#\# http://www.semanticweb.org/ontologies/2009/10/empresa.owl\#EhSubordinada

:EhSubordinada rdf:type owl:ObjectProperty ;

rdfs:domain :Entidade;

rdfs:range :Entidade .

\#\#\# http://www.semanticweb.org/ontologies/2009/10/empresa.owl\#EntidadeQueParticipou

:EntidadeQueParticipou rdf:type owl:ObjectProperty ;

rdfs:comment "É uma entidade que participou de um significado."

rdfs:subPropertyOf depoimento:Classifica ;

rdfs:domain depoimento:Significado ;

owl:inverseOf :EhEntidadeQueParticipou ;

rdfs:range :Entidade

\#\#\# http://www.semanticweb.org/ontologies/2009/10/empresa.owl\#EstaAssociadoProcesso :EstaAssociadoProcesso rdf:type owl:ObjectProperty :

rdfs:comment "É o processo em que o significado pertence." ;

rdfs:subPropertyOf depoimento:Classifica ;

rdfs:domain depoimento:Significado ;

owl:inverseOf :OcorrenciaNoProcesso ;

rdfs:range :Processo.

\#\#\# http://www.semanticweb.org/ontologies/2009/10/empresa.owl\#OcorrenciaNoProcesso

:OcorrenciaNoProcesso rdf:type owl:ObjectProperty ;

rdfs:subPropertyOf depoimento:EhClassificador ;

rdfs:range depoimento:Significado ;

rdfs:domain :Processo

\#\#\# http://www.semanticweb.org/ontologies/2009/10/empresa.owl\#PessoaEhlntegrante

:PessoaEhIntegrante rdf:type owl:ObjectProperty ;

rdfs:comment "Conjunto de pessoas que fazem parte de uma entidade." ; rdfs:range depoimento:Pessoa ;

rdfs:domain :Entidade .

\#\#\# http://www.semanticweb.org/ontologies/2009/10/empresa.owl\#Pessoalntegra

:Pessoalntegra rdf:type owl:ObjectProperty ;

rdfs:domain depoimento:Pessoa ;

rdfs:range :Entidade ;

owl:inverseOf :PessoaEhlntegrante .

\#\#\# http://www.semanticweb.org/ontologies/2009/10/empresa.owl\#TemCargosPossiveis 
: TemCargosPossiveis rdf:type owl:ObjectProperty ;

rdfs:comment "Cargo desempenhado em determinado momento." ; rdfs:range :Cargo ;

rdfs:domain :HistoriaPessoaCargo .

\#\#\# http://www.semanticweb.org/ontologies/2009/10/empresa.owl\#EhProcessoAnterior

:EhProcessoAnterior rdf:type owl:ObjectProperty ;

rdfs:comment "Indica o Processo anterior." ;

rdfs:domain :Processo ;

rdfs:range :Processo ;

owl:inverseOf :EhProcessoSeguinte .

\#\#\# http://www.semanticweb.org/ontologies/2009/10/empresa.owl\#EhProcessoSeguinte

:EhProcessoSeguinte rdf:type owl:ObjectProperty ;

rdfs:comment "Indica o Processo seguinte." ;

rdfs:domain :Processo ;

rdfs:range :Processo .

\#\#\# http://www.semanticweb.org/ontologies/2009/10/empresa.owl\#SeSubordina

:SeSubordina rdf:type owl:ObjectProperty ;

owl:inverseOf :EhSubordinada ;

rdfs:range :Entidade ;

rdfs:domain :Entidade

\#\#\# http://www.semanticweb.org/ontologies/2009/10/empresa.owl\#EhSubordinado

:EhSubordinado rdf:type owl:ObjectProperty ;

rdfs:comment "Indica a Pessoa subordinada ao chefe." ;

rdfs:domain depoimento:Pessoa ;

rdfs:range depoimento:Pessoa

\#\#\# http://www.semanticweb.org/ontologies/2009/10/empresa.owl\#Trabalhou

:Trabalhou rdf:type owl:ObjectProperty

owl:SymmetricProperty ;

rdfs:comment "Indica que uma Pessoa trabalhou com a outra Pessoa e vice-versa." rdfs:subPropertyOf depoimento:Conhece

rdfs:domain depoimento:Pessoa ;

rdfs:range depoimento:Pessoa .

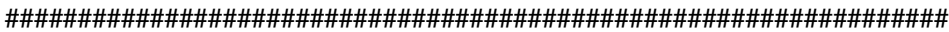

\# Data properties

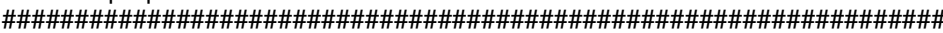

\#\#\# http://www.semanticweb.org/ontologies/2009/10/depoimento.owl\#fim

depoimento:fim rdf:type owl:DatatypeProperty :

rdfs:domain :HistoriaPessoaCargo .

\#\#\# http://www.semanticweb.org/ontologies/2009/10/depoimento.owl\#inicio

depoimento:inicio rdf:type owl:DatatypeProperty ;

rdfs:domain :HistoriaPessoaCargo .

\section{\#\#\#\#\#\#\#\#\#\#\#\#\#\#\#\#\#\#\#\#\#\#\#\#\#\#\#\#\#\#\#\#\#\#\#\#\#\#\#\#\#\#\#\#\#\#\#\#\#\#\#\#\#\#\#\# \\ \# Classes

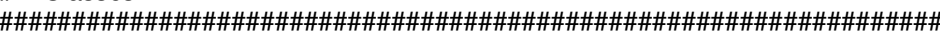

\#\#\# http://www.semanticweb.org/ontologies/2009/10/depoimento.owl\#Indice depoimento:Indice rdf:type owl:Class .

\#\#\# http://www.semanticweb.org/ontologies/2009/10/depoimento.owl\#Pessoa depoimento:Pessoa rdf:type owl:Class

\#\#\# http://www.semanticweb.org/ontologies/2009/10/depoimento.owl\#Significado depoimento:Significado rdf:type owl:Class .

\#\#\# http://www.semanticweb.org/ontologies/2009/10/empresa.owl\#Cargo

:Cargo rdf:type owl:Class ;

rdfs:subClassOf wiki:WikiPage ;

rdfs:comment "São os Cargos da empresa."

\#\#\# http://www.semanticweb.org/ontologies/2009/10/empresa.owl\#Entidade

:Entidade rdf:type owl:Class ;

owl:equivalentClass foaf:Organization ;

rdfs:subClassOf depoimento:Indice ;

rdfs:comment "É uma companhia, ONG, Governo, etc." . 
\#\#\# http://www.semanticweb.org/ontologies/2009/10/empresa.owl\#HistoriaPessoaCargo :HistoriaPessoaCargo rdf:type owl:Class ; rdfs:subClassOf wiki:WikiPage .

\#\#\# http://www.semanticweb.org/ontologies/2009/10/empresa.owl\#Processo

:Processo rdf:type owl:Class ;

rdfs:subClassOf depoimento:Indice :

rdfs:comment "É um processo da empresa." .

\#\#\# http://www.semanticweb.org/ontologies/2009/10/wiki.owl\#WikiPage

wiki:WikiPage rdf:type owl:Class .

\#\#\# http://xmlns.com/foaf/0.1/Organization

foaf:Organization rdf:type owl:Class .

\#\#\# Generated by the OWL API (version 2.2.1.1138) http://owlapi.sourceforge.net 


\section{Apêndice V - Modelo Navegacional do wiki semântico}

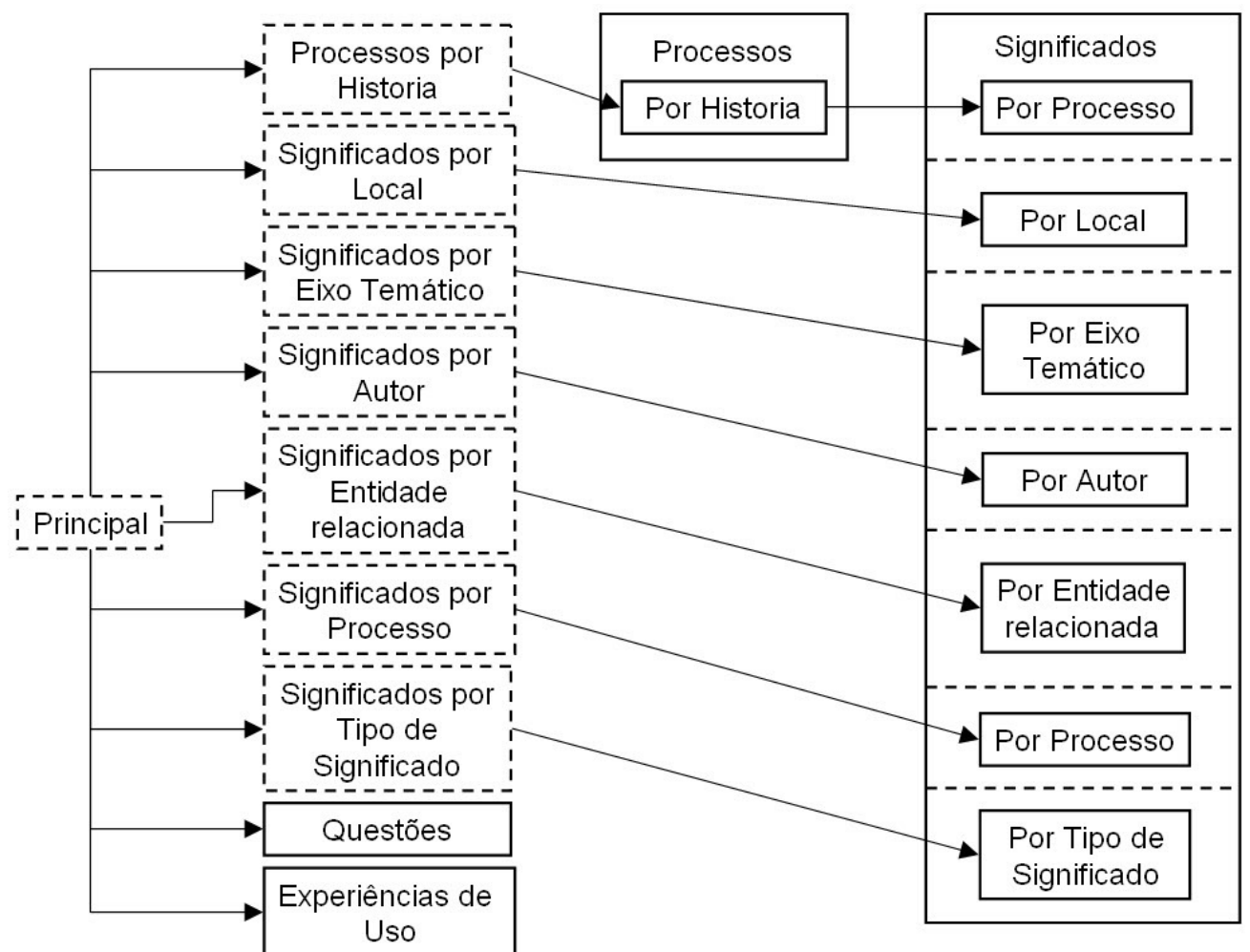

Figura 47 - Modelo navegacional do wiki semântico. 


\section{Apêndice VI - Entrevista dos Curadores}

1. Você teve alguma dificuldade em identificar depoimentos de interesse para a história/projeto que está sendo descrito na entrevista? Quais foram?

2. Você vê alguma outra informação de interesse que está na entrevista, porém não está sendo coletada?

3. Quanto tempo você gastou para identificar os depoimentos de interesse de uma entrevista? 